\title{
Traversing Physical Barriers and Activating Social Voids
}

by

\author{
Sara Ruffolo \\ B.Arch.Sc., Ryerson University, 2012
}

A design thesis project

presented to Ryerson University

in partial fulfillment of the requirements for the degree of

Master of Architecture

In the Program of

Architecture

Toronto, Ontario, Canada, 2014

(c)Sara Ruffolo 2014 



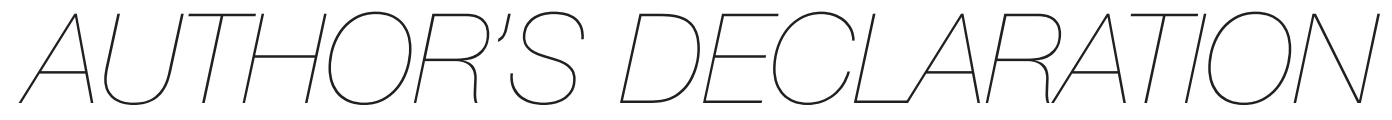

I hereby declare that I am the sole author of this thesis. This is a true copy of the thesis, including any required final revisions, as accepted by my examiners.

I authorize Ryerson University to lend this thesis to other institutions or individuals for the purpose of scholarly research.

I further authorize Ryerson University to reproduce this thesis by photocopying or by other means, in total or in part, at the request of other institutions or individuals for the purpose of scholarly research.

I understand that my thesis may be made electronically available to the public.

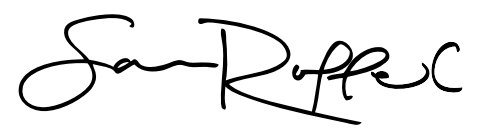

Sara Ruffolo 



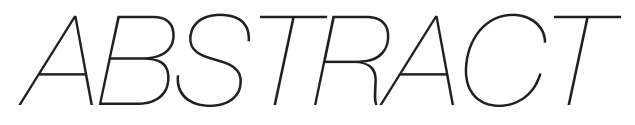

The following body of work is a culmination of theoretical analysis and design research that emerges on the recognition that within Toronto's priority neighbourhoods exists both physical and social barriers that weaken community ties and social resiliency. The physical barriers it refers to are the city's infrastructure and natural geographic features that commonly divide such neighbourhoods and create mobility issues for those residing within. At the same time they fracture social connections and the development of community ties. This becomes a larger internal issue as the majority of the population within priority neighbourhoods being new immigrants and visible minorities share mutual feelings of social isolation, segregation and discomfort.

This thesis investigates environmental psychology to better understand the relationship between the physical environment and its effect of human behaviour so that architecture can be conceived of as designed environments that indirectly influence the mood and behaviours of those occupying the space. The outcome is a complex system of applied architectural strategies that respond to physical, social, and psychological influences regarding the individual and the built environment. Collectively, the design strategies aim to reduce physical barriers, activate social voids, and create environments that enhance social behaviour among socially hesitant individuals. 



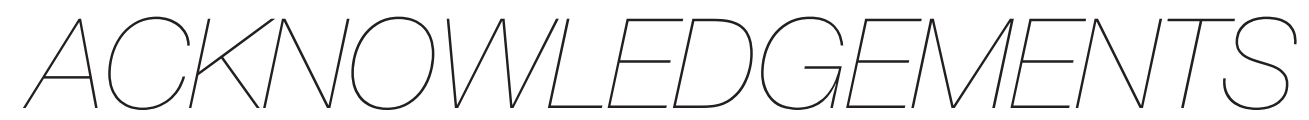

I would like to express great gratitude to my thesis supervisor Dr. Leila Farah not only for her insight and challenging critique, but also for her commitment to seeing that I succeed and reach my full potential. Looking at how far this thesis has come is a true testament to her dedication as a supervisor. I would also like to thank my second reader, Dr. Mark Gorgolweski. Your knowledge, advice, and guidance over the past two years have been truly valuable.

A special thank you to my family, Nadia, Lou, Amanda and Sonia Ruffolo for their constant support, love, and encouragement throughout this process. I would also like to thank my boyfriend, Dan, for his effortless patience and for always keeping me grounded.

Finally, thank you my fellow colleagues. It was a pleasure to collaborate with such creative and talented minds. 

To my loving parents, Lou and Nadia. 



\section{CONTENTS}

Author's Declaration

iii

Abstract

Acknowledgements

Dedication

List of Figures

2.1 Connect

2.2 Activate

2.3 Encounter

2.4 Social Control

3.0 PRIORITY NEIGHBOURHOODS

3.2 Physical Barriers

3.3 Weston-Mt. Dennis

4.0 CONNECT: Increase Access to Social Resources

5.0 ACTIVATE: Provide an Outlet for Social Interaction 50

5.1 Community Needs

5.2 Dispersed Moments of Activity

6.0 ENCOUNTER: Increase Participation

6.1 Intersection of Movement

7.0 CONTROL: Contact Between Different Social and Ethnic Groups

7.2 Provide a Range of Social and Private Spaces 



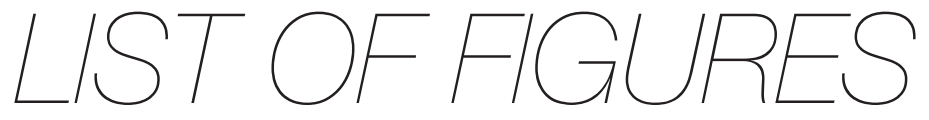

Unless cited otherwise, figures were created by the author

Figure 2.1.0 Bridge vs. Permeate

Figure 2.2.0 Weston-Mt. Dennis: proximity to services

Figure 2.3.1 Edge, Niche, Seating overlooking other people

Source: Gehl, 2010, p.15

Figure 2.3.2 New Road pedestrian street before and after

Source: Gehl, 2010

Figure 2.4.1.1 Social density diagram

Figure 2.4.1.2 Spatial density diagram

Figure 2.4.1.3 Potsdamer Platz

Source: http://www.alanzeleznikar.com/blog/

Figure 2.4.2.1 Invite vs. Repel

Source: Gehl, 2010, p.237

Figure 2.4.2.2 City Centre and Pavilion Main Square

Source: http://www.dezeen.com/2013/09/25/city-centre-and-pavilion-main-square-by-comac/

Figure 2.4.2.3 Visual and auditory control strategies

Figure 3.1.1 Toronto's priority neighbourhoods

Figure 3.2.1 City service lines in relation to priority neighbourhoods

Figure 3.3.1 Weston-Mt. Dennis

Figure 3.3.2 Social and community services

Figure 3.3.3 Low-income areas

Figure 3.3.4 Physical barriers

Figure 3.3.5 Railway condition 
Figure 3.3.6 River condition

Figure 4.0.1a Site conditions

Figure 4.0.1b Site conditions

Figure 4.0.2 Path of connection 1

Figure 4.0.3 Path of connection 2

Figure 5.1.1 Programs on grade

Figure 5.1.2 Programs on bridge

Figure 5.2.1 Dispersed activity nodes

Figure 6.1.1 Existing trail through site

Figure 6.1.2 New bike path

Figure 6.1.3 Ground floor intersection

Figure 6.1.4 Section A-A

Figure 6.1.5 View of ground floor intersection

Figure 6.1.6 Intersection on bridge

Figure 6.1.7 View of intersection on bridge

Figure 6.1.8 View walking towards the intersection

Figure 6.1.9 Expansion and compression of ribs

Figure 7.1.1 Architectural Depth through built form

Figure 7.1.2 Partitioned interior space

Figure 7.1.3 Separated social sapces

Figure 7.2.1 Section B-B

Figure 7.2.2 Section C-C

Figure 7.2.3 Section D-D 



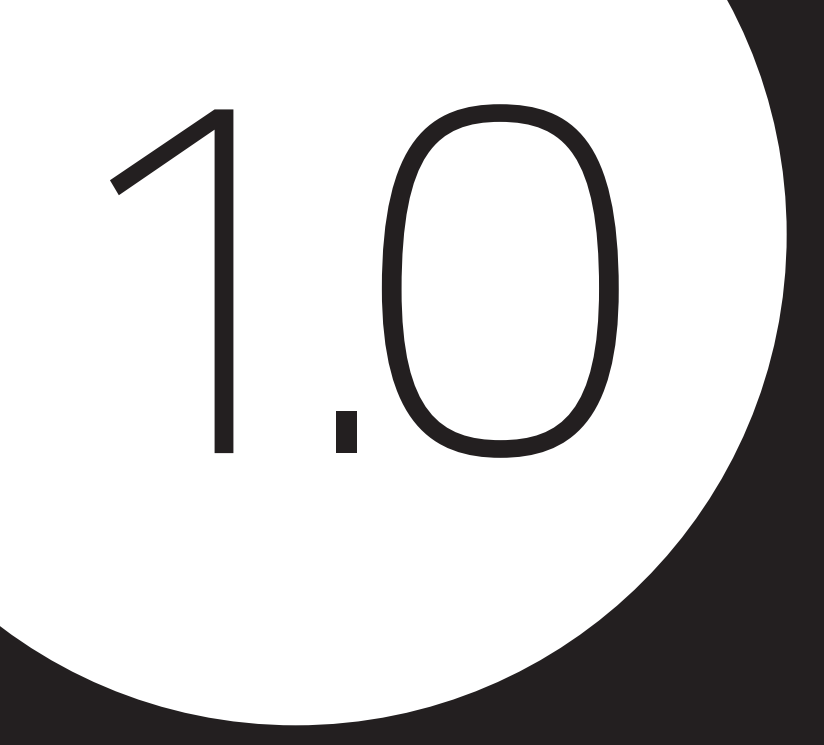




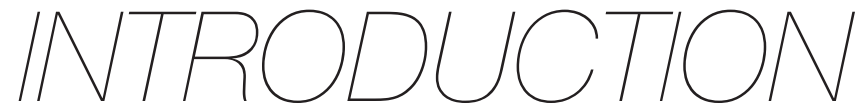

The research, iterative design, and evolution of this thesis revolves around the understanding that there is an apparent relationship between the physical environment and its effect on human behaviour. More formally known as environmental psychology, a concept that revolves around the idea that people live in an environment with which they have a symbiotic relationship (Meacham, 2012). The field emerged in the late 1950s and early 1960s as a distinct aspect of psychology. It was during this time that the relationship between humans and their environment became a relevant discussion as post-war architects and planners were confronted with large-scale urban renewal projects.

It was the first time that professional architects and planners recognized that they could no longer fully know and understand the future inhabitants of their buildings in the way that had been possible when architects worked closely with and for private patrons

(Canter and Craik, 1981, p.3).

Since the early 1960s research in environmental psychology and architecture have overlapped. It is the only recognized academic discipline that bridges design and psychology so that architects and planners can better understand the ways in which environments effect people and inform the design and construction of the places we inhabit. Today, re- 
search in environmental psychology has predominantly extended to the realm of hospital and healthcare design. In the 1990s there was a growing recognition that risks and hazards of health care associated injury were not a result of poor performance by individual provider but rather the design of the systems of care. As a result, the primary focus of healthcare facilities became designing safer and more efficient hospitals (Pati and Branch, 2010). The research that followed provided evidence that if increasing natural daylight, providing views of nature and increasing access to nature or gardens can improve patient recovery time and well being (McCunn, 2014).

To understand the role of the built environment in people's lives one has to comprehend the nature of human behaviour (Lang 1987, p.99). Environmental psychology provides the means to understand human behaviour in relation to the built environment and in what ways architecture can influence those environments. This has an effect on social behaviour and users' mood, productivity, and to some degree their health and wellbeing (Ayers, 2007, p.23). Understanding how design can influence a person's behaviour gives architects the power to design spaces that

Perception is defined by Lang (1987, p.79) as the physiological and psychological process of obtaining information from the environment. provoke a specific mood or perception in order to achieve a desired set of behaviours (Ayers, 2007). This can be achieved by manipulating the physical structure of space, including: the amount of open space, the presence or lack of walls and windows, the brightness of lighting, etc. (Idib, 2007).

With the increasing emphasis on evidence-based design, or evidence-informed design, it is timely to focus on educating designers to underpin their design decisions with the constructs of theories that explain human behaviour... Understanding theories about design and human behaviour can increase the probability that our prediction will work. This is the method that new designers will use to optimize the design of environments that support people's behaviours, activities, cultures, and norms and prevent harm from coming to them in the spaces in which they lead their daily lives.

(Kopec, 2012, p.15).

This thesis sees the potential to expand the application of environmental psychology outside the realm of healthcare design and understand how 
such studies and theories can be used as design strategies to increase social behaviour and interaction in socially stagnate settings. Social voids, or the lack of social institutions devoted to social integration, are a common characteristic of many lower-income neighbourhoods. The need for social interaction is still a fundamental basic human need and is a critical attribute for such low-income neighbourhoods that have a high population of new immigrants and visible minorities who commonly experience social isolation and segregation, and discomfort in social settings.

\section{Social Isolation and Segregation}

Beverly Nann, Coordinator at Immigrant Resources Project in British Columbia, believes that in any society, there is the usual suspicion of newcomers by more established groups ("Common issues for newcomers," n.d.). This can result in the exclusion or alienation of new immigrants and visible minorities from the Canadian mainstream leading them to feel a weak sense of belonging to Canada (Wu, et al., 2010, p.10). One of the top ten difficulties new immigrants face after arriving in Canada (cited four years after arrival) is the lack of social interaction (Shellenberg \& Maheux, 2007). Statistics Canada published an article titled New Immigrants' Assessment of Their Life in Canada, which found that such feelings result in vulnerable groups "hesitant to invest themselves in their host communities because of the perception that discrimination will depreciate the return on their investment" (Shellenberg and Maheux, 2007). These feelings have also been found to limit such groups from creating networks, developing social ties and they reduce their overall sense of belonging.

When immigrants arrive to a new country their family ties and deep friendships are frequently severed. If they lack social resources such as friends and family in their host communities, or access to social services to draw upon to support them through new experiences and difficulties, feelings of loneliness and isolation are commonly experienced ("Common issues for newcomers," n.d.). These feelings are only reinforced by segregation. All forms of segregation (social, residential, spatial) have produced a number of social issues. Residential segregation, or spatial concentration, tends to increase the social isolation of visible minorities,
Social Isolation

According to Nicholson (2009), social isolation is defined as, "a state in which the individual lacks a sense of belonging socially, lacks engagement with others, has a minimal number of social contacts and they are deficient in fulfilling and

quality relationships."

Residential Segregation

Bolt, Özüekren, and Phillips (2010, p.171) understand residential segregation as, "a neutral concept referring to the unequal distribution of a population group over a particular area."

Spatial Segregation

Scholarly research has defined spatial segregation as "the overrepresentation of a particular group in some parts of a city and the under-representation of the same group in other areas" (Bolt, Özüekren, and Phillips, 2010, p.171). Some refer to spatial segregation as spatial assimilation, which is "the residential exposure of minority populations to members of the ethnic majority and this exposure is generally assumed to increase as the assimilation process in other domains (acculturation, socioeconomic mobility) proceeds" (Idib, 2010, p.171). 
or other marginalized groups, and acts as a barrier to the integration of new immigrants into their host communities (Wu, et al., 2010 \& Ray, 2008 , p.1). This is especially true for priority neighbourhoods where infrastructure acts as a physical barrier around certain areas refraining those within to access people and services outside of those boundaries. Residential segregation also prohibits social mixing from taking place. A number of academics have stated that segregation of ethnic groups, or ethnic enclaves, can grow into areas with a high concentration of poverty, racial underclass and disadvantaged socioeconomic groups (Idib, 2010, p.21). The isolation of poorer groups can lead to social problems such as unemployment and deprivation (Lawton, 2013, p.98).

This thesis project targets areas within priority neighbourhoods where high concentrations of poverty exist and where physical barriers isolate people from accessing community/social service or engaging with others in the community. It looks for ways to reduce social isolation and segregation by creating inclusive public spaces that bring people together and encourage them to participate within the public realm.

\section{Discomfort and Discrimination}

Using data from the Ethnic Diversity Survey, Ray and Preston (2009) found that feelings of discomfort and discrimination are common among visible minorities in Canada's immigrant gateway cities (Montreal, Toronto and Vancouver). Citizenship and Immigration Canada have also reported discomfort, discrimination, and insecurity to be emotions commonly felt by new immigrants to Canada ("After you arrive," 2010). This thesis recognizes that it's not enough to create an outlet for vulnerable groups to interact; rather these spaces have to be designed with their social discomforts in mind. Theories and studies in environmental psychology are used within this context to develop a stronger understanding of the way public space can be designed to respond to varying human psychological needs.

Zheng Wu, professor of Sociology at the University of Victoria, believes that "The key challenge to the preservation of social cohesion is ensuring the social integration of newcomers and eliminating socially constructed boundaries." (Wu, et al., 2010, p.5). According to a number of research 
papers by the Longitudinal Survey of Immigrants to Canada (LSIC) and

the General Social Survey (GSS) (Zhao, et al., 2010; Houle \& Schellenberg, 2010; Van Kemenage, et al., 2006), such boundaries can be eliminated by:

a) Increasing access to social resources,

b) Providing an outlet for social interaction,

c) Participation, and

d) Contact between different social and ethnic groups

These findings were derived from studies that surveyed over seven thousand recent immigrants to Canada over a period of four years. The survey addressed a number of issues that were ultimately concerned with how newly arrived immigrants adapt to living in Canada during their first four years. Such issues included: social interaction, groups and organizations and perceptions of settlement. The outcome of the survey and subsequent research concluded that the social integration of newcomers and socially constructed boundaries could be eliminated by: increasing access to social resources, providing an outlet for social integration, increase participation, and contact between different social and ethnic groups.

\section{Increase access to social resources}

Many low-income neighbourhoods in Toronto, particularly priority neighbourhoods are without many social and community services (Hulchanski, 2007, p.10). While my research does not get into specific about increasing access to social resources in priority neighbourhoods, my own investigation of such neighbourhoods shows that many low-income pockets are segregated community and social resources within the area. Increasing access to these services can help reduce feelings associated with social isolation and segregation that are commonly reported by new immigrants.

\section{Provide an outlet for social interaction}

The term "social capital" is a hybrid notion that "brings together the theoretical and empirical rationale for considering social ties as a potentially important ingredient of well-being and prosperity in society" (Policy Re- 
search Initiative, 2005, p.37). It is a concept "based on the premise that an interpersonal network provides value to its members by giving them access to the social resources available within the network" (Staber, 2006, p.190). The LSIC reveals the importance of social capital to the integration of immigrants to Canada. It states that friendship networks play an important role in the health of recent immigrants (Zhao, et al., 2010, p.19). Social infrastructure, such as community centers, public open space, playgrounds, etc., that allow friendships and social bonds to form, can benefit new immigrants. Priority neighbourhoods having limited social services and a high population of new immigrants, it is important to consider implementing social infrastructure that works to reinforce social networks.

\section{Participation}

Houle \& Schellenberg's research indicates that life satisfaction among the immigrant population is negatively correlated with social isolation but show a positive correlation between social ties and participation to one's well being. The casual social exchanges one has with their neighbours can have a positive effect on immigrants' well being (if they perceive their neighbor to be friendly) (Houle \& Schellenberg, 2010). Ray \& Preston (2009, p.246) reveal that behavioural characteristics, such as, trust in others and especially in neighbours, reduces the odds of reporting racial discomfort and discrimination. Although their studies have shown a greater number of participants only engage in limited social encounters with their neighbours, these casual or informal types of socializing can help build a sense of belonging, especially among new comers to Canada. Schellenberg (2004) supports this claim as his research has shown that social interaction between immigrants and the Canadian-born helps to build trust, which is important for establishing mutual feelings of connectedness to place.

\section{Contact between different social and ethnic groups} Social mixing is based on the premise that social problems of deprived groups can be alleviated by mixing people from different backgrounds, such as by ethnicity or social class (Lawton, 2013, p.101). With a greater presence of middle-class residents in lower-income neighbourhoods, problems related to social stigmatization can be reduced if the urban en- 
vironment provides the surface for social interactions between different

groups to occur. The benefits of social mixing include: the development of social networks, greater levels of social control, and the transformation of behavioural norms. The research of by van Kemenade et al. (2006) shows that access to close networks of people from the same cultural origin - as well as programs to support these networks - can help immigrants integrate socially and economically in the host country. It is therefore important for contact between different ethnic groups to exist. This can be achieved by bringing people from different ethnic groups together in a common space that holds interest to all parties. All of these strategies will help reduce the social distance between them (Wu, et al., 2010, p.18). More importantly, the density and ethnic diversity of friendship networks have profound effects on immigrants' self-rated health status.

The following body of work further breaks down these four strategies (increasing access to social resources, providing an outlet for social integration, participation, and contact between different social and ethnic groups) and investigates how each can be represented architecturally. Chapter 2 translates each strategy into architectural principles, which are further broken down into architectural strategies. Chapter 3 takes a closer look at Weston-Mt. Dennis, one of Toronto's priority neighbourhoods, and breaks down the neighbourhood's physical and social context down into a series of maps that are used to pinpoint areas for further intervention. The remaining chapters individually look at how each principle and their related strategies form the design of this thesis project. The result is a reinterpretation of social strategies that work to eliminate socially constructed boundaries through a series of architectural interventions. 


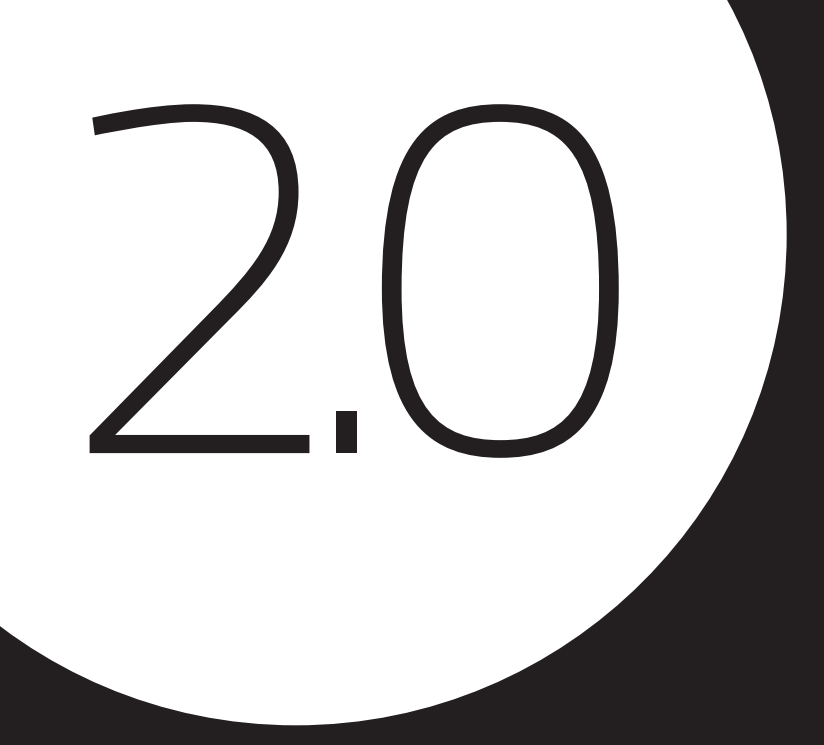




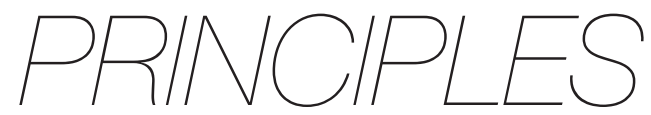

The following chapter looks more closely at the four social strategies, described in the introduction, that are proven to preserve social cohesion and ensure the social integration of newcomers by eliminating socially constructed boundaries (social isolation /segregation and discomfort). Each strategy is reinterpreted as an architectural principle that can be applied to this thesis in order to meet the same goals the LSIC sets out. In short, each social strategy has an architectural counterpart for which I have developed design strategies that will work to eliminate socially constructed boundaries. This approach to design is based primarily on theories and studies by psychologists, sociologists and architects that have emerged over the past 50 years.

\subsection{CONNECT: Increase Access to Social Resources}

Many lower-income neighbourhoods in Toronto are situated alongside some of the city's major service lines and natural geographic features. Highways, railway corridors, major roads and rivers cut through and delineate territories within these neighbourhoods. My analysis of such segments of the city illustrates these service lines as physical barriers that limit lower-income pockets within priority neighbourhoods from being able to easily or safely access community/social services or other social groups within the neighbourhood. The first principle, connect, emerged 
from these findings and looks for ways to open up boundaries and create a safe and direct link between social voids and provide better access to people and social resources in the urban landscape. Increasing access to these services can help reduce feelings associated with social isolation and segregation that are commonly reported by new immigrants.

The preconceived notions around infrastructure and its mono-functionality conceal the potential for such sites to be absorbed by the community and be reclaimed as public space. While some might view infrastructure as a disadvantage to its immediate surroundings, others see it as an opportunity. A number of architects and planners have recently begun to investigate the potential that lies around the underutilized spaces around city infrastructure. Create connections between the physical barrier, activate space by bringing new programs and people to these underutilized sites, increase the city's green space, and revitalize the local ecology are among the many interventions that have sparked a design movement focused on reclaiming residual space. This thesis is specifically interested in restoring safe connections by investigating ways to make direct links between divided territories to enhance pedestrian mobility through these corridors. Within this exists opportunities to generate new lines of movement through these sites and create new experiences by opening up connections between neighbourhoods that have been fragmented by infrastructure. Various ways to make these connections, including permeate, bury, and bridge, are presented.

\section{Permeate}

The term permeate means "to spread or flow through" or "to pass through the openings or interstices of" ("Permeate", n.d.). This formal move would allow the functions of infrastructure and humans to share the same plane and form a dynamic network of moving parts. This is however dependent on the duration and frequency of the service line. A highway for instance is active throughout the day with its volume of use fluctuating regularly. A railway corridor, on the other hand, runs less frequently and for shorter periods making it a more appropriate candidate for this dynamic network to function. Permeating through infrastructure at predetermined moments along the service corridor will allow people to cross over during periods of low frequency. 
Burring the infrastructure below grade gives the opportunity to play with the entire ground plane without people or activities being interrupted by the flows of infrastructure. The critique however, is hiding infrastructure when there exists the potential to create new urban spaces and networks by merging urban life, people and infrastructure on the same plane (Strang, 1996).

\section{Bridge}

It is easy to interpret the term bridge architecturally. The term appears in this context naturally as a device used to span over physical obstacles. Its application would be dependent on the site and type of infrastructure but would ultimately work as a link allowing people to span from one side to the other without interfering with the function of the infrastructure on site. Structures elevated above service lines can work to establish new ground planes and create a network of connections.

Bridging above or below infrastructure and natural features found in priority neighbourhoods is the most appropriate means of connecting since it has the least interference with the existing lines of movement and it can be applied to all conditions whereas permeate and burry are dependent on the type of infrastructure and their frequencies (Figure 2.1.0). 


\section{BRIDGE}

PERMEATE

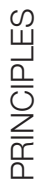
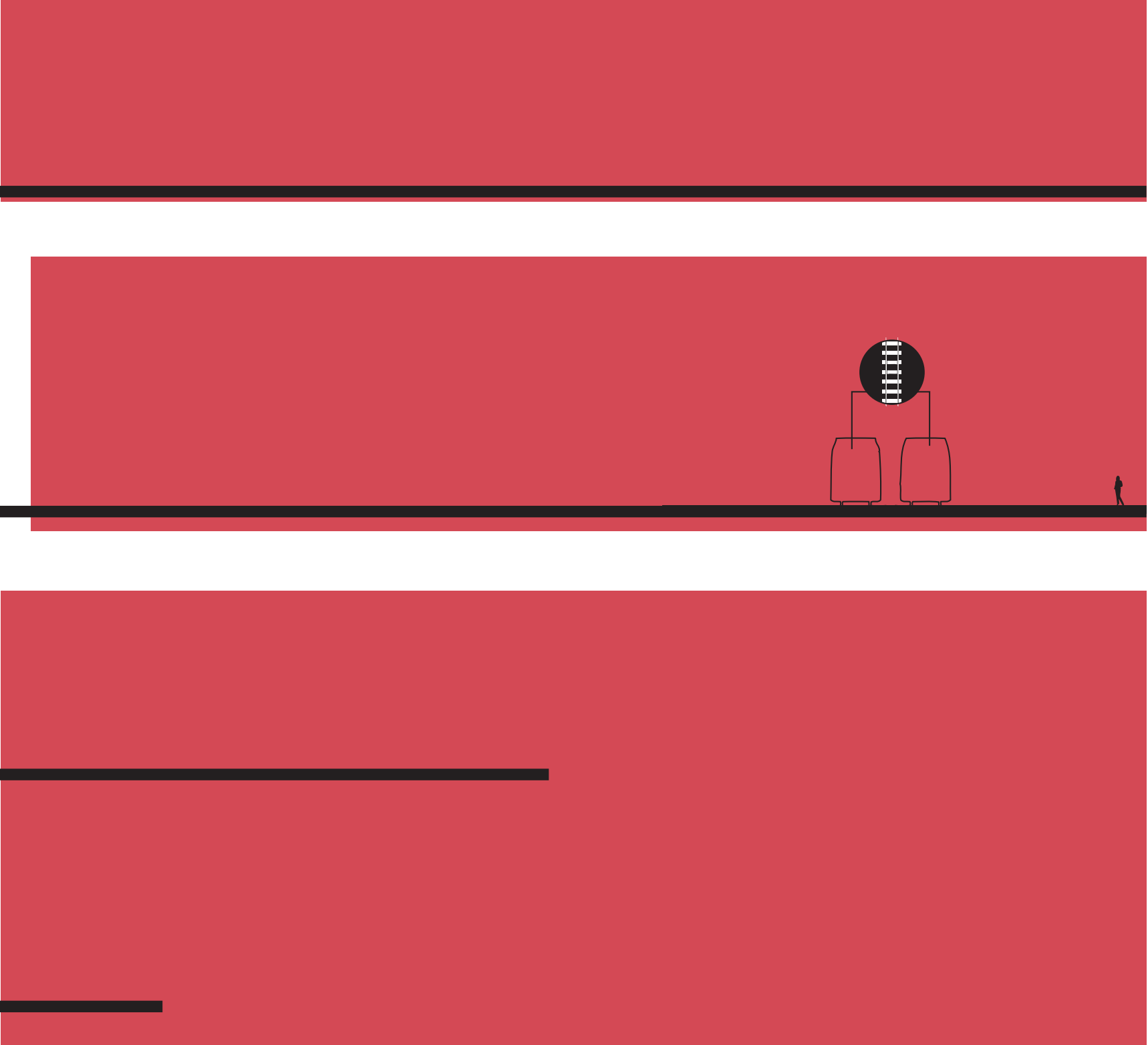


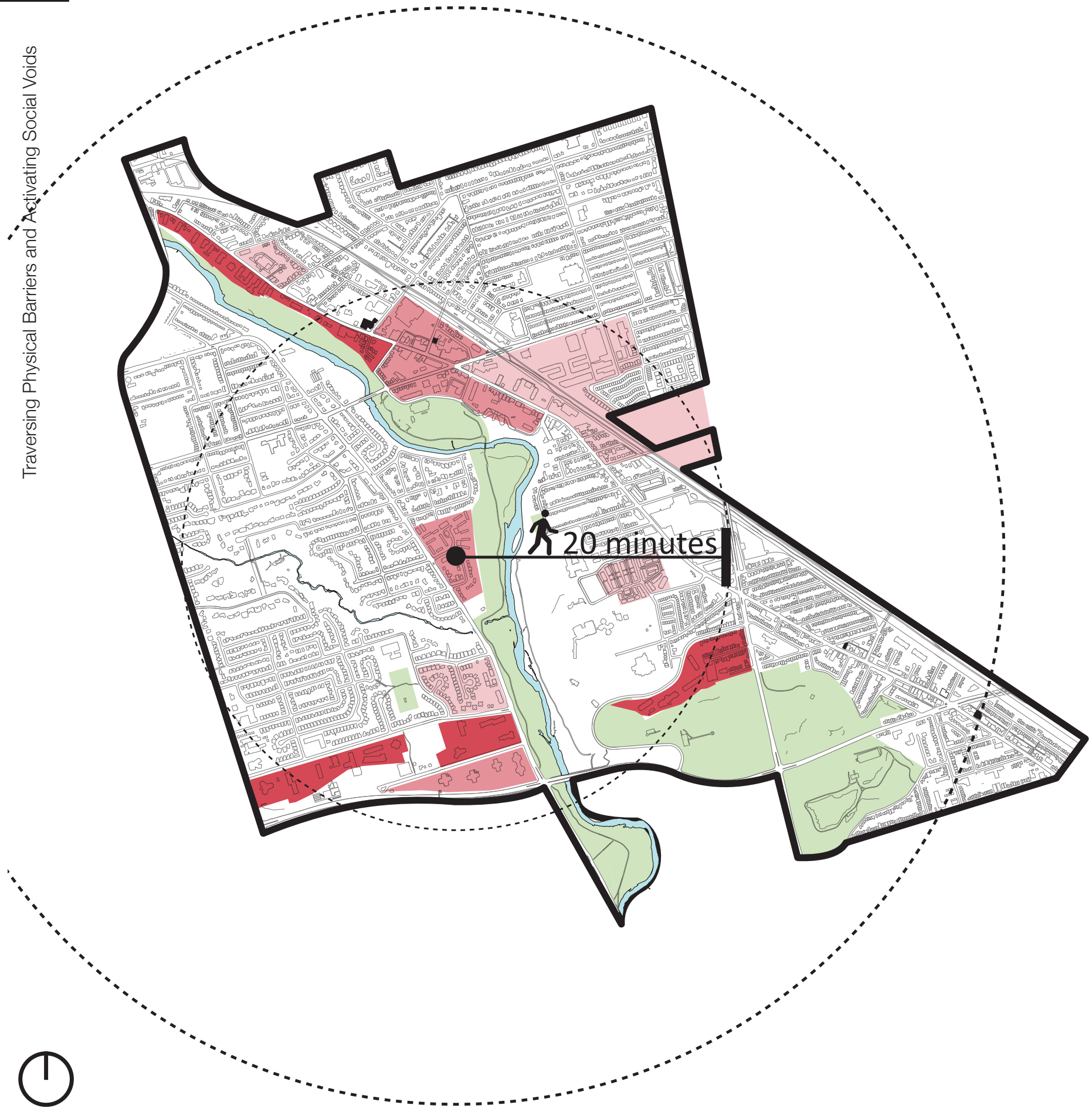

Figure 2.2.0 Weston-Mt. Dennis: proximity to services 
While bridging does open up connections between segregated communities and neighbourhood services, this thesis recognizes that priority neighbourhoods, especially Weston-Mt. Dennis, lack the proper social and community infrastructure in place to alleviate marginalized groups from social segregation. Zannalyn Robest, a resident of Weston-Mt. Dennis, explains that the neighbourhood is in need of a community center where opportunities can be reached by those facing barriers to education, employment, and safe housing (Robest, n.d.). For instance, Figure 2.2.0 shows that the closest community centers or libraries are between a 20 to 40 minute walking distance from Scarlettwood Court.

Robest (n.d.) also claims the organizations that exist in the community are not inclusive in that the issues of the most vulnerable residents are being ignored. Rather than creating a link between low-income areas and neighbourhood community centers and social services, the bridge will act as a destination. Activating the bridge with programs that reflect the needs of the surrounding community will bring needed services closer to underserved areas, create a place for people to meet and interact, and open up the passage not only for lower-income residents, but also for those residing on the other side, thus offering more possibilities for social mixing to take place. (A more comprehensive breakdown of the strategies that form this principle can be seen in chapter 5 )

The first two principles, connect and activate, work together to generate an influx of people and services and become the foundation for new networks to form. 

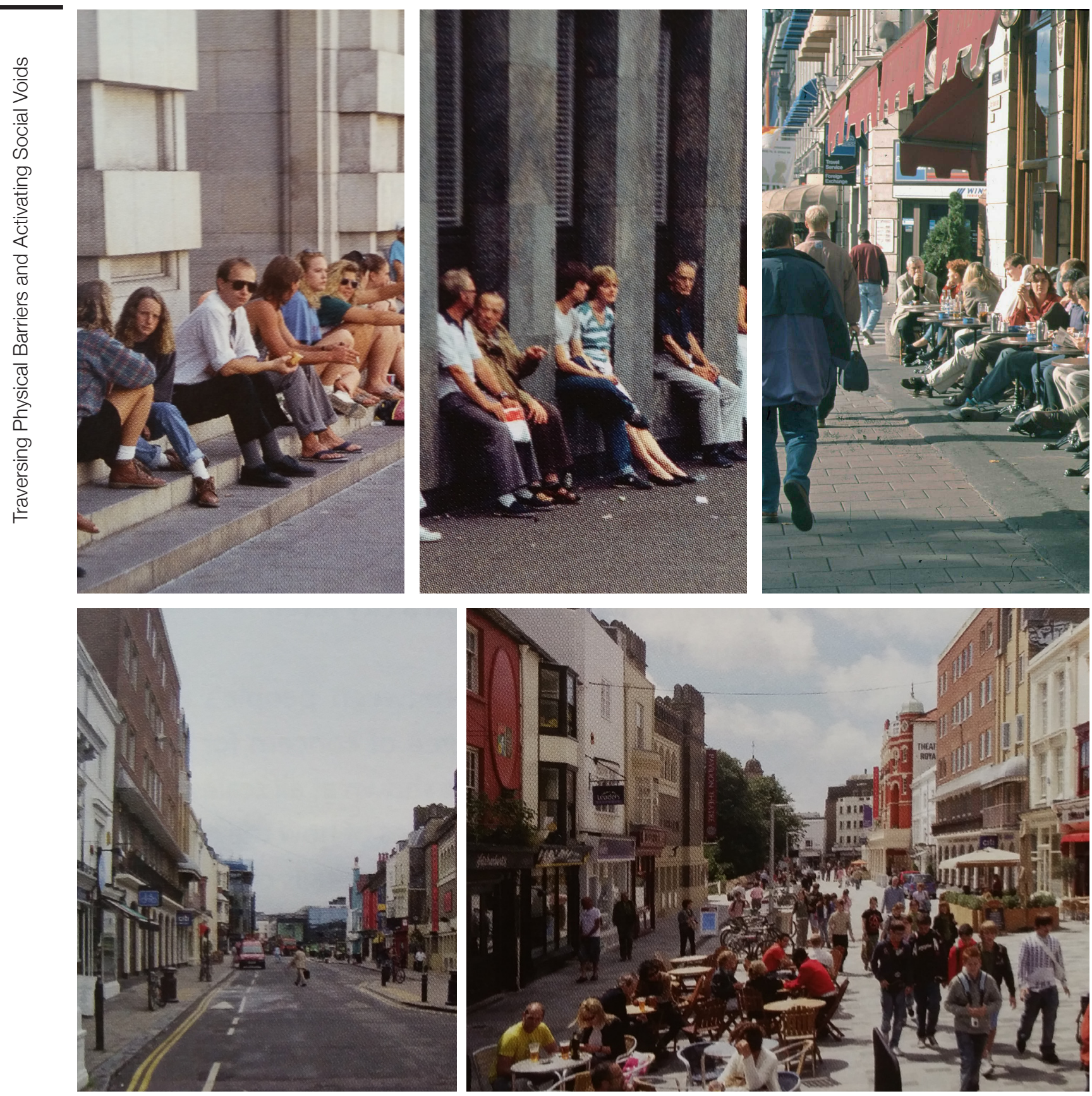

"If there is life and activity in city space, there are also many social exchanges"

(Gehl, 2010). 
Looking at ways to increase participation is an important aspect of this thesis since the targeted demographic group includes those who are hesitant to invest themselves in their communities. Research has shown that casual or informal types of socializing can help build a sense of belonging, especially among new comers to Canada. Jan Gehl's theories and observations of people's relationship to public space is studied to better understand what attracts people to a space and how to encourage them to stay within an area and participate on a formal or informal level.

Gehl says that whenever people stay for a while they seek out places along the edge of space. Otherwise known as the edge effect, this phenomenon gives people a place to sit or stand at the edge where they are not in the way of other pedestrians and provides a space in front to watch everything while having their back protected. Caves and niches are also attractive places for people to stop and stay for the same reasons but provide more protection physically and psychologically. Furthermore, people are attracted to stay where there is seating that overlooks a view of other people or scenery (Figure 2.3.1).

A series of studies Gehl conducted in Copenhagen of benches and chairs in city space show that the seats with the best view of city life are used far more frequently then those that do not offer a view of other people. "After the conversion of New Road to a pedestrian-priority street in Brighton, England, pedestrian traffic increased by $62 \%$, while the number of staying activities increased by 600\%." (Gehl, 2010, p.15) (Figure 2.3.2).

Such design strategies can be implemented into the design of buildings, streets, and public space to encourage people to stop and stay. If these elements are included in the design, people will be more willing to occupy the space, especially if there are others around. Creating such environments opens up the potential for increased participation within the public realm, even if it is informally. This principle looks at how to implement these strategies at targeted locations that will intersect with the flows of movement and activity across the site. The goal is to ultimately bring people together from different social and ethnic backgrounds in a common space that holds interest to all parties.

Opposite page:

Figure 2.3.1 Edge, Niche, Seating overlooking other people

Figure 2.3.2 New Road pedestrian street before and after 
Low Social Density

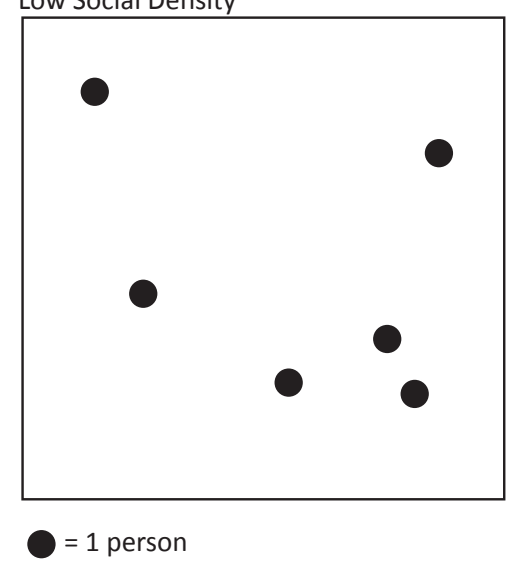

High Social Density

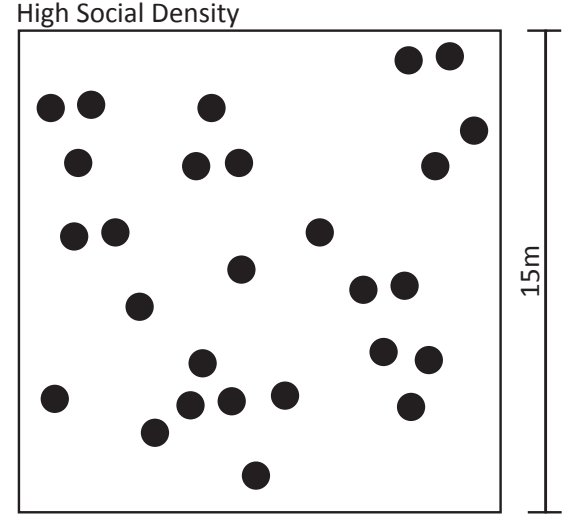

Low Spatial Density

High Spatial Density

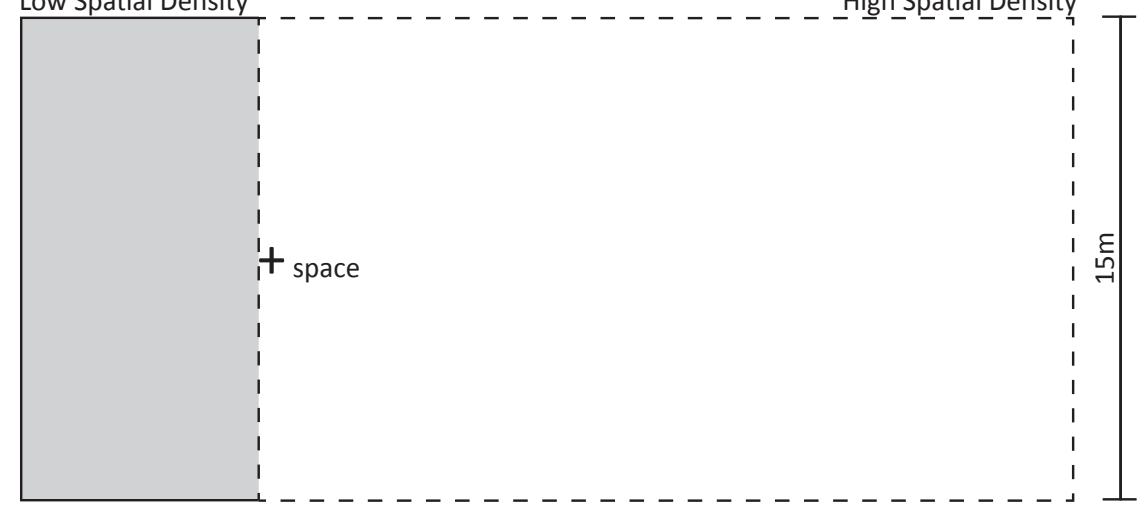




\subsection{CONTROL: Contact Between Different Social and Ethnic Groups}

While this thesis looks for ways to increase access to social resources, provide an outlet for social interaction and increase user participation, it does recognize that this may not be enough to foster stronger social behaviour, especially among more socially hesitant individuals. The design, therefore, looks more closely at how to increase contact between different social and ethnic groups by designing comfortable social environments. The last principle, control, uses strategies that are proven to indirectly influence the mood of those using a space. They include: the perception of density, privacy, and user control (Ayers, 2007, p.23). All three of these variables are studied from the point of view of sociologists and psychologists and translated into architectural strategies that can create comfortable social environments.

\subsubsection{Control the perception of social and spatial density}

Controlling the perception of social and spatial density helps to regulate user comfort and increase their perception of control over ones social experience. Social density is a term that refers to how many people are in a given area. The understanding is that more people occupying a space, the higher the social density will be (Figure 2.4.1.1). Spatial density refers to how much space there is, or how much space one perceives there to be. The more space available the greater the spatial density (Figure 2.4.1.2).

These two terms are related in that if one increases, the other will decrease (Meacham, 2012). Therefore, if a space is accommodating a large group of people, the social density increases and the environment is no longer comfortable for people to interact and socialize with others around them. It threatens the control an individual tries to maintain over privacy and regulation of social interactions. By lowering people's perception of social density through design, public spaces can be available to a large number of people without the stress of crowding refraining users of the space from engaging in social behaviour. Lowering the perception of social density by partitioning a space, for instance, will in-

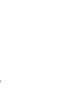




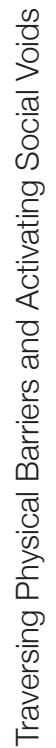

Figure 2.4.1.3 Potsdamer Platz

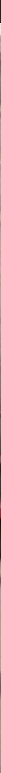


crease the perception of control over ones social experience, thus reduc-

ing stress and discomfort while support local control over shared space (Ayers, 2007, p.24). This can also be referred to as Architectural Depth:

Architectural Depth (AD) can be used to measure the social behavior in a building. $A D$ is the number of spaces one must pass through to get from one room to another. This reflects the environments variety of space, complexity and privacy. High AD is associated with less social withdrawal and buffering of crowding (Ayers, 2007, p.24).

Kristen K. Roessler, Professor of Psychology at the University of Southern Denmark, conducted a series of studies on how certain environments can provoke or reinforce certain emotions. One of her studies is conducted at Berlin's Potsdamer Platz (Figure 2.4.1.3). The large square surrounded by skyscrapers is located at a main intersection within the city. Roessler describes her experience of the space to be overwhelming as she tries to "find opportunities to withdraw and experience a sense of safety." As she crosses the square she feels constantly visible and has nowhere to retreat to: "I feel alone and alienated even if I know that I am constantly surrounded by other humans" (Roessler, 2012, p.84). Her study concluded that expansive open spaces that hold a lot of people and therefore carry both high social and spatial density are uncomfortable environments that leave the user feeling separated and seeking refuge. Dividing up the space in a way that increased individual privacy can decrease behaviours that are associated with overcrowding such as withdrawal (Ayers, 2007).

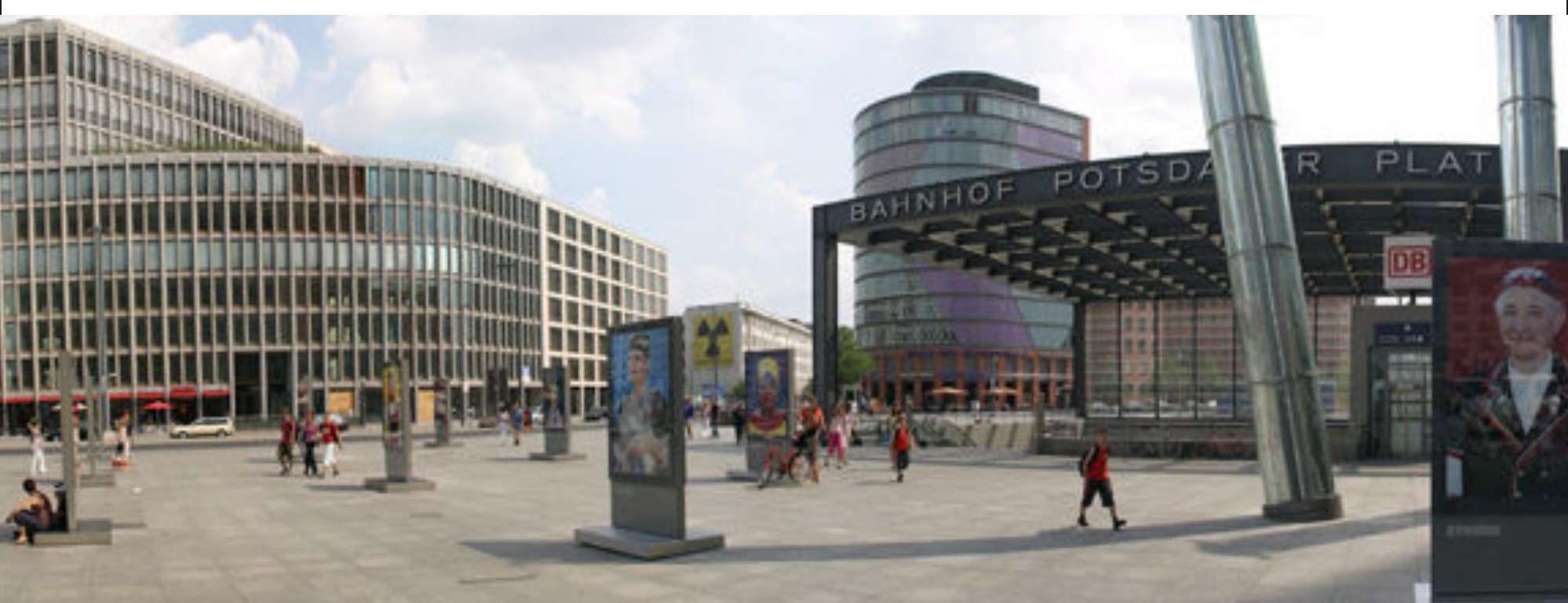


To Invite

No walk
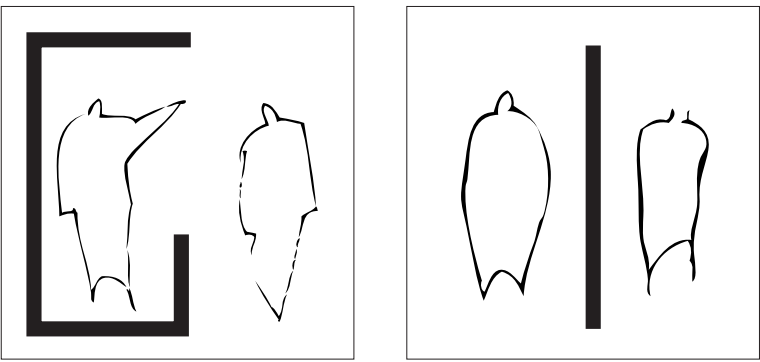

Walk
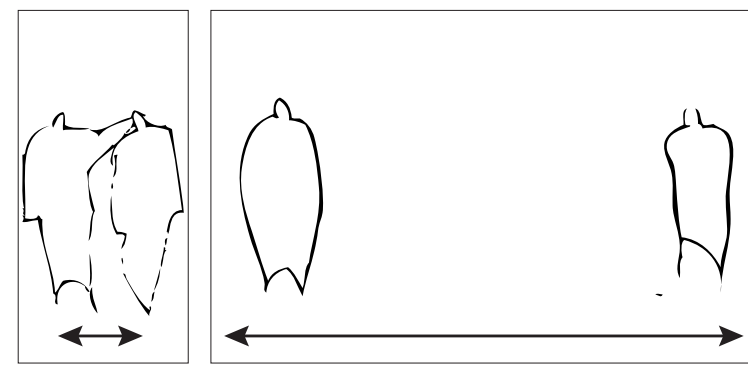

Short distances
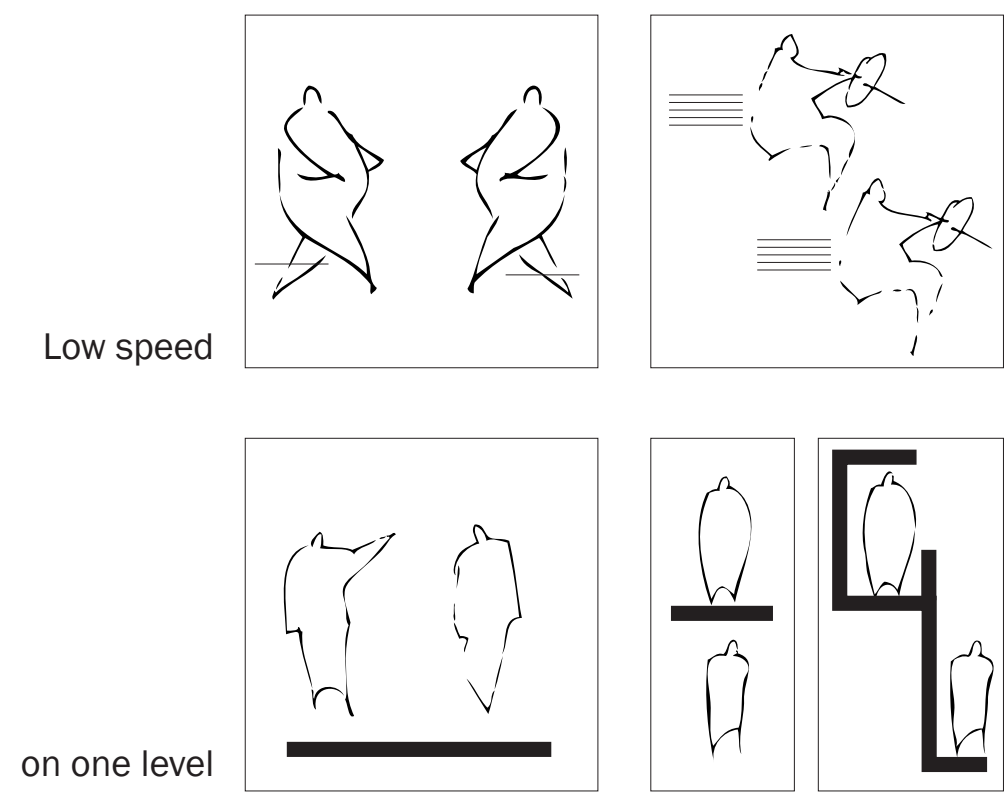

stackiang, several

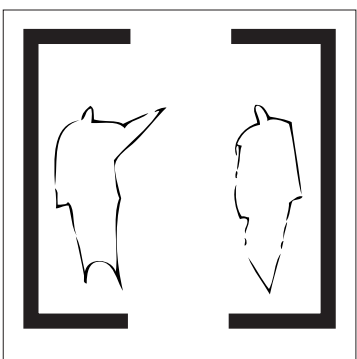

High speed
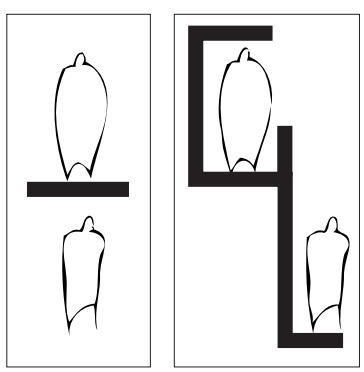
levels

Great distances

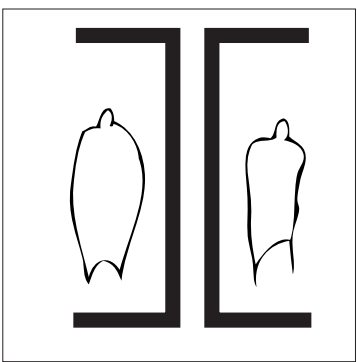

Back-to-back orientation 


\subsubsection{Provide a range of social and private spaces}

According to the article Privacy, the central concept behind the term is the ability of an individual to make "decisions about openness/closedness, as well as abilities to control degrees of openness, vary with time and circumstance" (Werner, Brown \& Altman, 2004). Privacy therefore depends on: the protection of information or physical contact, and making these available to others. Those seeking privacy are looking to control their visual and/or auditory interactions with others. While some people feel comfortable in large groups, others may feel like their personal space is being invaded. Spaces that control privacy are therefore important in public spaces since they are strongly correlated to minimizing social withdrawal, increasing ones sense of control, positive mental health, and a decreased tendency to react negatively to minor annoyances (Straub, 2007).

Studies have shown that "we tend to tolerate or allow closer interpersonal distances when we feel strong, secure, or safe. Conversely, we tend to require more interpersonal space when we feel weak, insecure, or at risk" (Kopec, 2012, p.77). These requirements relate to varying personality traits such as extroverts who prefer to be around other people and larger social gatherings that generate interaction and stimulation, they prefer physical closeness to others, and opt for more open furniture arrangements. Introverts on the other hand tend to have more guarded personalities and their environmental preferences include safe haven or privacy where there is less social contact and the ability to escape. In addition, they prefer closed spaces or seating arrangements that establish distance such as chairs opposed to sofas (Kopec, 2012, p.73-76).

In his book, Cities for People, Jan Gehl writes about what spatial attributes contribute to comfortable environments. Figure 2.4.2.1 is his interpretation of how our senses and built environments have a major impact on the interaction we have with other people. He concludes that inviting requires unobstructed views, short distances, low speeds, staying on the same level and orientation towards what is to be experienced. In contrast, interrupted lines of vision, large distances, high speeds, multisensory placement and orientation away from people deter people from seeing others (Gehl, 2010, p.236). 


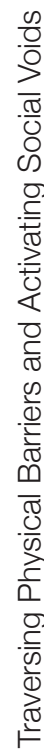
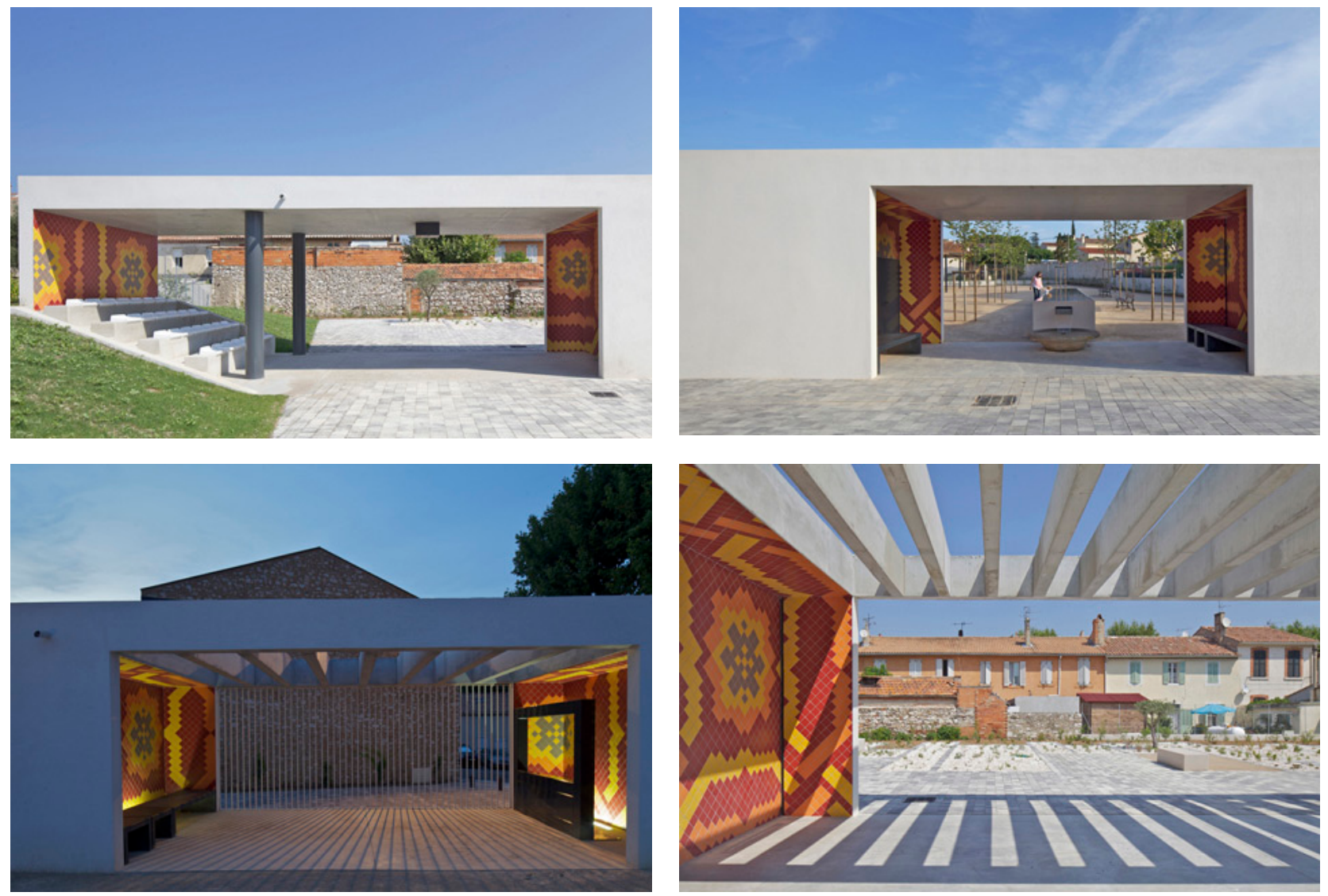
City Centre and Pavilion Main Square in Marseille is a clear example of

how the juxtaposition between private and social spaces can be interpreted architecturally (Figure 2.4.2.2). The pavilion is a long concrete structure featuring a variety of openings ranging in degrees of openness and closedness. Each compartment is designed differently to hold different activities and create a variety of experiences. Some spaces are completely open to the adjacent squares while others feature screens and niches that create more private environments. "The entire urban project is creating several intimate spaces and foster social gatherings and activities." (City Center, 2013).

All of these strategies can be used to create a variety of social environments ranging from high social spaces that allow formal and informal social behaviour to flourish, or areas of retreat where users can control their visual and auditory interactions with others. The following are my interpretation of similar architectural strategies that can be used to create a variation of social spaces that range from high privacy to low privacy in order generate a range of private and social spaces that can be used in the design to give users control over their environments.

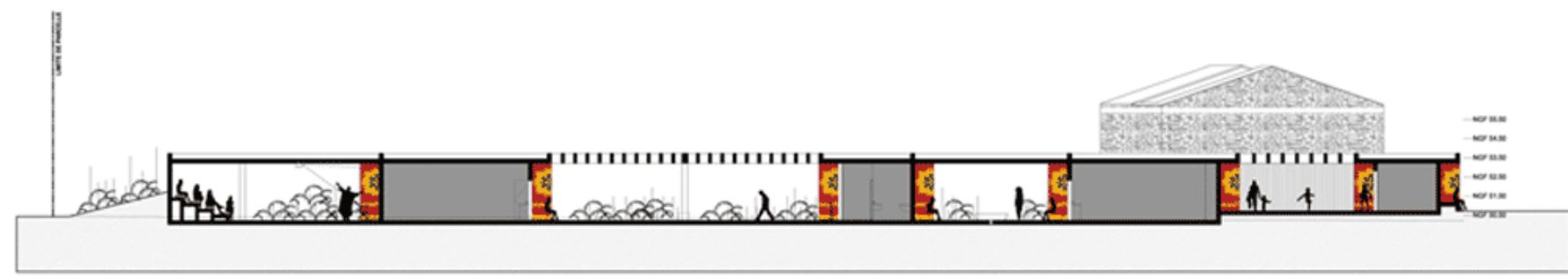



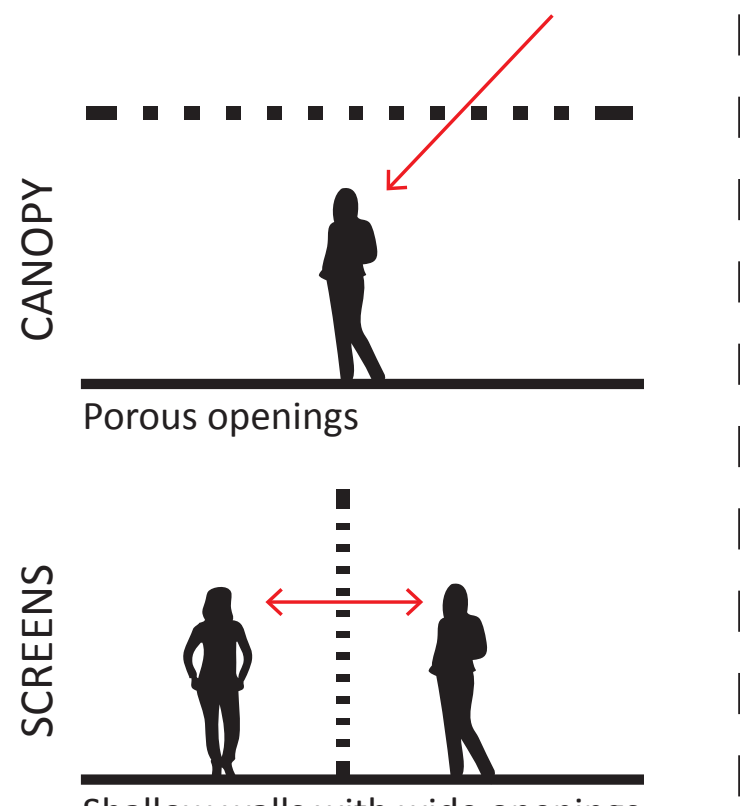

Shallow walls with wide openings

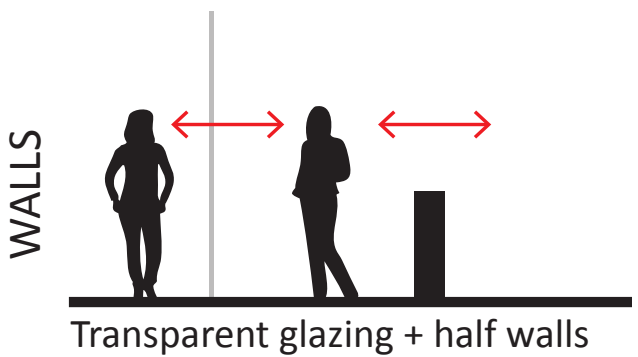

Full coverage
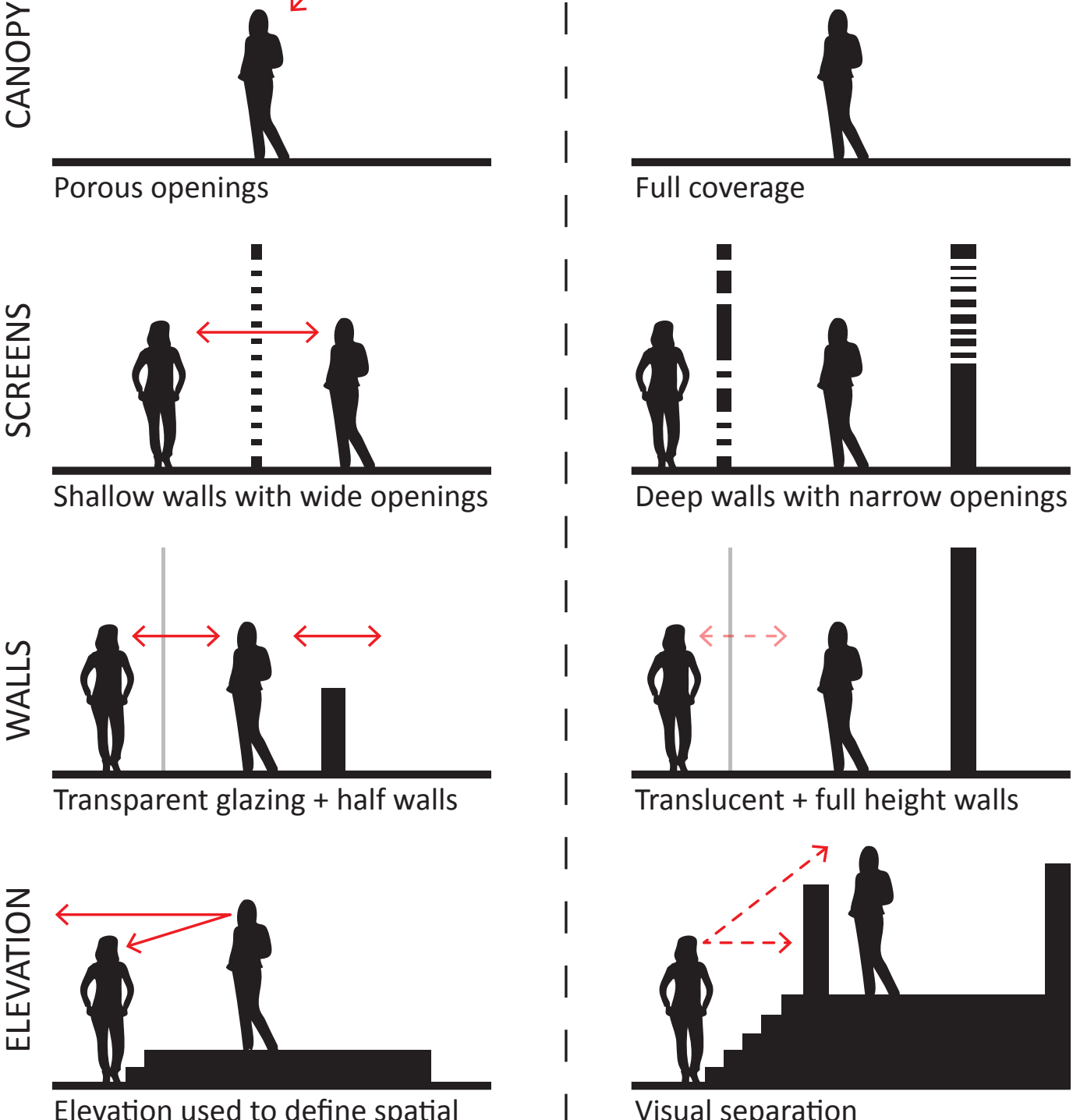
change

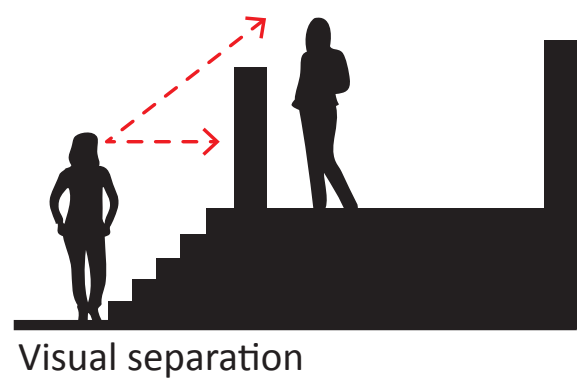


MIN. AUDITORY CONTROL
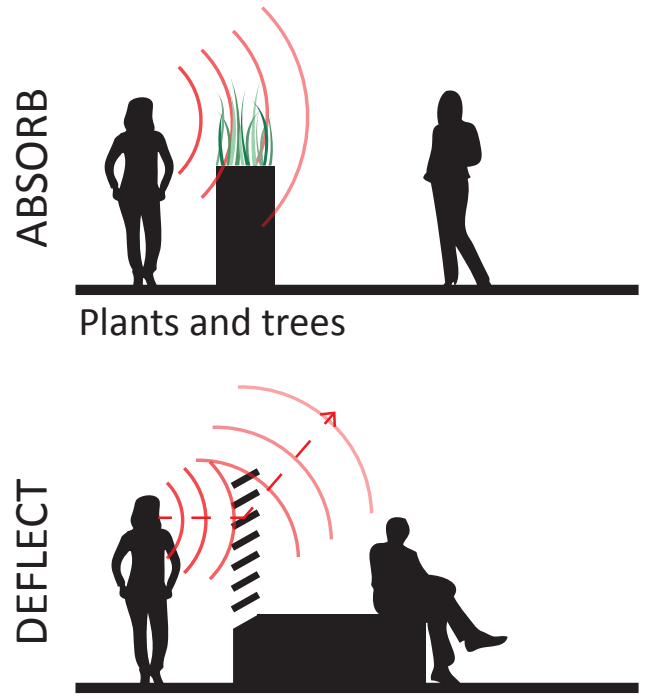

Sound deflection screen

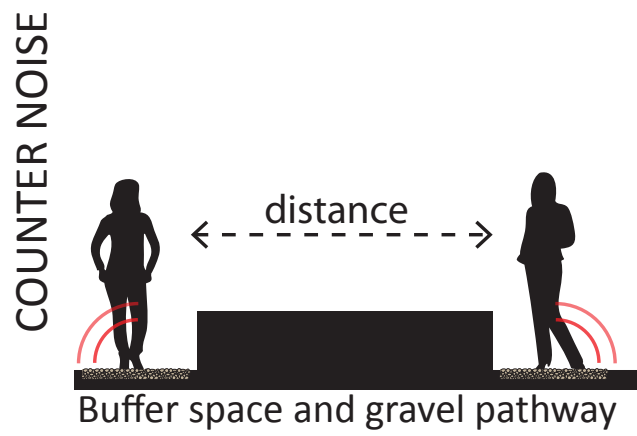

MAX. AUDITORY CONTROL

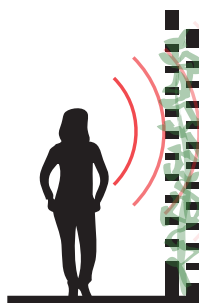

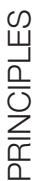

Screen with vertical foliage

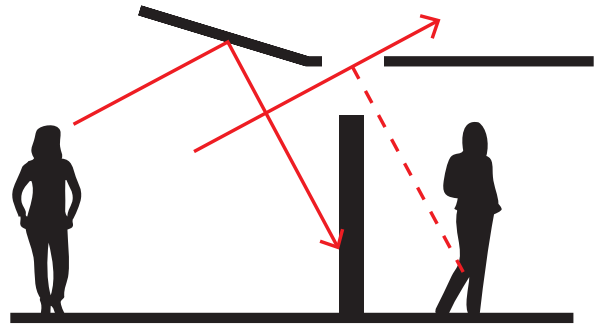

Manipulating form to deflect noise

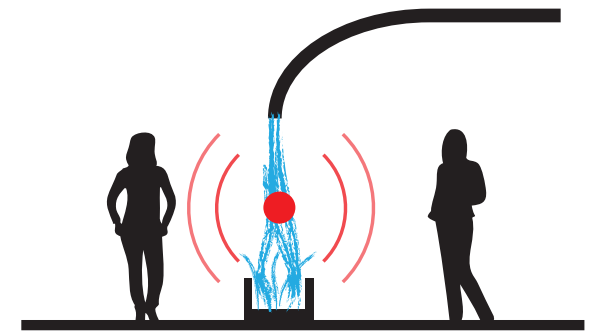

Water screen and noise buffer 
Openness and closedness implies being able to control degrees of exposure in a public environment. Open is least private as it suggests being fully exposed to ones surroundings while closedness implies a sense of enclosure where one finds privacy in confined spaces. Openness and closedness also refers to ones relationship with their visual and auditory environment.

Those seeking privacy are looking to control their visual and auditory interactions with others. They are areas of retreat where one can escape from an exposed environment and control their degrees of openness. Social spaces on the other hand are connected to their surroundings, and to other people and activities around the site. Within the design, spaces that are meant for more public, social encounters are pushed to the edge of the activity nodes so they are adjacent to the intersections and other activities around the site. The social spaces are left relatively open and exposed and act more as circulation or informal socializing spaces. The more private areas are held within an enclosed interior volume, which also works to break up the social spaces into smaller volumes that are more comfortable to be in. Figure 2.4.2.3 shows a series of strategies that provide a range of private and social environments.

\section{Expansion and Compression}

Psychologist Joan Meyers-Levy conducted an experiment that examined the relationship between ceiling height and thinking style. When people are in a high-ceiling room, they are more likely to excel at puzzles that related to themes of freedom, such as "liberated" and "unlimited". These spaces also allow people to zoom out and engage in more abstract styles of thinking (Lehrer, 2011). For new immigrants and visible minorities who are trying to break away from feelings of isolation and exclusion, these spatial qualities can help them feel liberated and encourage them to engage in more open discussions; they are therefore ideal for social spaces. On the other hand, when people are in low ceiling rooms they are better able to solve anagrams related to confinement, such as "bound", "restrained" and "restricted" leading us to focus on specific details (ibid, 2011). Confined spaces such as this are ideal for privacy zones intended for personal discussions between small groups. 


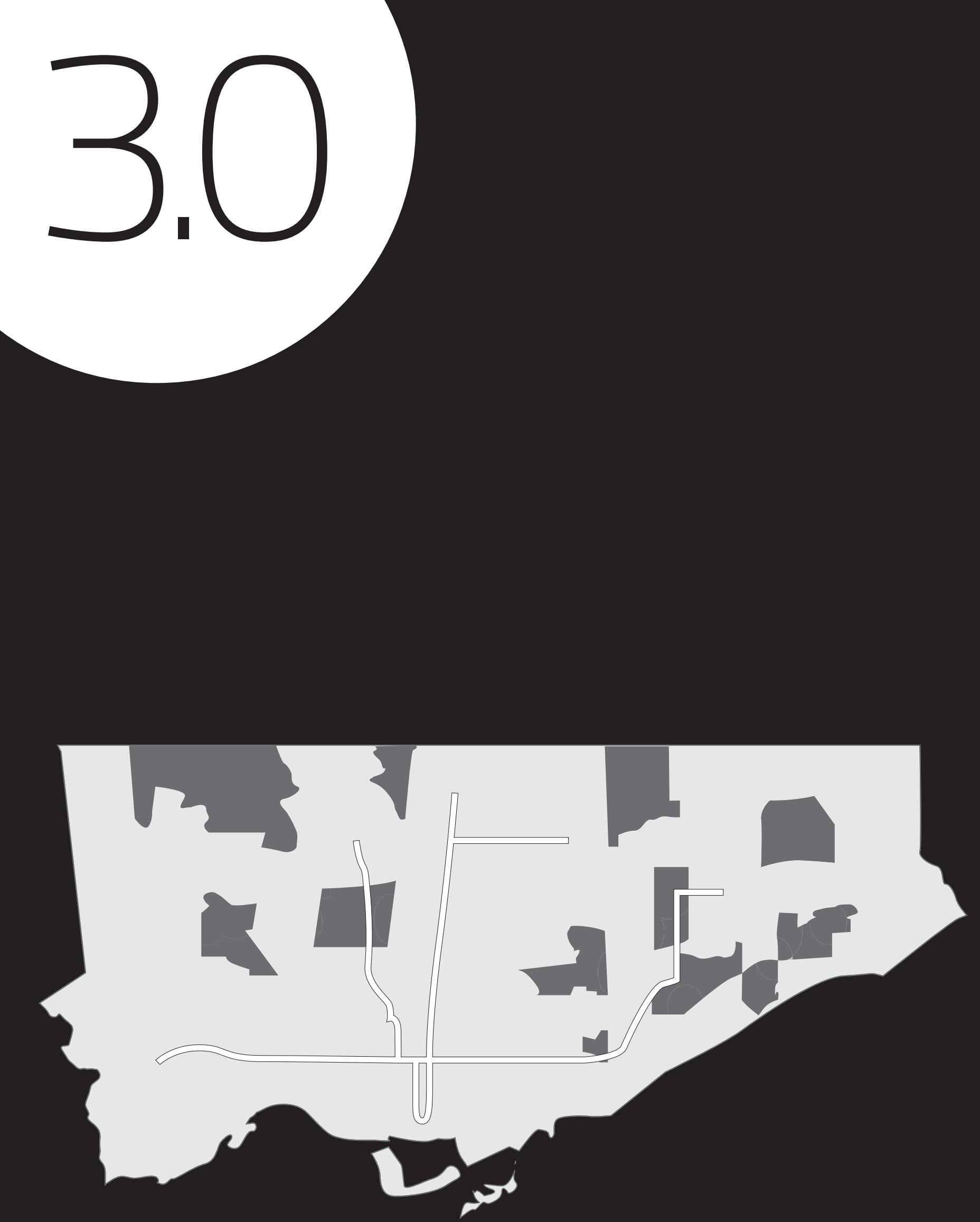

(1)

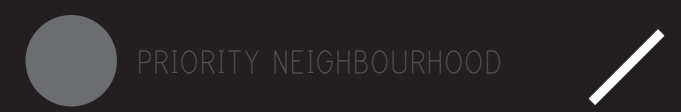




\subsection{CONTEXT}

Priority neighbourhoods are defined as, "areas with extensive poverty and without many social and community services" (Hulchanski, 2007, 10). The City of Toronto and the United Way of Greater Toronto have identified thirteen priority neighbourhoods within the city's inner suburbs (Figure 3.1.1). In 2005, nine priority neighbourhoods were recognized based on poor access to services, a large population of recent immigrants and low-income residents. Shortly after, areas with high violence were added to the list, bringing the number of priority neighbourhoods to its current total ("Priority Neighbourhoods", n.d.). In short, these neighbourhoods can be characterized by lower incomes, violence, lack of investment in community and social services, and a higher than average at-risk population including recent immigrants and visible minorities. Visible minorities represent 66 percent of the population in priority neighbourhoods compared to 47 percent in Toronto while recent immigrants represent 14 percent compared to Toronto at 10.7 percent ("2006 census update", 2008).

Opposite page:

Figure 3.1.1 Toronto's priority neighbourhoods 


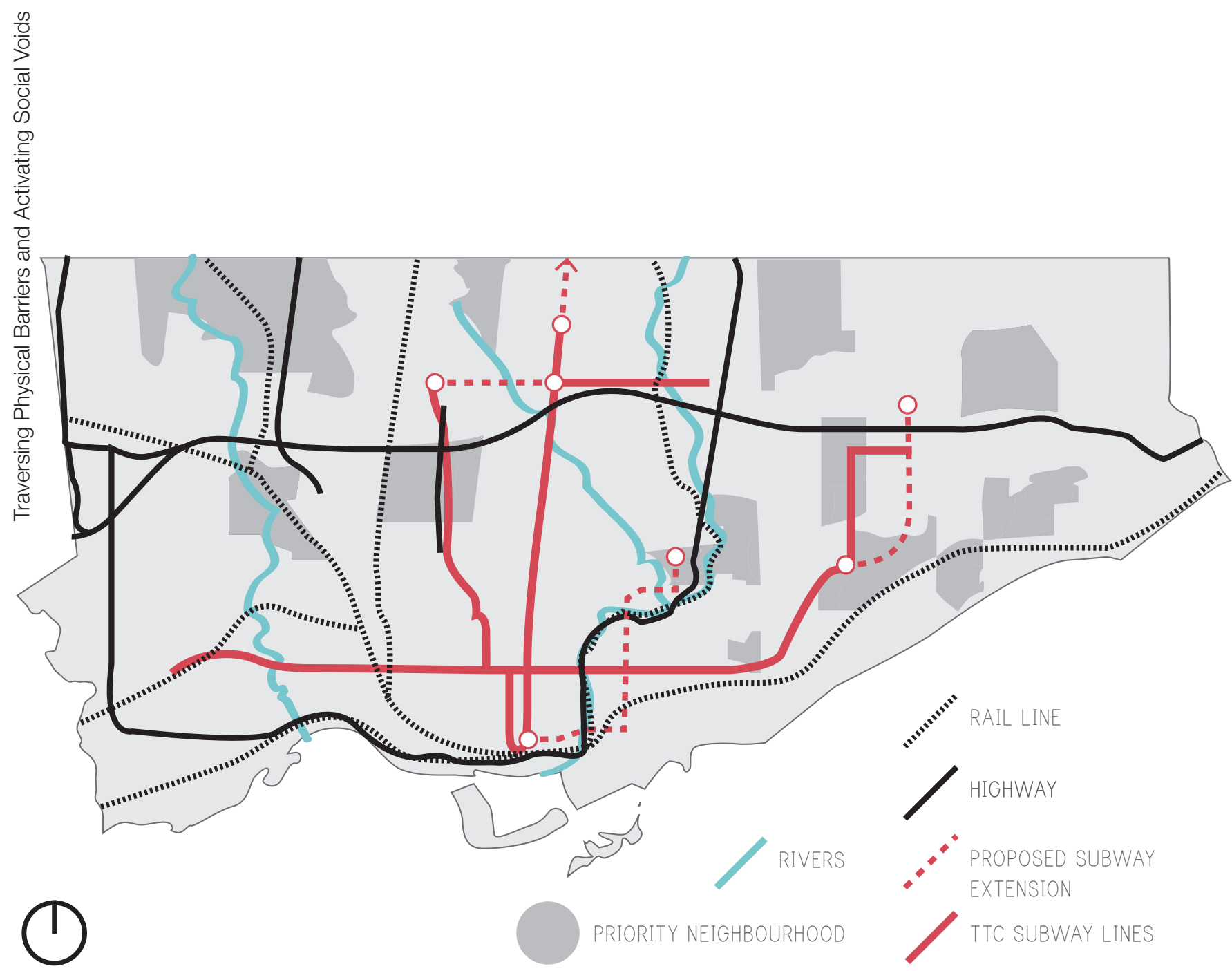

Figure 3.2.1 City service lines in

relation to priority neighbourhoods 
Many priority neighbourhoods in Toronto are situated alongside some of the city's major service corridors and natural geographic features (Figure 3.2.1). Major roads, highways, railway and hydro corridors are some of the services that carry food, water, and power to support the operations of our society. Overtime, the city has grown and radiated from these service lines creating a network connecting the inner city and outer suburbs. While proximity to these services can offer great convenience, they are largely deemed unpopular settlement areas due to the noise, light and air pollution that they carry/emit. The market value for the residences along these undesirable corridors is therefore lower and becomes appealing for persons of lower income and, in many cases, new immigrants to settle. This isn't to say that everyone who lives in a priority neighbourhood falls under new immigrant status or is classified as low-income, rather, what this thesis has analyzed is the high concentration of lowincome persons adjacent to these less sought after areas.

The service corridors and natural features that abut these low-income pockets can become physical barriers restricting those from within the boundary to safely or easily access services and people that lie on the other side. While infrastructure meets the needs of the growing and far reaching population it does so at the expense of the local ecology and overall livability around such sites. The physical link that is severed by these natural and man-made arteries is detrimental to lower income areas where access to services is already limited. 


\subsection{WESTON-MT. DENNIS}

The neighbourhood of Weston-Mt. Dennis has been selected to examine the extent of these physical barriers' effect on surrounding communities. Weston-Mt. Dennis is a priority neighbourhood located south of highway 400 and 401 and bound on either side by the Humber River and an active railway corridor (Figure 3.3.1). This affluent neighbourhood of recent immigrants and a range of socio-economic demographic provide a number of opportunities to demonstrate this thesis through design.

Figure 3.3.2 highlights the neighbourhood's community and social services including schools, churches, community centers, sports centers, and libraries (for a full breakdown see Appendix A). The neighbourhood is also home to a number of low-income persons, dispersed in clusters around the site (Figure 3.3.3). Most of these clusters abut major roads, railway corridors, and the Humber River (Figure 3.3.4), which restricts these areas from easily or safely accessing the neighbourhood's community and social services.

Figure 3.3.1 Weston-Mt. Dennis

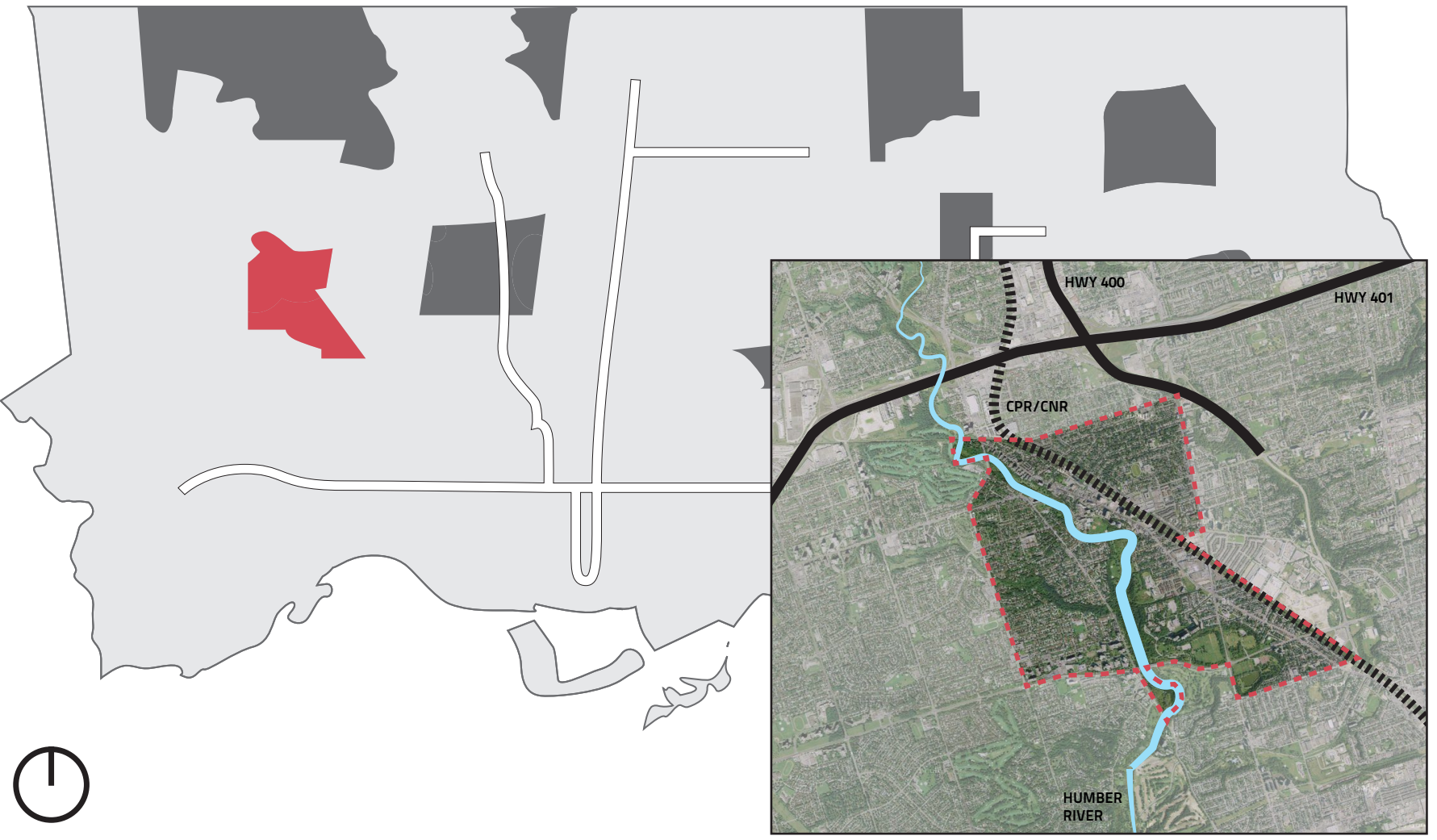



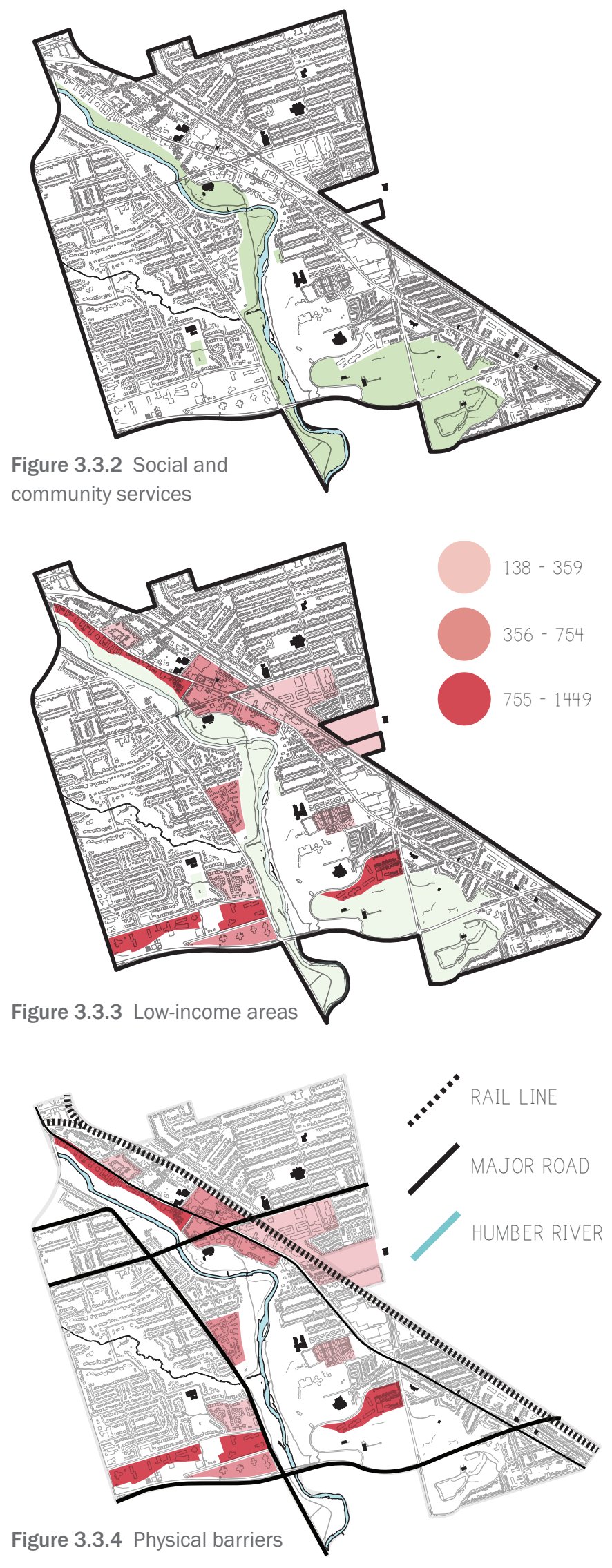


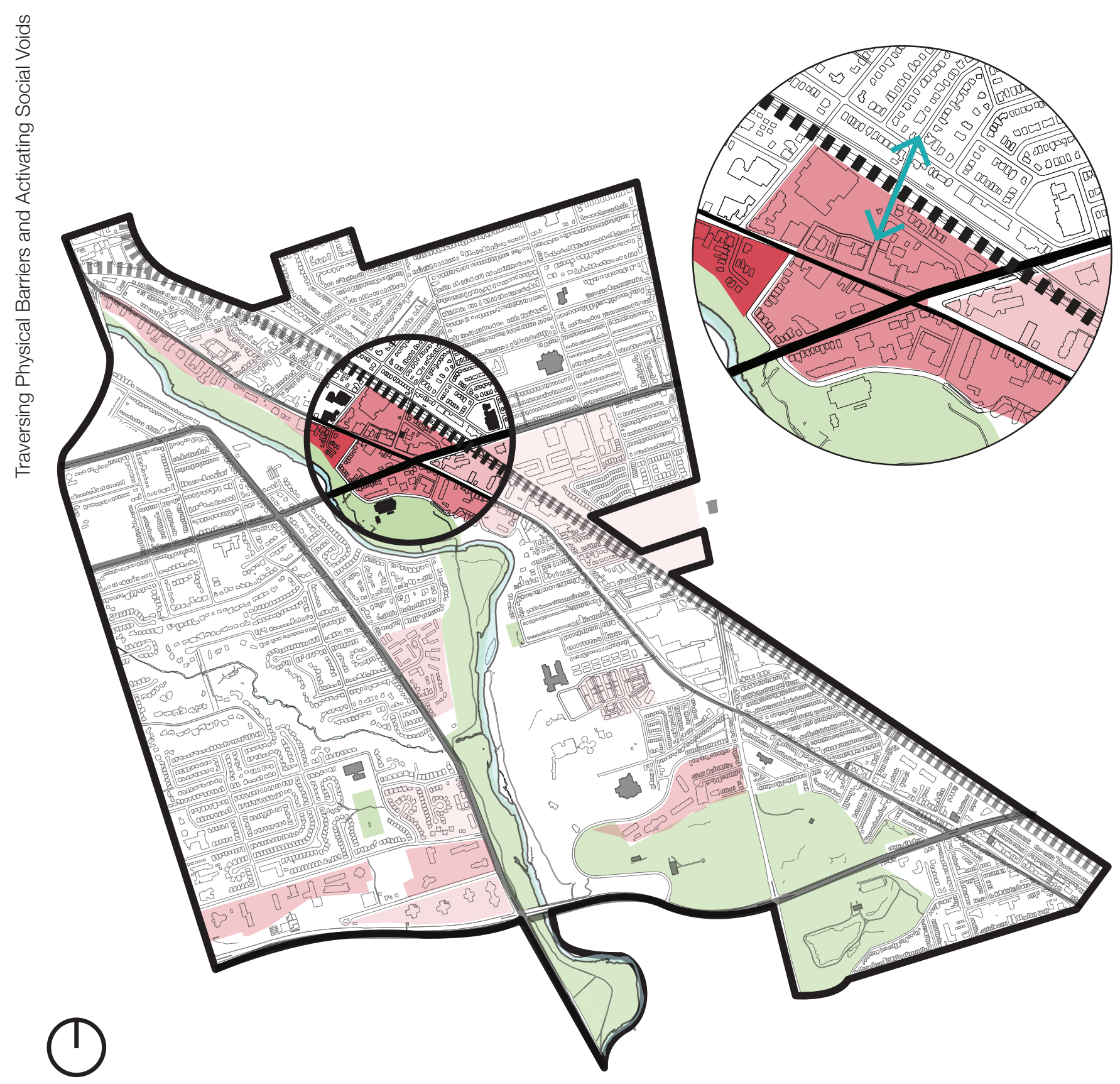

Figure 3.3.5 Railway condition 
From these maps, two potential locations were identified where inter-

ventions at a smaller scale could have been made to better connect low-income areas to community and social services. At the scale of the neighbourhood, one can identify all areas where low-income pockets are restricted from accessing services and other communities due to physical barriers present in the urban landscape. Targeting these areas as locations for further investigation is a part of a master plan approach to resolving barrier issue at a larger scale. Overcoming these barriers will better connect the neighbourhood and the communities within.

The first location, as illustrated in Figure 3.3.5, is a low-income area located on the Northeast corner of the neighbourhood. The site sits next to an active railway corridor and Weston road where most of the neighbourhood's commercial activity takes place. Although the low-income pocket has access to most of the services within the area, this location is relevant because of the physical divide created by the railway corridor that makes a clear division between different income groups. This site was not selected for further intervention because it did not pose an extreme scenario in which this thesis could be fully represented. The GO Transit line that passes through this site is currently being relocated below grade leaving only one line active on grade. The remaining line is only active for short periods of the day and plans underway to convert one of the roads passing between one side of the track and the other into a pedestrian street. The current developments on the site left little room to fully express the defining principles of this thesis through an architectural intervention.

The selected area of intervention is located in the center of the neighbourhood alongside the Humber River (Figure 3.3.6). On the one side sits Scarlettwood Court is a small community built by Toronto Community Housing in the 1960s. A more recent profile of Weston-Mt. Dennis shows that Scarlettwood Court is home to 360 - 754 low-income persons (“Weston-Mt. Dennis Priority Area Profile," 2008). This location was chosen because it is geographically isolated from the neighbourhood's recreational and social services. The Humber River in particular acts as a physical barrier restraining direct access to Portage Trail Community School, one of the only middle and junior schools in the area that serves close to 700 students from diverse cultures, races and ethnic 
backgrounds (“Portage Trail Community School”, n.d.). Unlike the railway condition, this site poses a serious threat to the residents within Scarlettwood Court. Opening up this physical divide will simultaneously open up connections between different social and ethnic groups and create

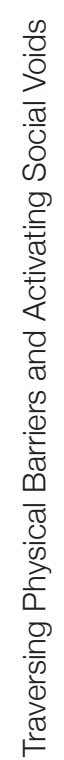
better access to needed services.

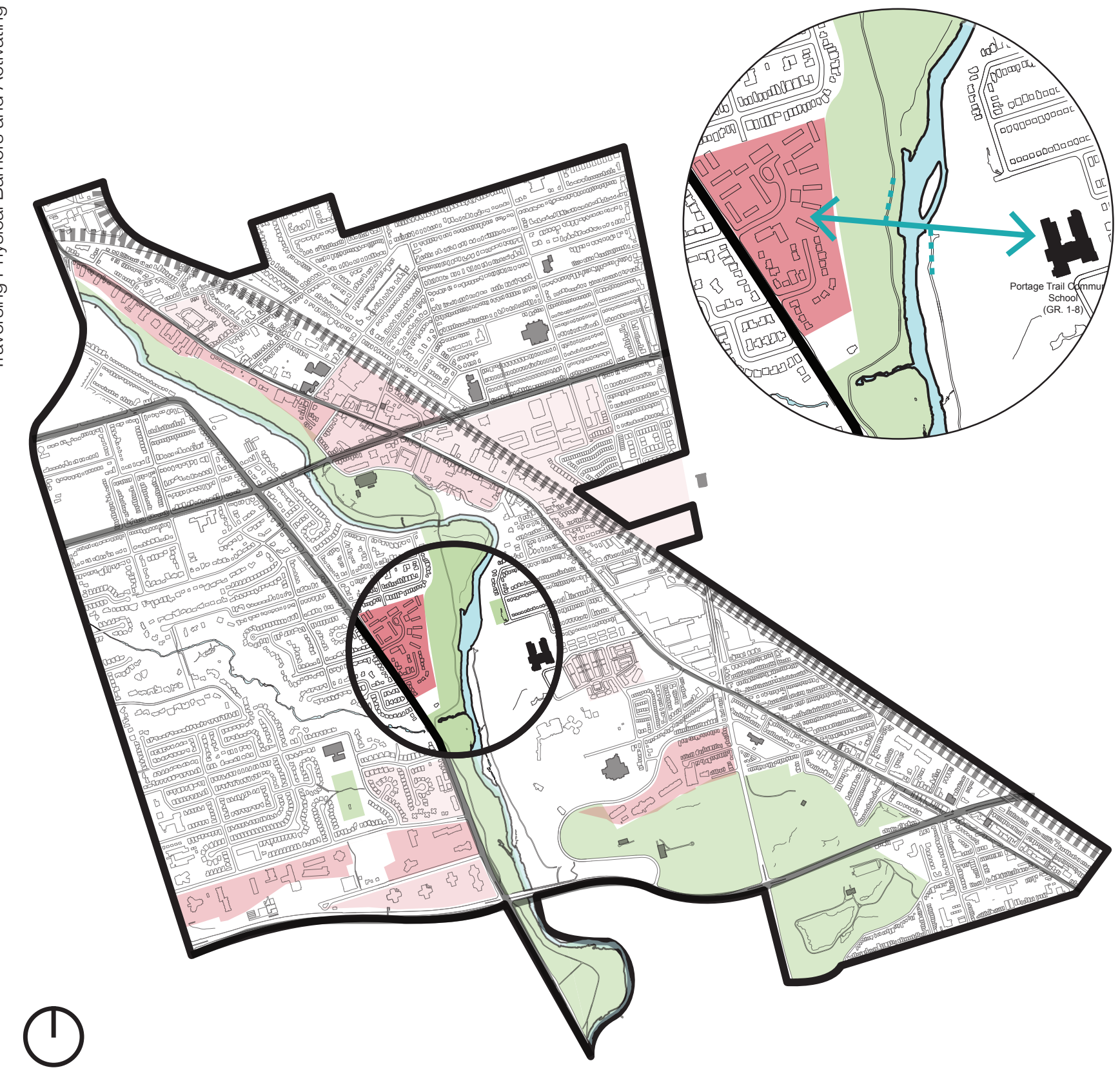

Figure 3.3.6 River condition 



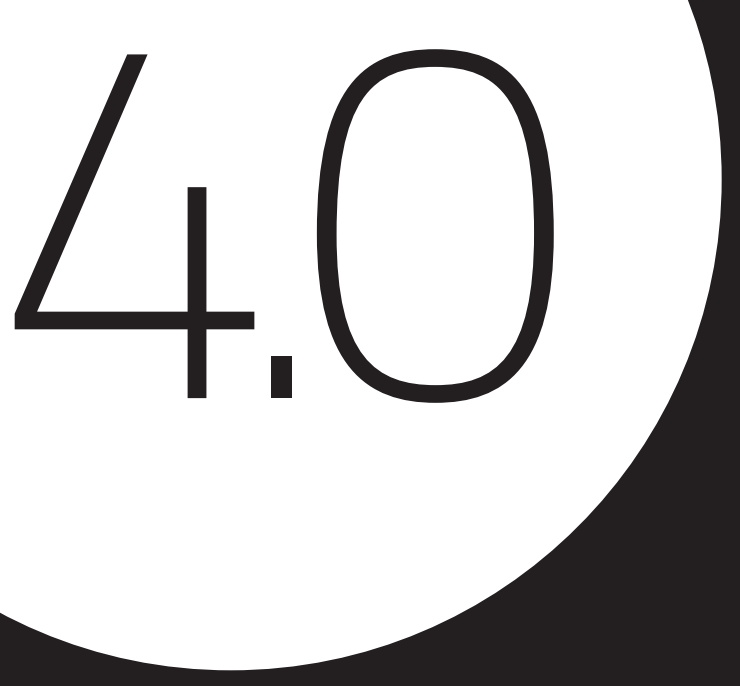




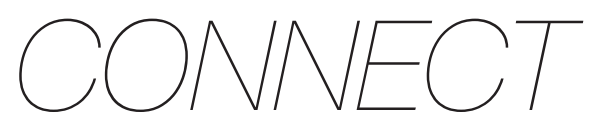

increase access to social resources $<<<$

In an effort to increase access between low-income areas and social resources within priority neighbourhoods, the following principle makes a safe and direct pedestrian and bike network between Scarlettwood Court and Portage Trail Community School on the East side of the Humber River. A secondary connection is also made to the Humber River Trail that runs parallel to the Humber River on either side (Figure 4.0.1).

Figure 4.0.1a Site conditions

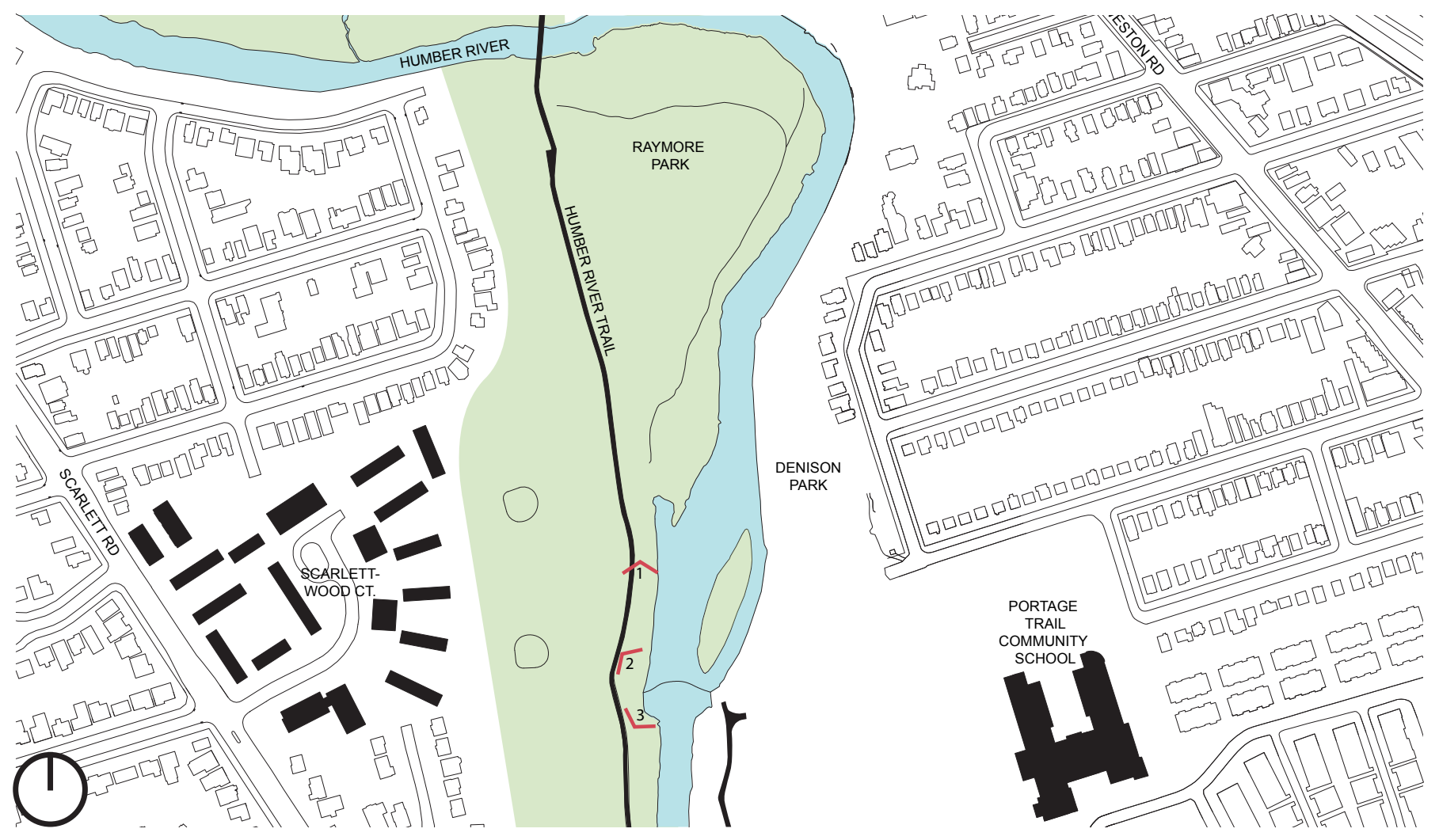




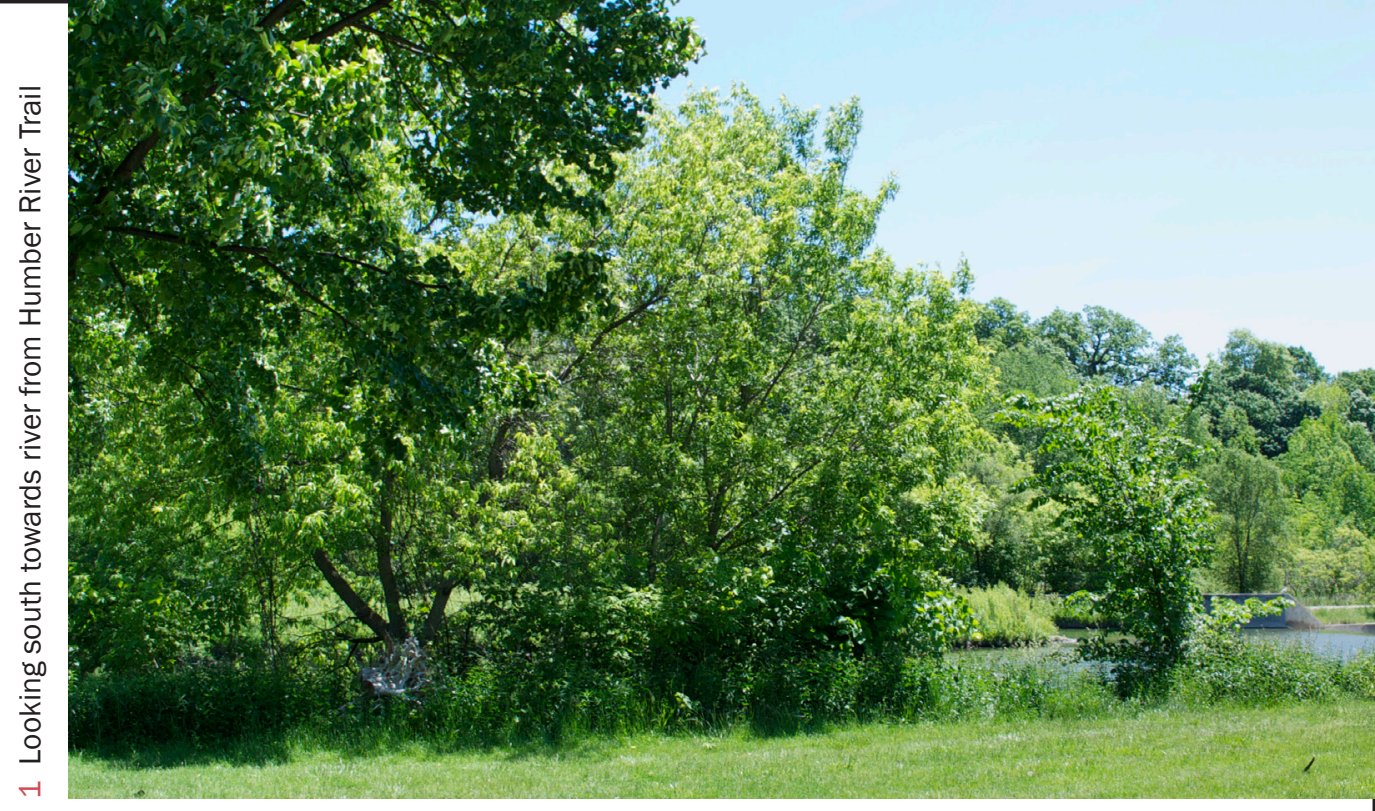

Figure 4.0.1b Site conditions

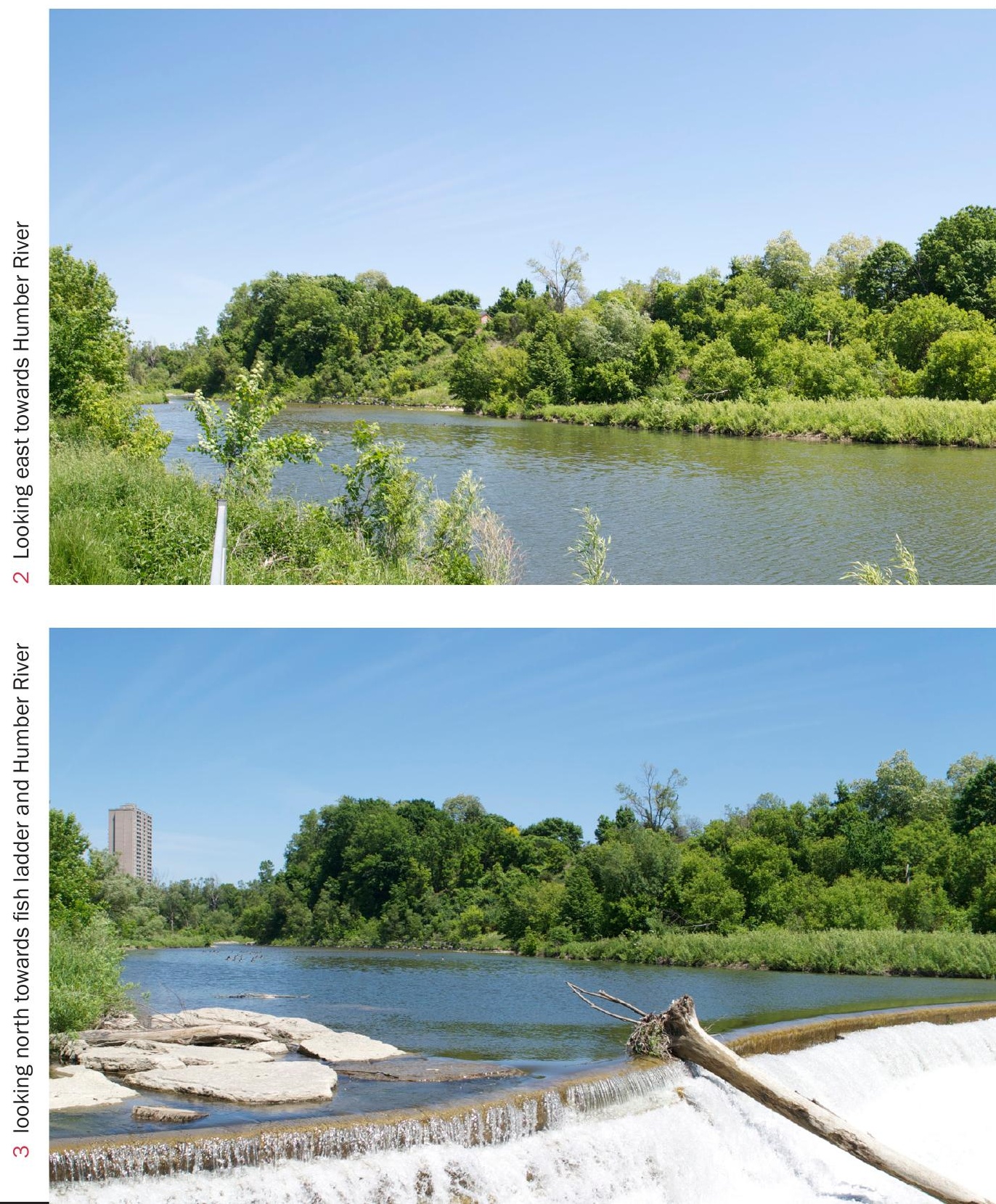




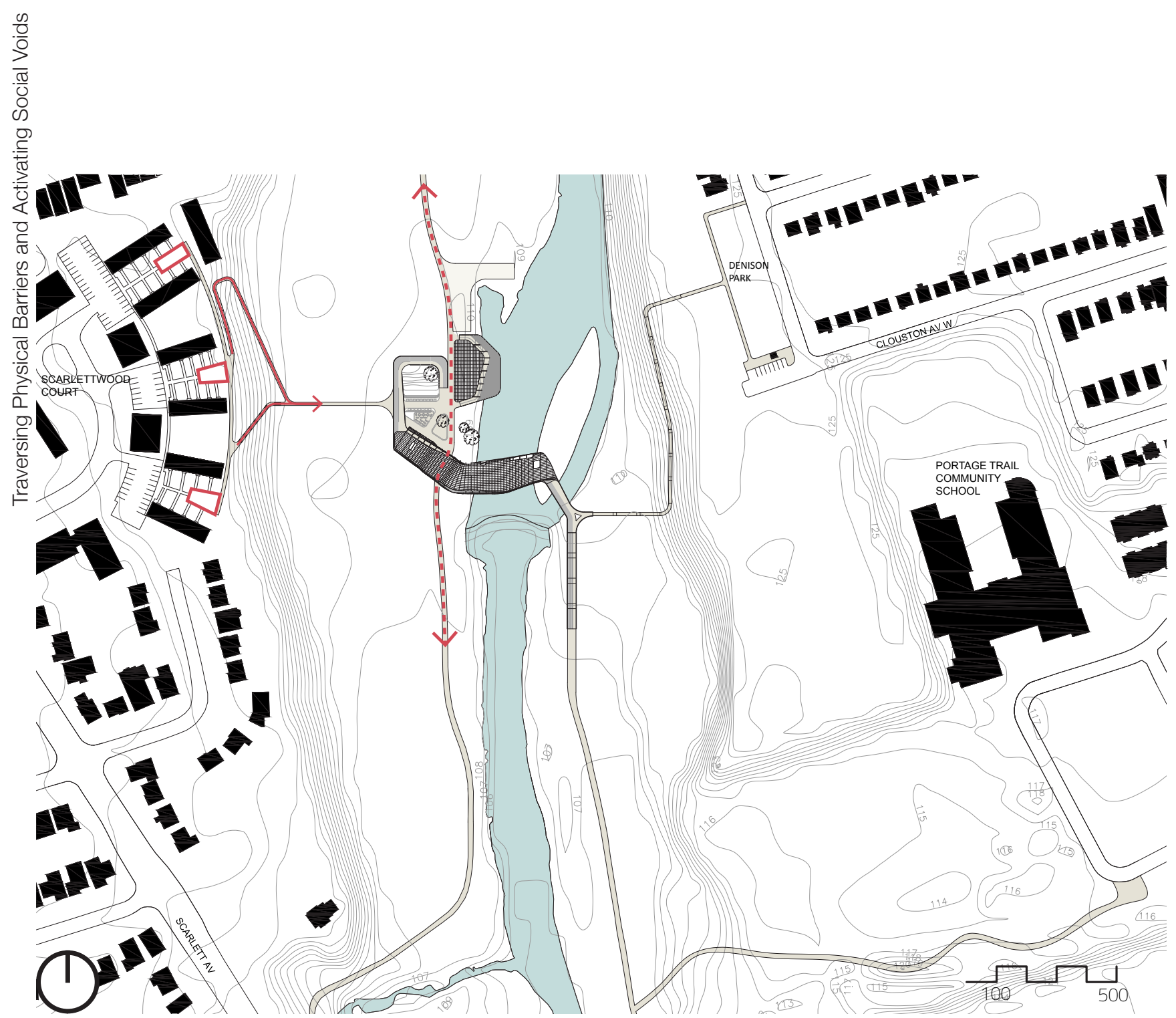

The new path connects to three existing communal courtyards in between 6 row houses within scarlettwood court and from there ramps and steps down the valley making a connection to the Humber River Trail (Figure 4.0.2). 


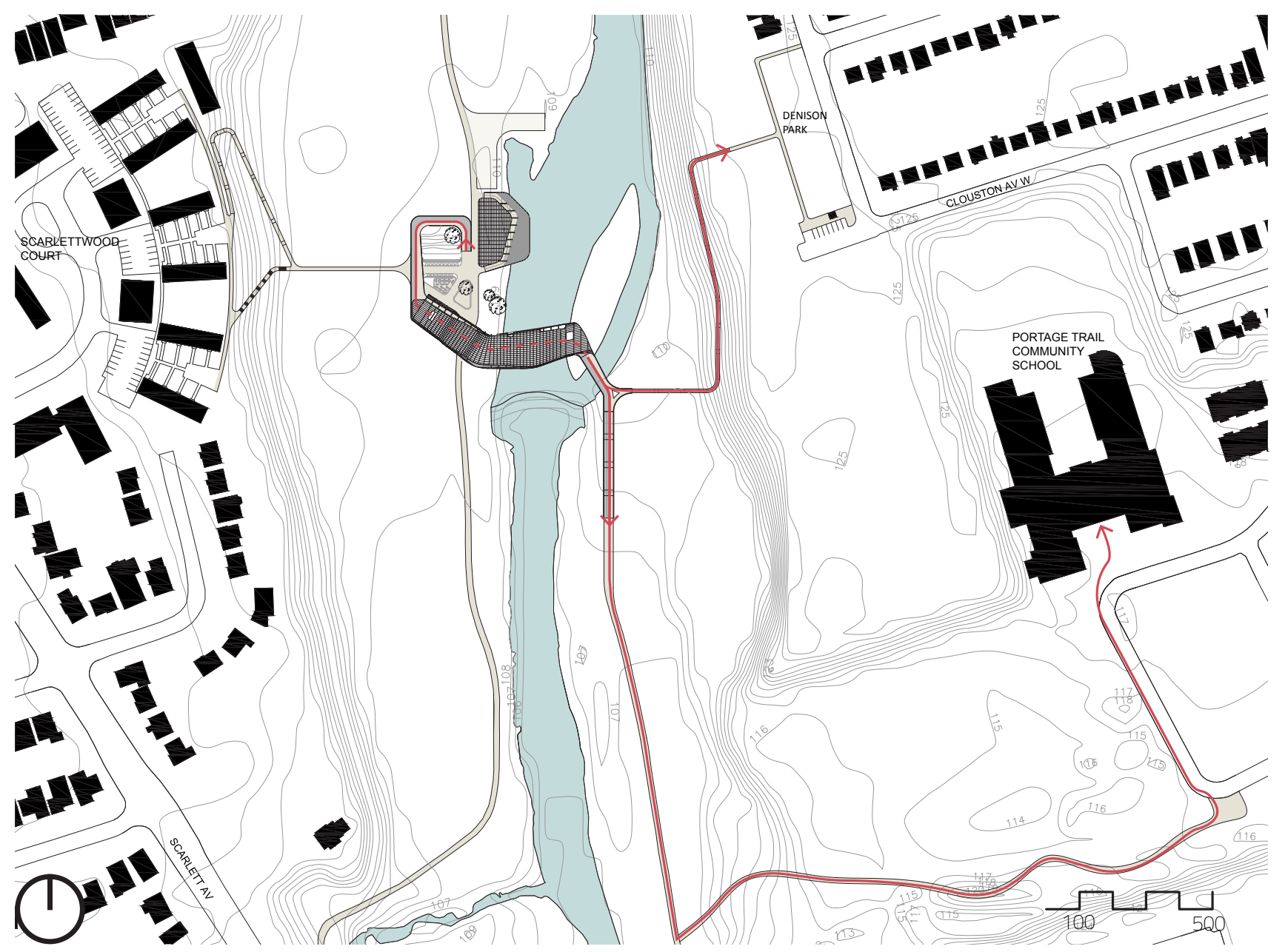

From this point, a new pedestrian and two-lane bike path ramp over the river to connect to the other side. From here, one can continue up a new ramp to Denison Park and the community on the other side of the valley, or follow the Humber River Trail to an existing pathway that leads to the front of the school (Figure 4.0.3). 


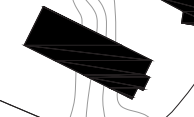

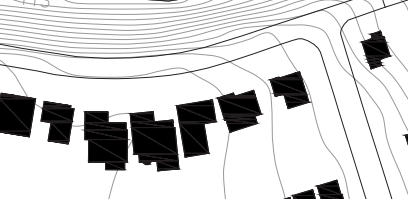
Bit

IS' (allinillit

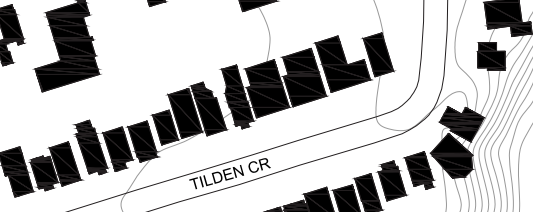

11n

E."

- ip-ing

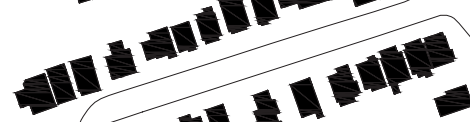

IIIIII

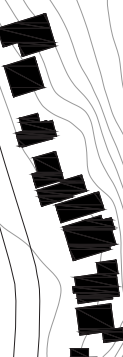

Z Hinkinn

(nit)

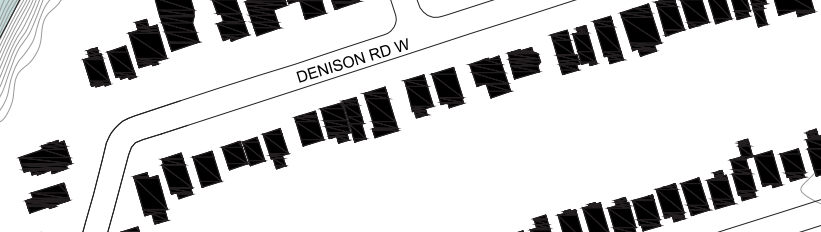

-

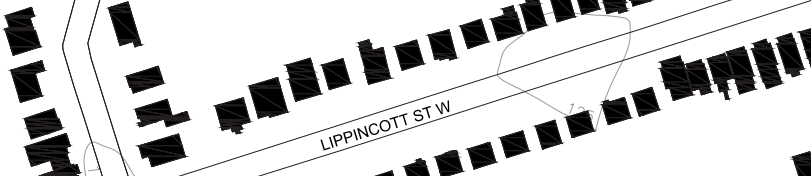
utavis

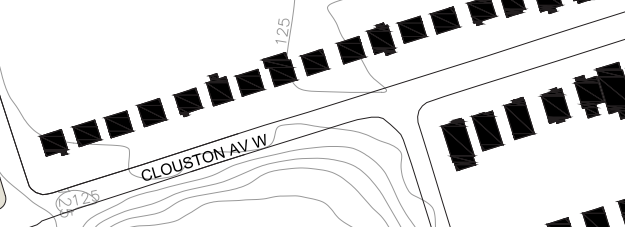

(E)

-

14atit:

$-(1)=$

$-$

(III)

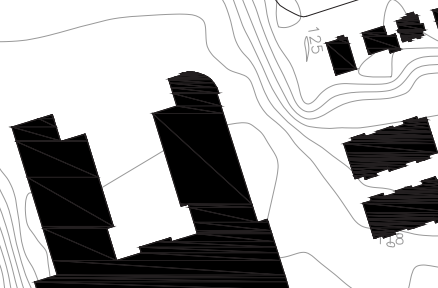





$$
5.0
$$




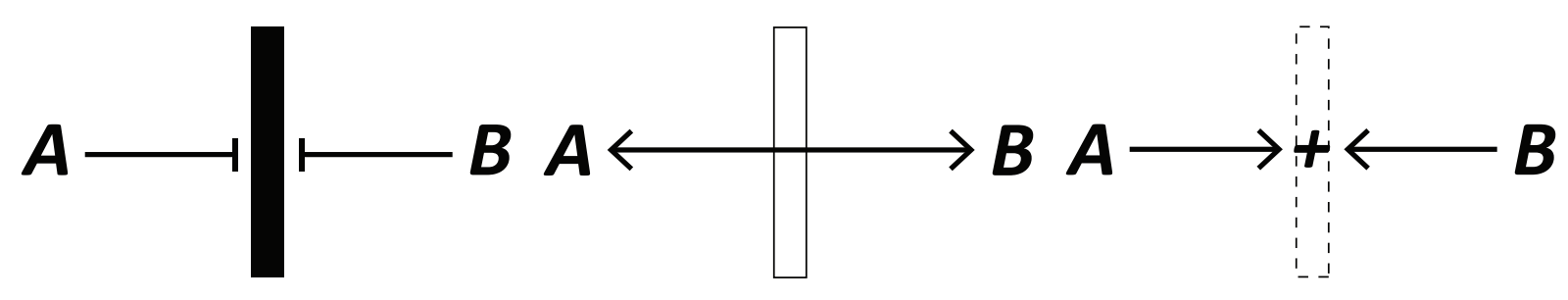

Since most priority neighbourhoods, especially Weston-Mt. Dennis, lack the proper social and community services that allow social interaction to take place, this thesis uses the point of connection as an opportunity to infill the network with programs that reflect the needs of the surrounding community. This will help draw people into the site not only to use it as a bridge to cross from one side to the other but see it as a destination in itself. This will increase opportunities for people to interact and socialize with others in the community. 


\subsection{Community needs}

In order for the bridge as a destination to be successful, it has to reflect the community and their collective needs. In the case of priority neighbourhoods, these needs include better access to services and more community facilities (Hulchanski, 2007, 10). The programs that have been selected to activate the bridge are therefore a reflection of the surrounding community and the social infrastructure that is not accessible to them.

Before establishing the program that would activate this site, I looked at the existing and future users that will occupy it and its surroundings. The existing users are primarily those using the Humber River Trail that runs alongside the river. Most people use this trail to bike, walk, jog, etc. The green space around the site is also used as outdoor space for picnicking, nature walking and sunbathing. To accommodate and enhance the existing uses of the site, the proposed program utilizes the ground floor as a rest stop with a café/eatery adjacent to the Humber River Trail as well as an equipment rental facility so people using the trail can rent bikes and water equipment. The courtyard in between these activities acts as

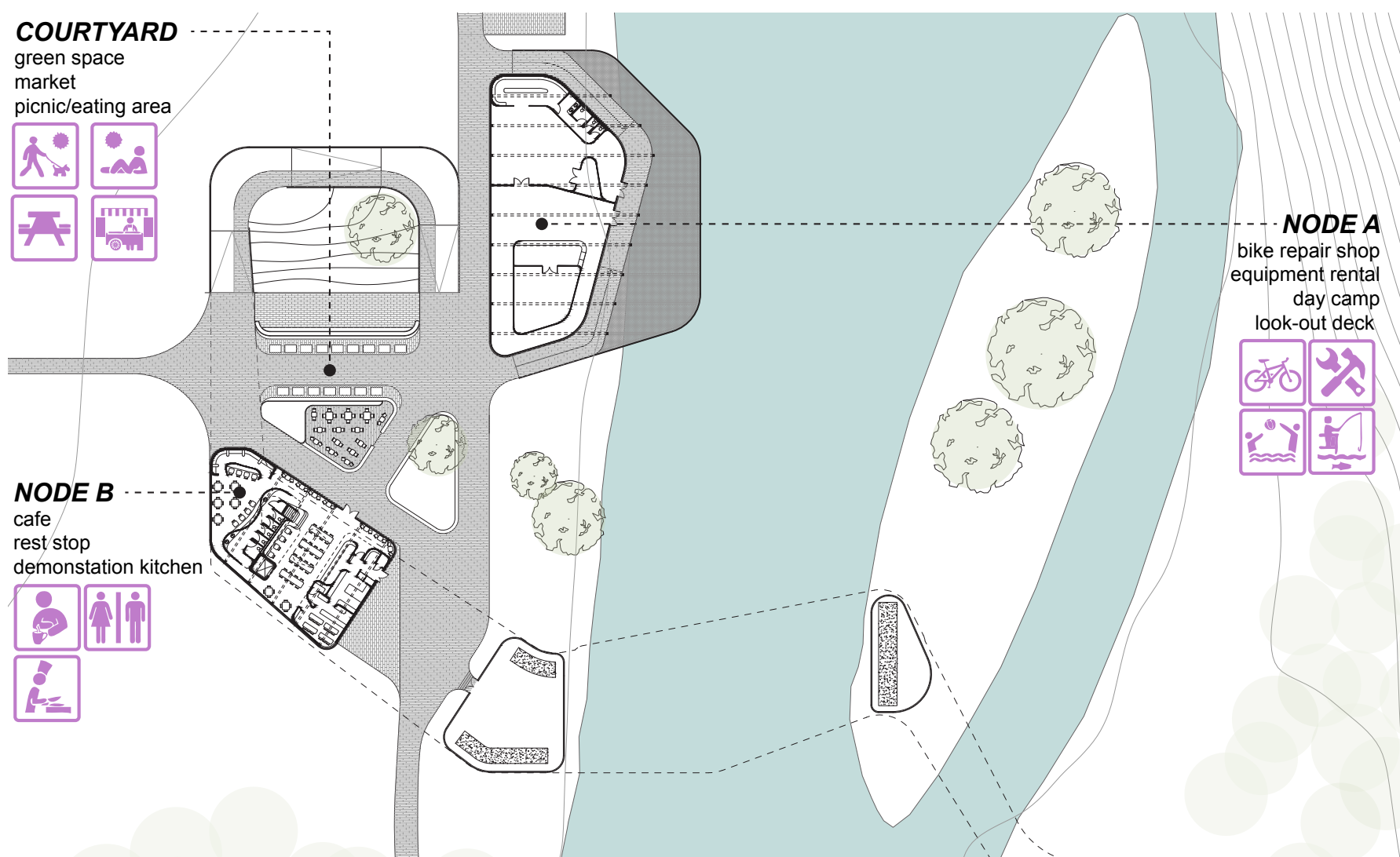


an extension of the trail system and a spill-out area for outdoor activities

such as playing, picnicking, sunbathing, gardening, and market shopping (Figure 5.1.1). These spaces enhance the existing, informal uses of the site by creating an outdoor public space with an enhanced multifunctional program suited to all age groups.

Along the bridge the programs become more specific to the surrounding community. Since the primary link is between the low-income neighbourhood (Scarlettwood Court) and the Community school (Portage Trail Community School), the program along the link that connects the two is directed towards community building and learning. Above the café is a community multi-purpose space that can be rented out for community events or extracurricular classes, student exhibitions, or fitness/ dance/art classes. The last activity node along the bridge is a community learning facility for the students and adults equip with open and private study spaces, reading lounges, a lecture hall for workshops and classes, a com $\neg$ puter lab and a resource library. Currently, Weston-Mt. Dennis has two libraries and one community center (see Appendix A for maps), both of which are far from this site. Incorporating these facilities into this bridge network is important and relative to the needs of this community (Figure 5.1.2).

Figure 5.1.2 Programs on bridge

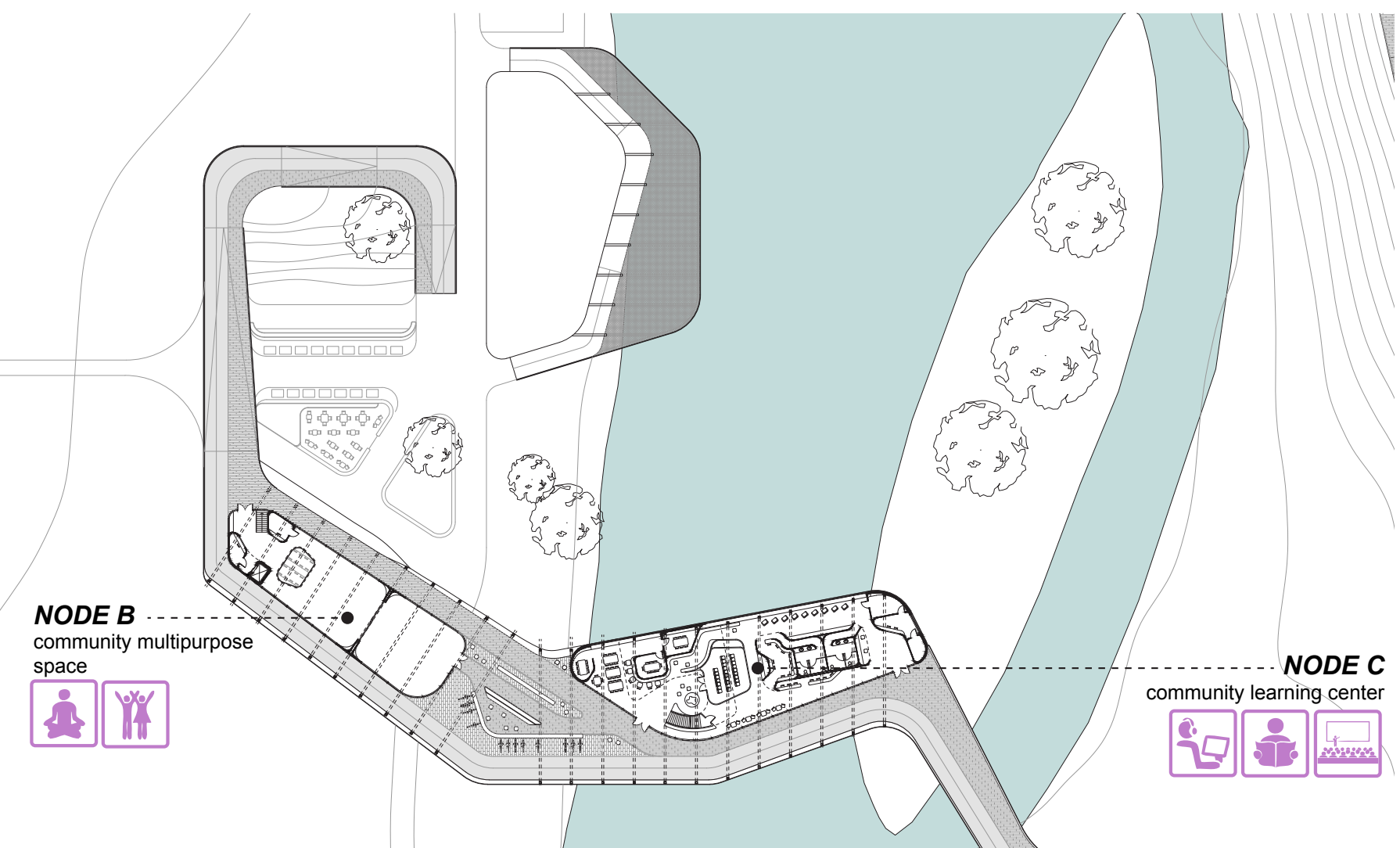




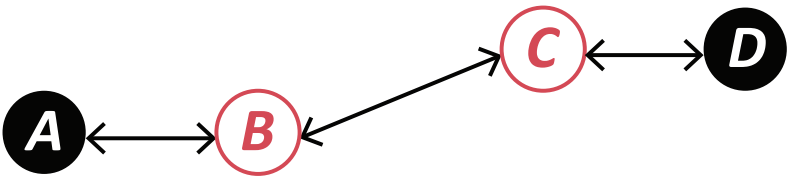

Rather than merely creating a link between point $A$ and $D$, this thesis aims to break up the program into multiple destination points along the path of movement. Distributing programs rather than clustering them into one area, or one building, extends the procession from one end of the bridge to the other opening up the chance for informal interaction to take place. The spaces in-between the activity nodes act as informal social space with non-fixed programs that can adapt to individual user's needs. Dispersing the programs into various fixed nodes along the path ultimately increases the circulation and informal social space around them (Figure 5.2.1). In addition, this strategy breaks away from the concept of creating a direct route between point where one can see the whole route at a glance before starting and instead wraps the path of movement around dispersed activity nodes and creates multiple experiences along the way. "Walking is a form of transport, but it is also a potential beginning or an occasion for many other activities." (Gehl, 2010, p.120)

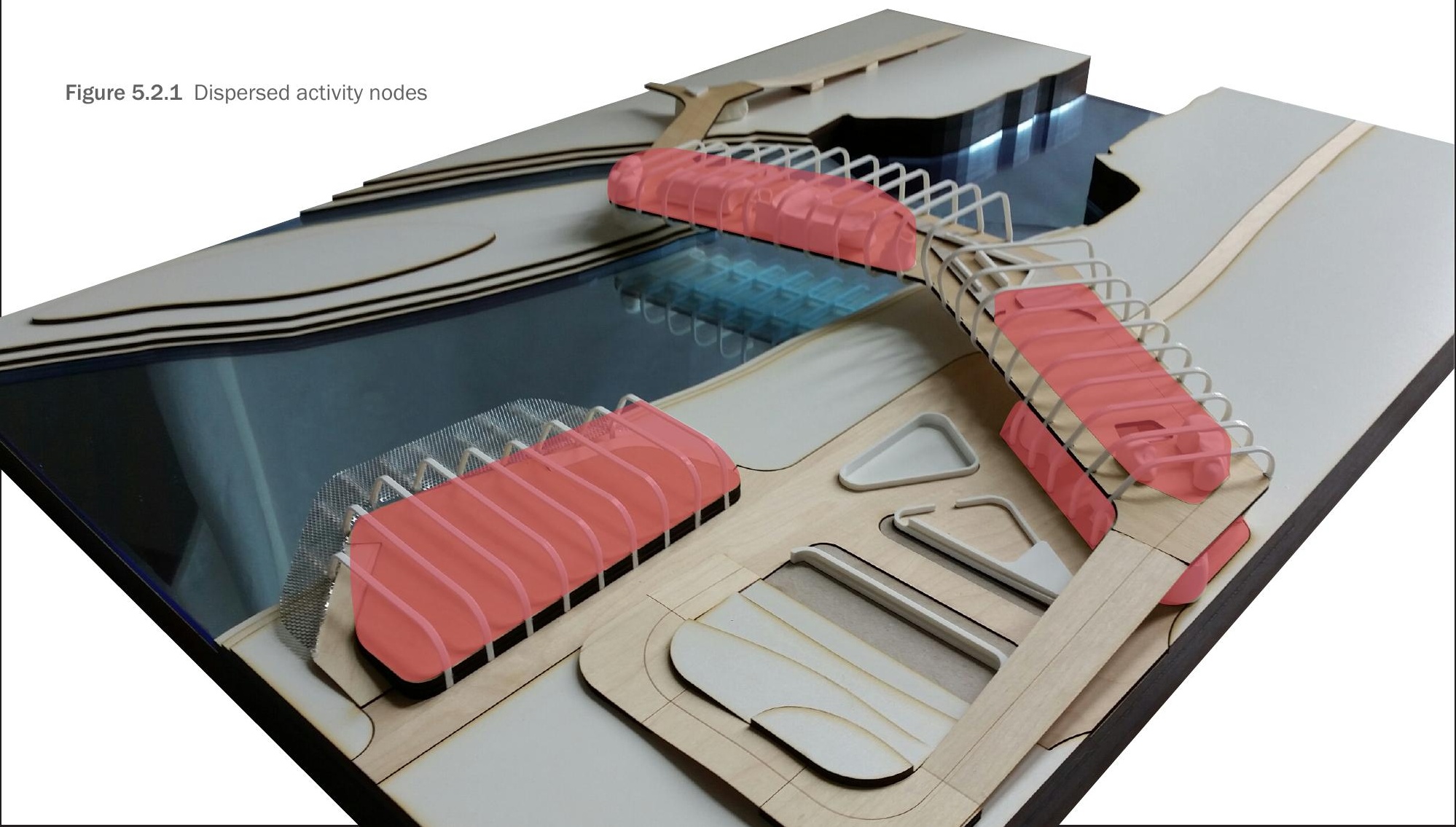





$$
6.0
$$




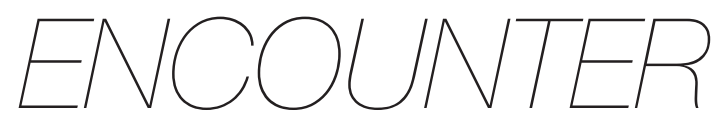
increase participation $<<<$

"People gather where things are happening and spontaneously seek the presence of other people"

(Gehl, 2010, p.25).

Canadian journalist, Bert Archer (2013), claims that those living in Weston-Mt. Dennis lack a sense of belonging to the community and do not feel like they can go out and openly interact with others. The third principle looks for ways to increase participation among socially hesitant individuals by designing spaces that increase the chance of encounter. Studies by Jan Gehl were looked at to understand what attracts people to a space and what encourages them to stay and participate on a formal and informal level. The following strategies incorporate the findings from Gehl's observations and enhance their probability to work by placing them at the intersection where flows of people and activity meet. 

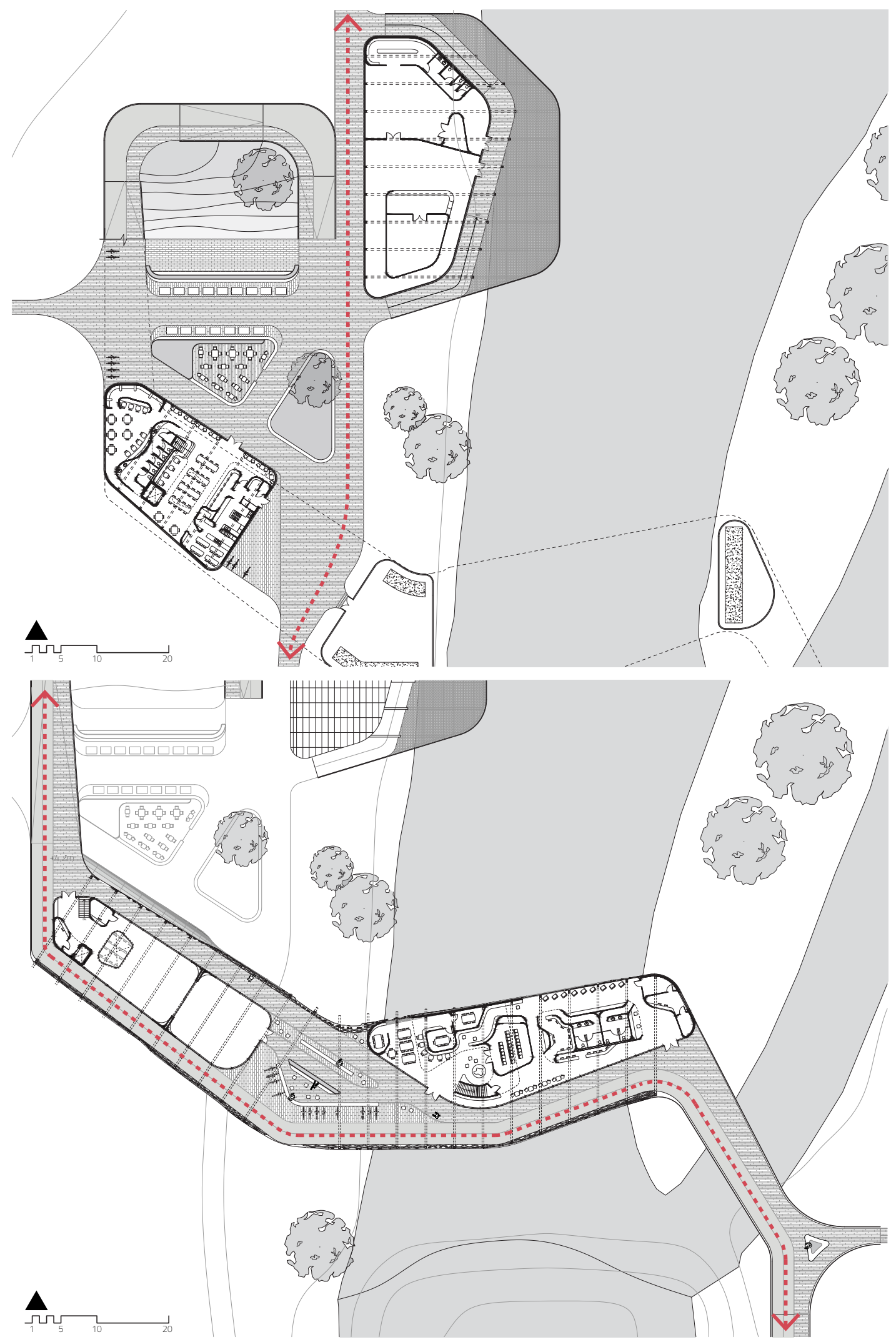


\subsection{Intersection of movement}

There are three types of movement patterns that run through the site. Those cycling, running, or using any other non-motorized device are categorized under fast movement; slow movement includes those walking through the site or between activity nodes; and fixed movement is anyone immobile or participating within one of the activity nodes.

Those using the Humber River Trail to bike or run can continue to use the trail for its original purpose. The existing path of the trail runs directly through the new site without any visual or physical impediments (Figure 6.1.1).

A separate bike path is built into a new network that bridges over the Humber River. The use of a paved concrete finish for the bike lane distinguishes itself from the walking area and lends itself to the conveniences for those commuting or traveling at faster speeds (Figure 6.1.2)

Unlike those following the fast lines of movement, ' 'walkers can effortlessly stop underway to change direction, maneuver, speed up or slow down or switch to a different type of activity such as standing, sitting, running, dancing, climbing or laying down ' (Gehl, 2010, p. 119). These lines of movement are therefore located in relation to the activity nodes on site. Wood is used as a surface treatment in walking or slow movement areas. This material was chosen for its subtle appearance in a natural environment and for its soft qualities, ideal for a walking surface.

In a way to increase social encounter and participation along the bridge, there are dedicated areas for informal interaction placed at the intersection of these lines of movement. These areas feature edges, niches and places to sit to watch people and activities. These areas will be successful incubators for social engagement and participation since they are at the intersection of movement so there will be opportunities to watch people and activities. Providing places to sit and edges and niches that face people and activity increases people's perception of them as places to gather. 


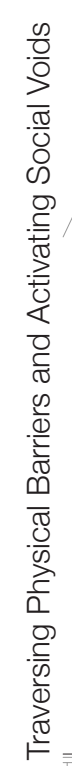
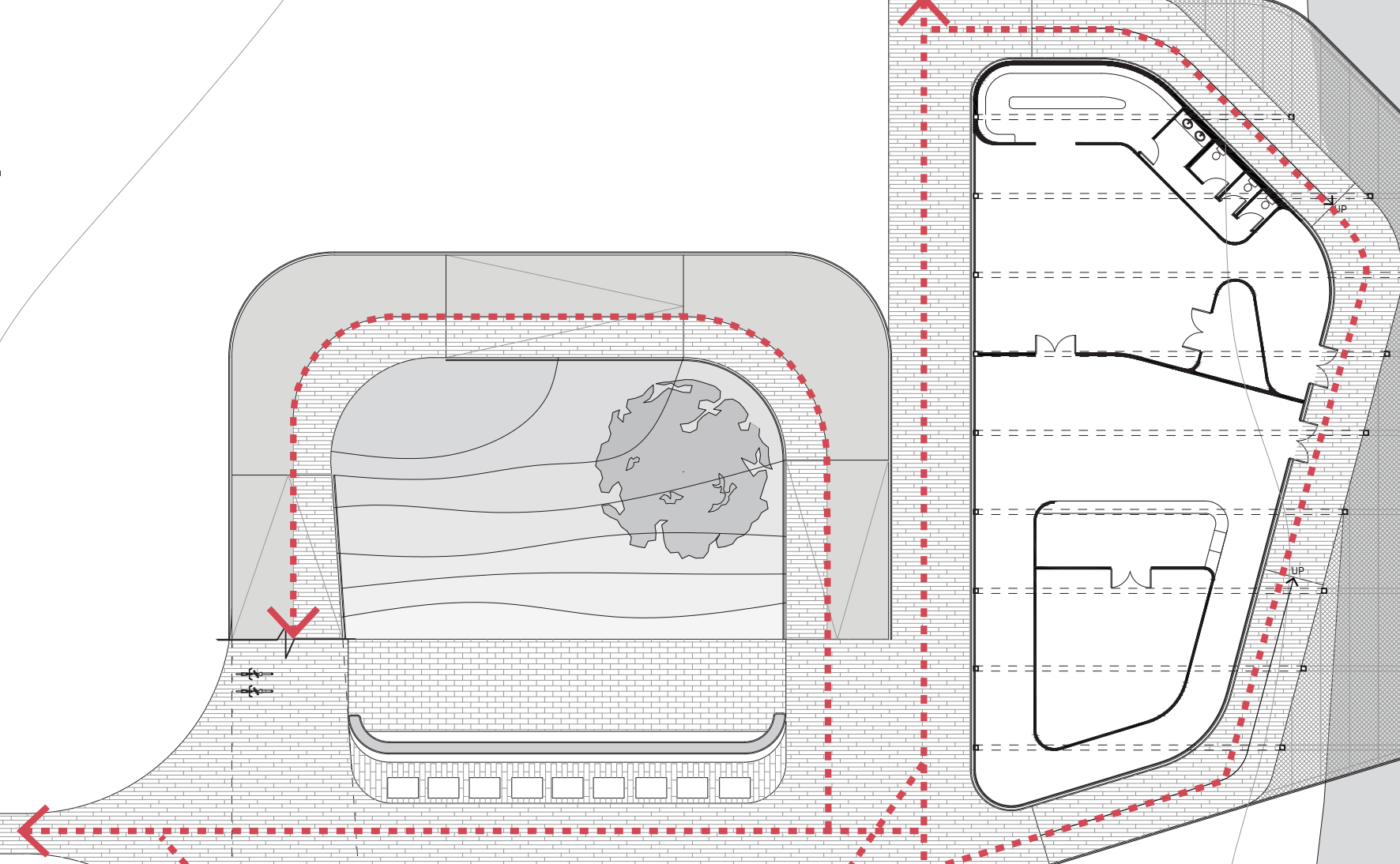

$\Delta$
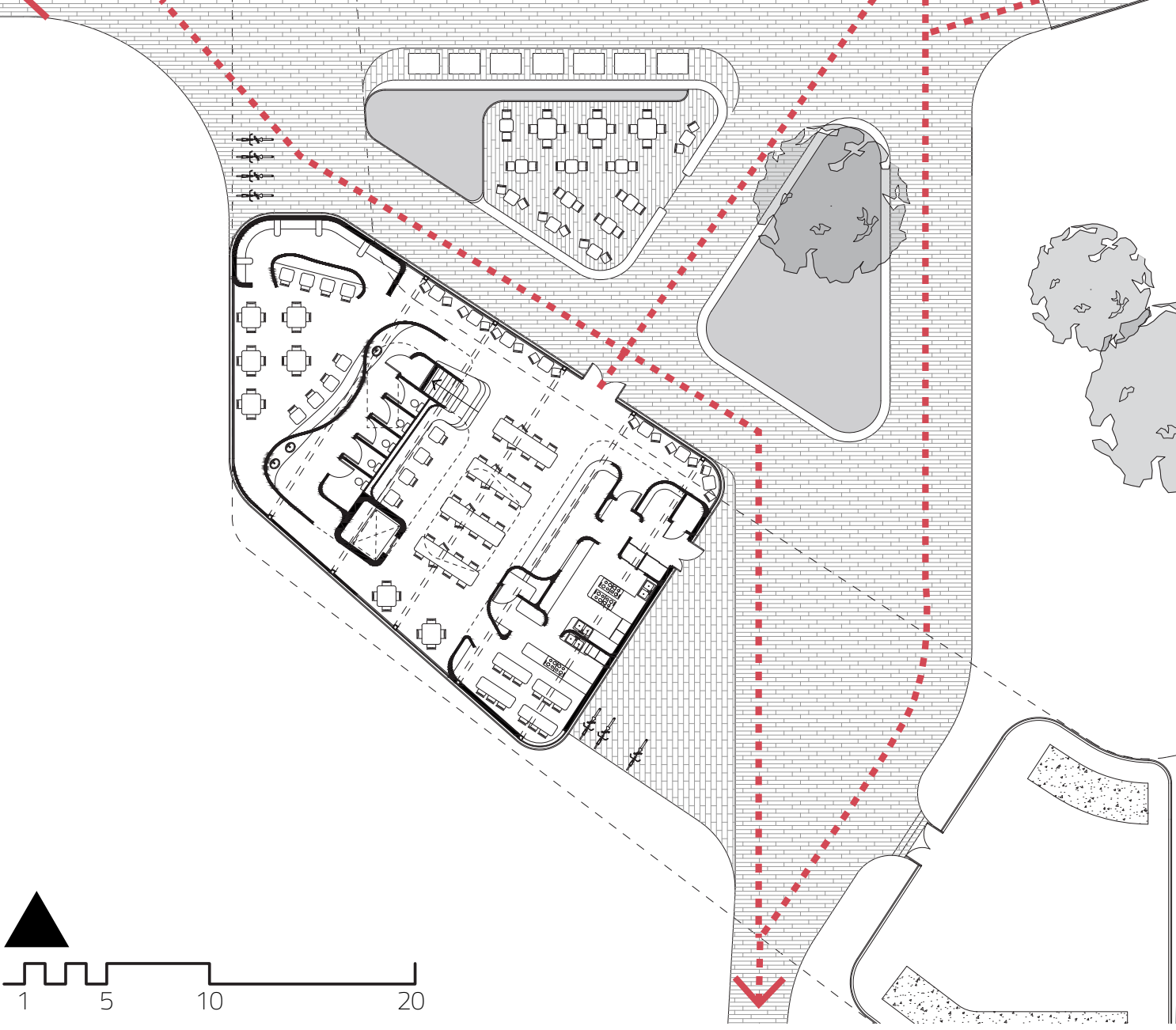
On grade, there is an intersection formed by the path entering the site from Scarlettwood Court and the Humber River Trail passing through the site (Figure 6.1.3). This intersection features spill-out activity from the surrounding activity nodes and informal seating to further accommodate interaction. 


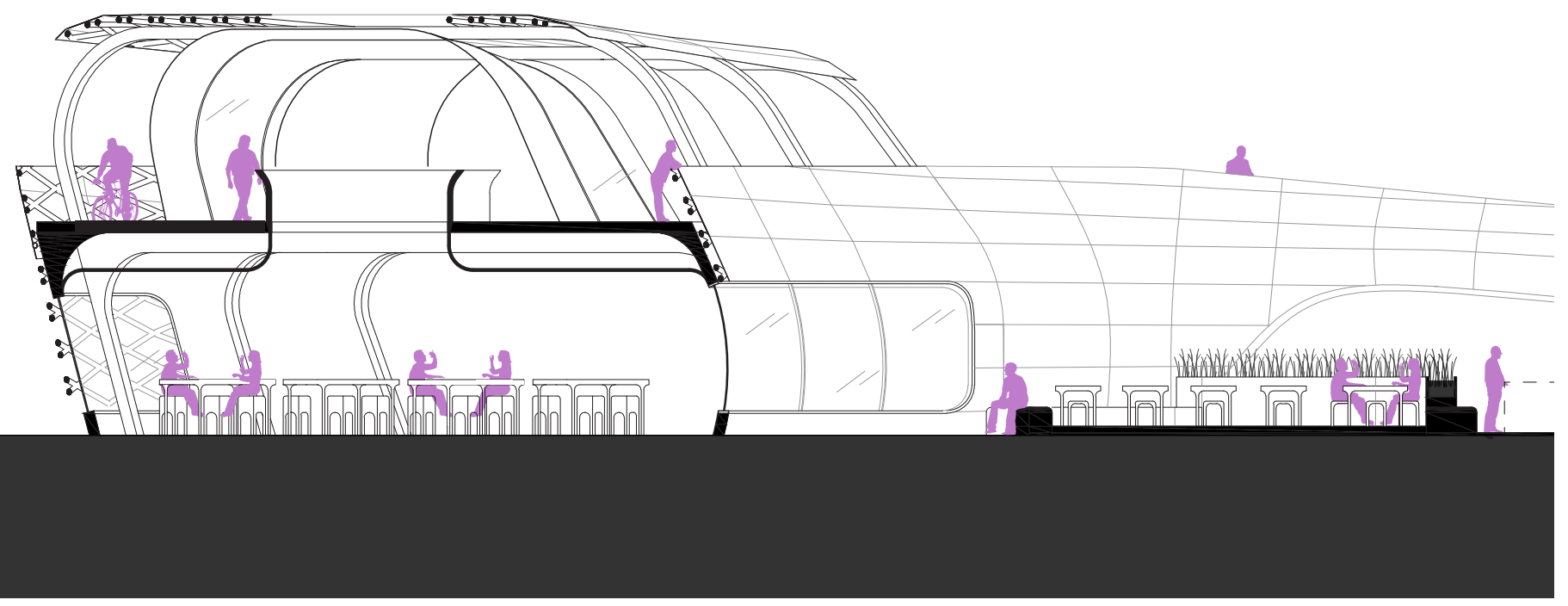

There is an elevated platform across the entrance to the café for people to sit and eat outside or just watch people walk by. This area is bordered with an edge featuring high planters to increase privacy from the path of entrance from Scarlettwood Court. The side that faces the café however is designed with a lower bench that wraps around the elevated platform. This opens up views to the café and creates an informal place for people to sit while subtly separating the outdoor eating area from the pathway. The path of entry from Scarlettwood Court draws people into the site through an informal market lane. Residents can use this area to set up market stalls and sell food and goods on the weekend. It is a point of entry that is active and will help draw people into the site to see what is going on. 


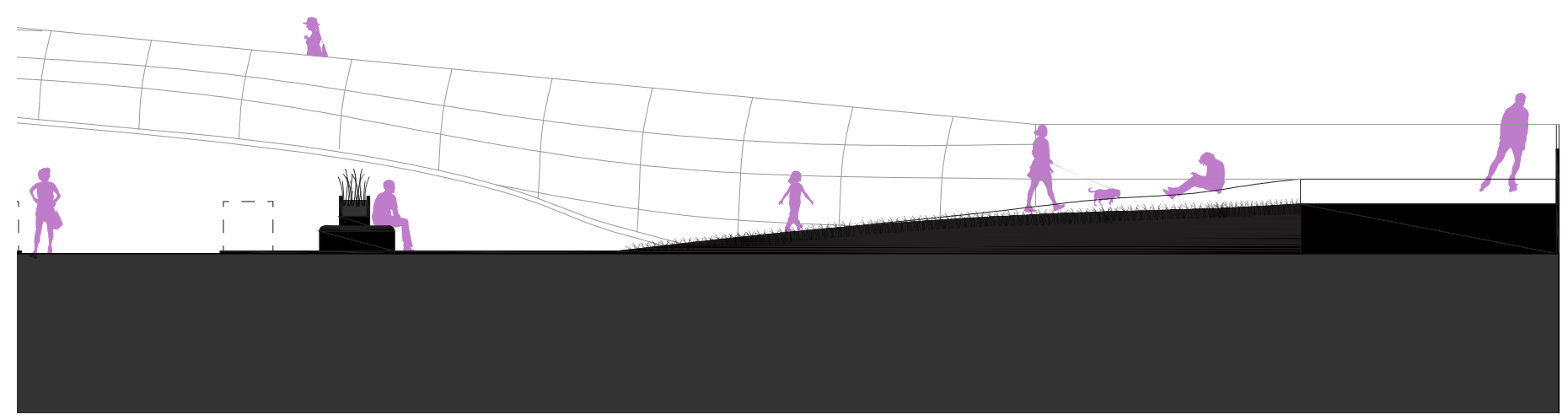

On the other side of the market lane is a landscaped mound that can be used as an informal sitting area, a place to watch people, sunbathe, or toboggan down in the winter. The use of planters, benches, and changes in floor materials helps to create an edge that differentiates the outdoor café, market, and landscaped mound from one another and transforms what would otherwise be a large open space into a series of loosely programed open spaces. All three are visually and acoustically connected to one another but stand out as independent elements. 


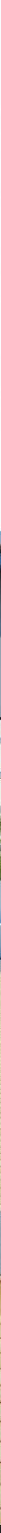




$$
21
$$
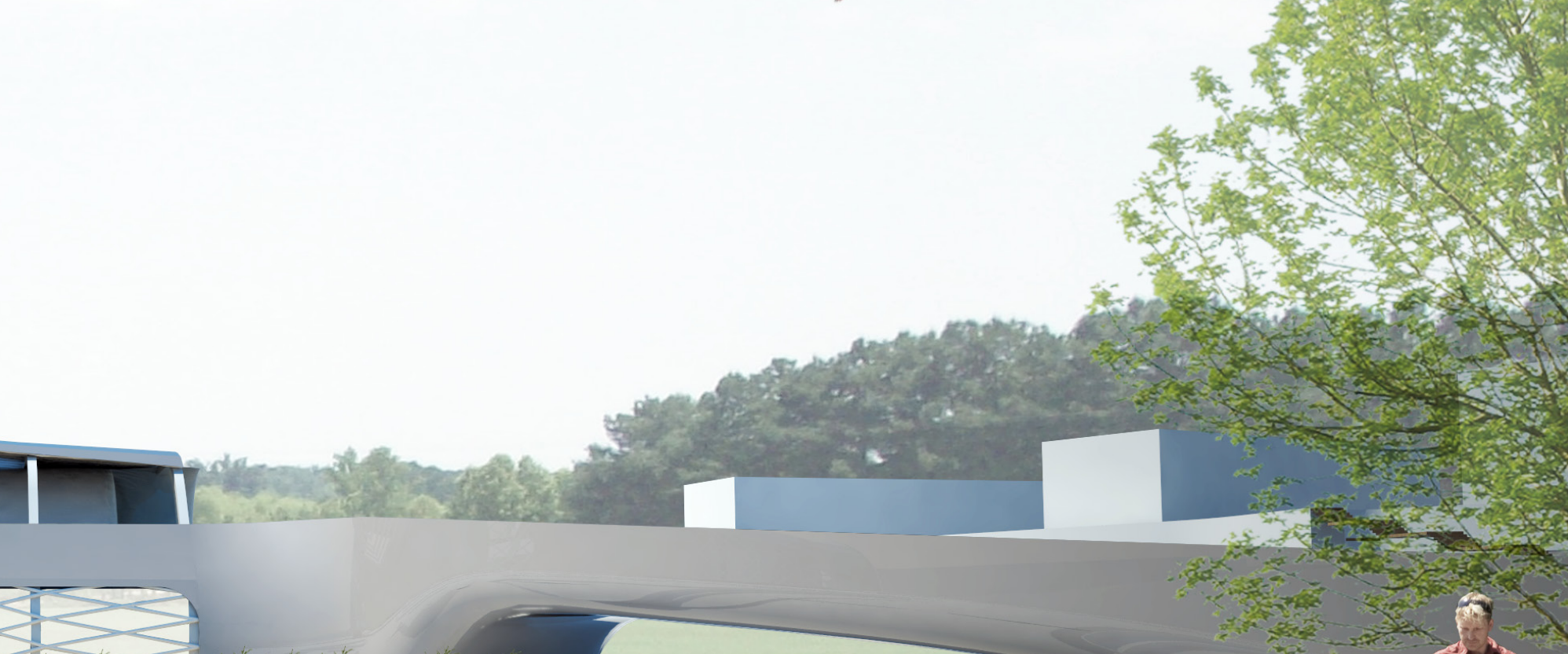

\section{tiste
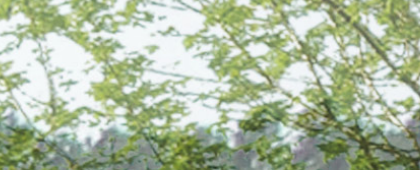

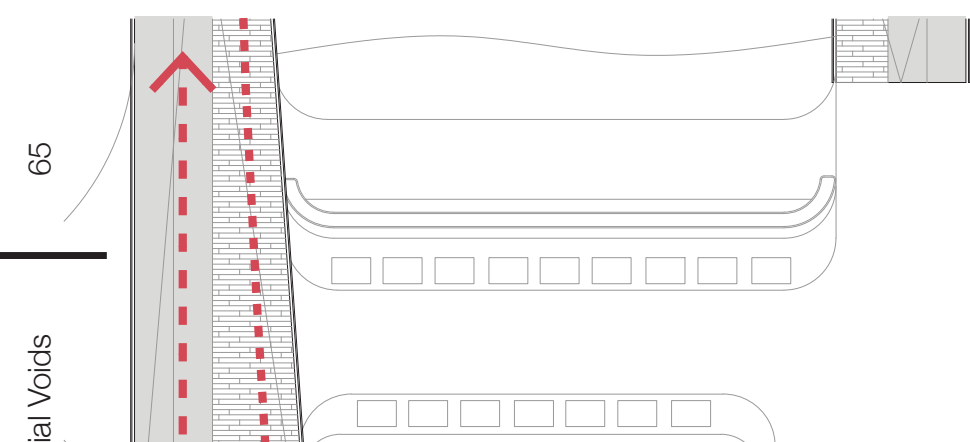
Along the bridge a similar intersection between crossing lines of movement occurs between two activity nodes and at the intersection of walking and bike paths (Figure 6.1.6). The paths of movement are clearly outlined with wood planks while seating areas are formed from the negative space around these movement patterns.

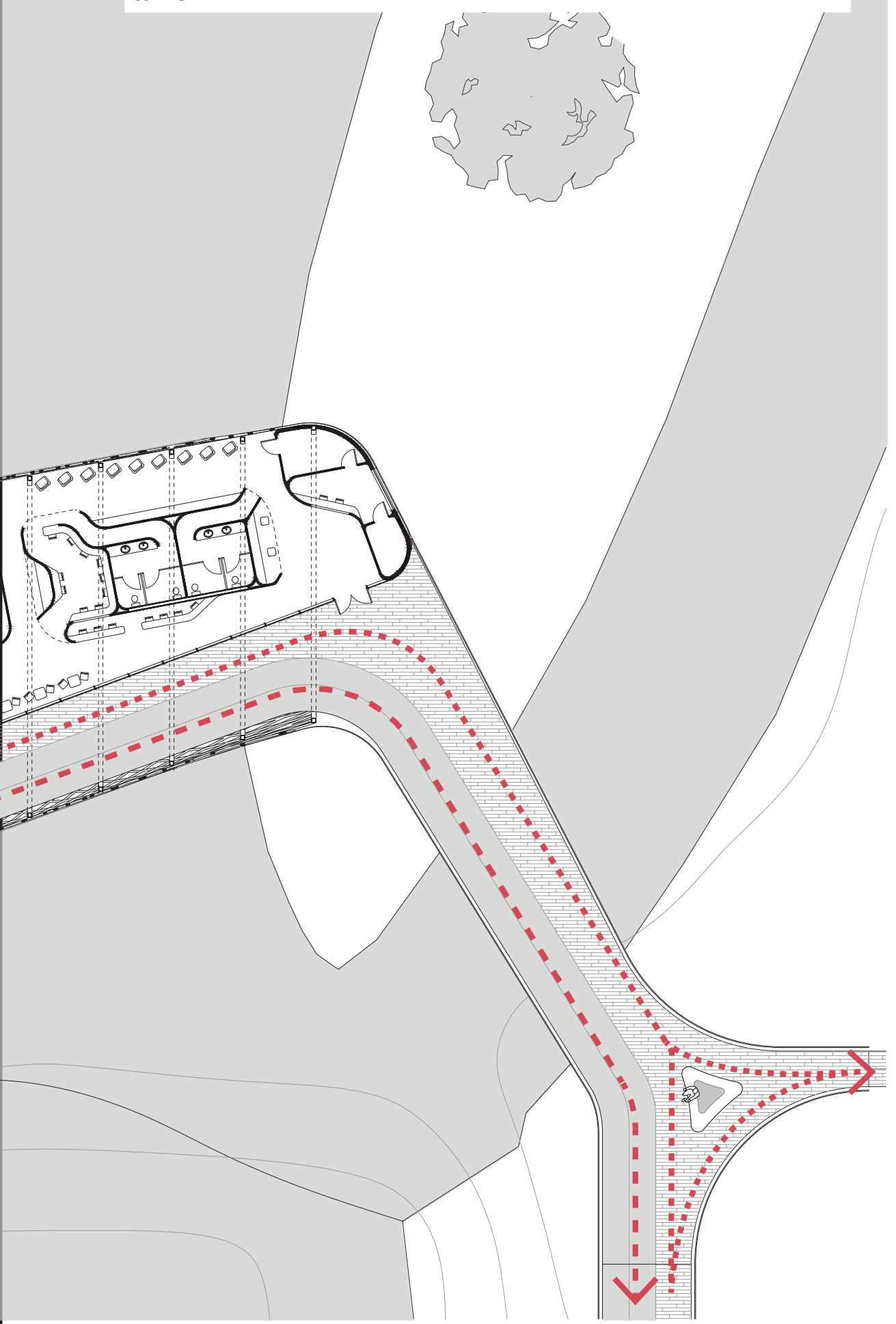




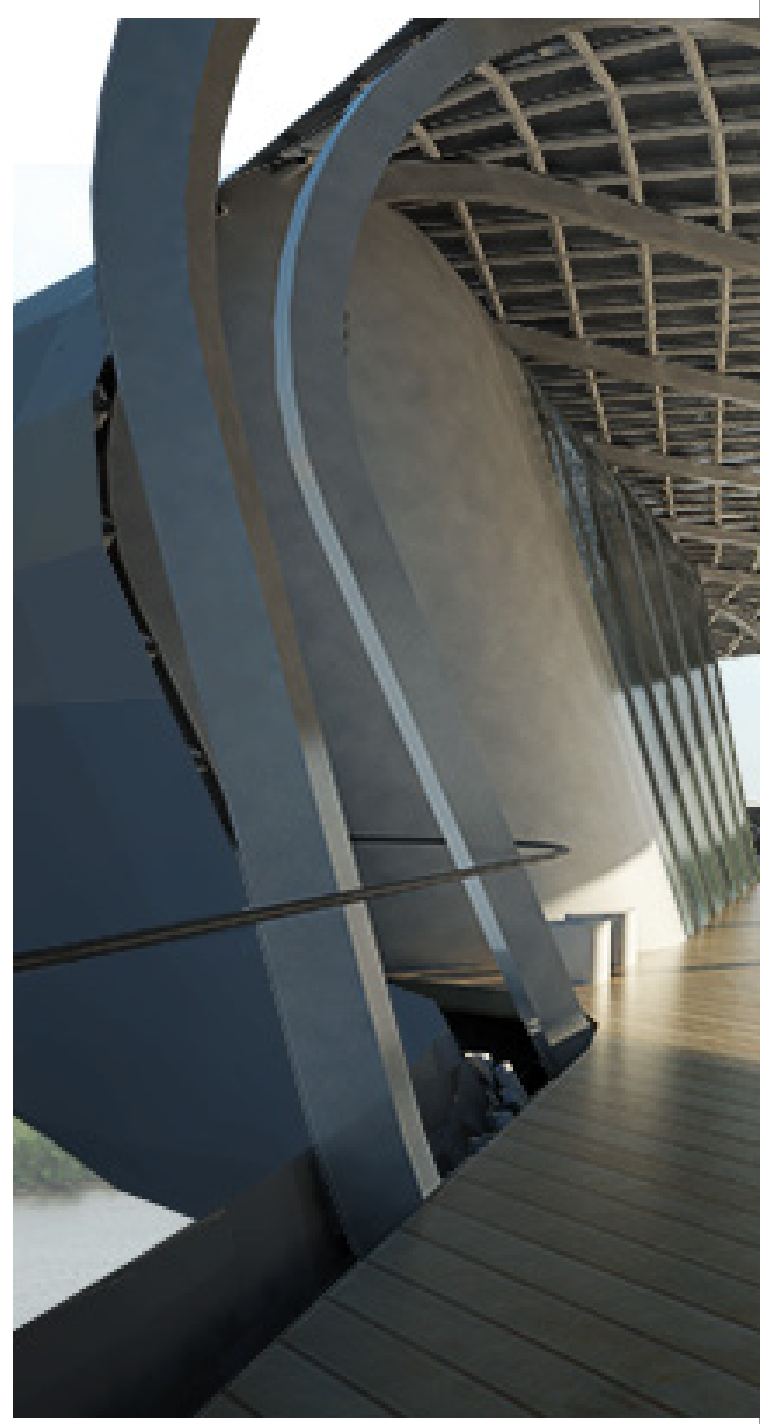

Figure 6.1.7 View of intersection on bridge 


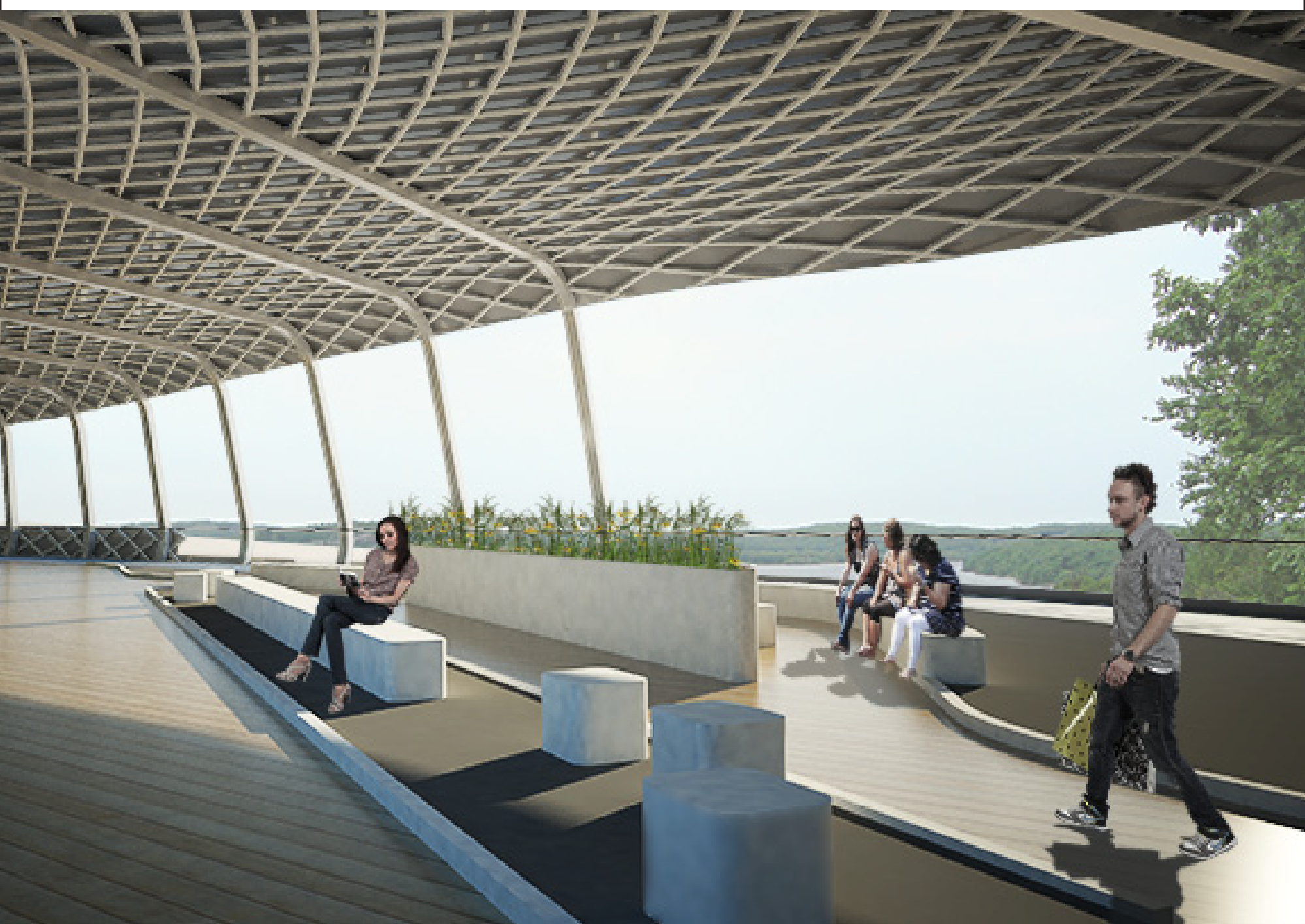

Permanent seats are designed with high backs formed by planter boxes. The tall grass that grows in these planters helps to divide the seating area from the pathway creating a comfortable microclimate appropriate for stimulating informal social behaviour (Figure 6.1.7). Moveable seating is also incorporated along the path to allow people to shift seating arrangements depending on their personal needs -for example, some people will want to create a cluster grouping depending on who they are with and others may want to move their seats in the shade or in a more sheltered area depending on weather conditions (Shaftoe, 2008, p.102). 


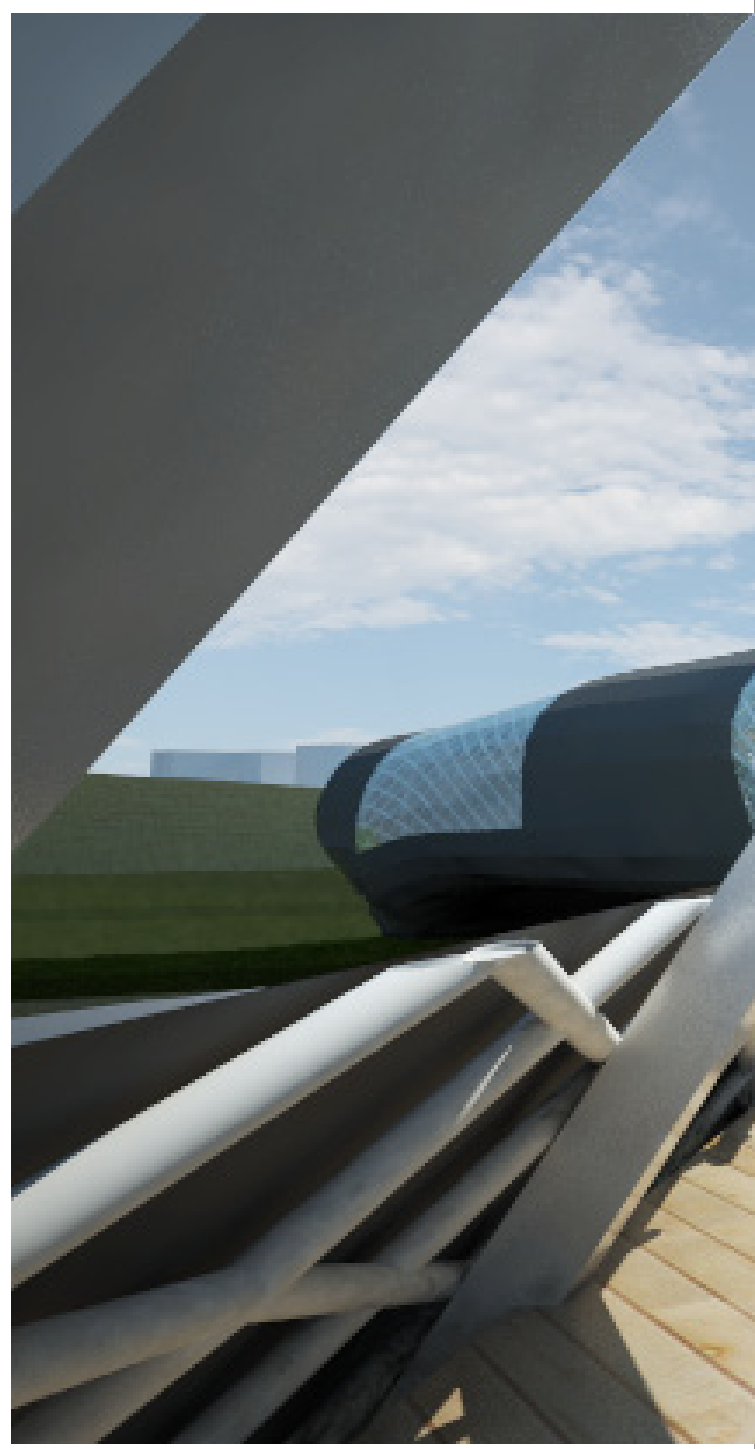

Figure 6.1.8 View walking towards the intersection 


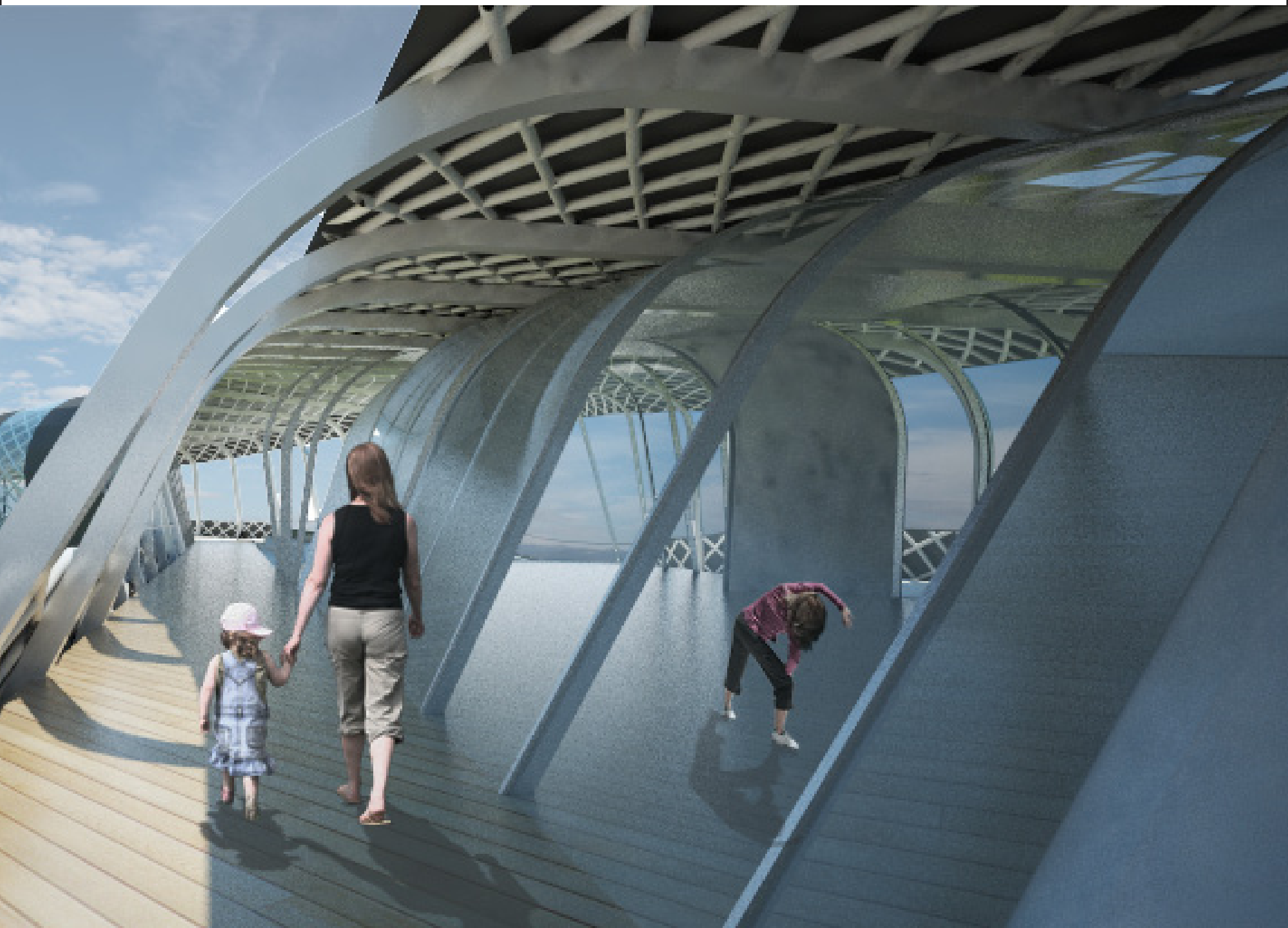

The steel ribs supporting the bridge are exposed in areas to help express the form of the structure and reveal its subtle movement. Entering the bridge from either side, the ribs are compressed and lean away from the intersection. As one moves towards the center the ribs gently open up and start to lean towards the intersection (Figure 5.1 .8 \& 5.1.9). This movement welcomes those entering at a human scale and gently guides them and brings their focus towards the intersection. This formal move highlights the intersection as a place for gathering and encounter. 
These intersections were designed as spaces that could be manipulated to accommodate different needs. Keeping the space relatively open and not designating programs to each space gives users the freedom to manipulate the space to their specific needs. This provides them with a sense of control over their environment while offering them a sense of ownership and belonging. The design does not cater to one specific group but rather leaves the space open so it can be adapted to the needs of those using the space. With cities and neighbourhoods constantly in flux, it is important that the built environment is not restrictive to future inhabitants that may have different values and uses for a space.

Figure 6.1.9 Expansion and compression of ribs

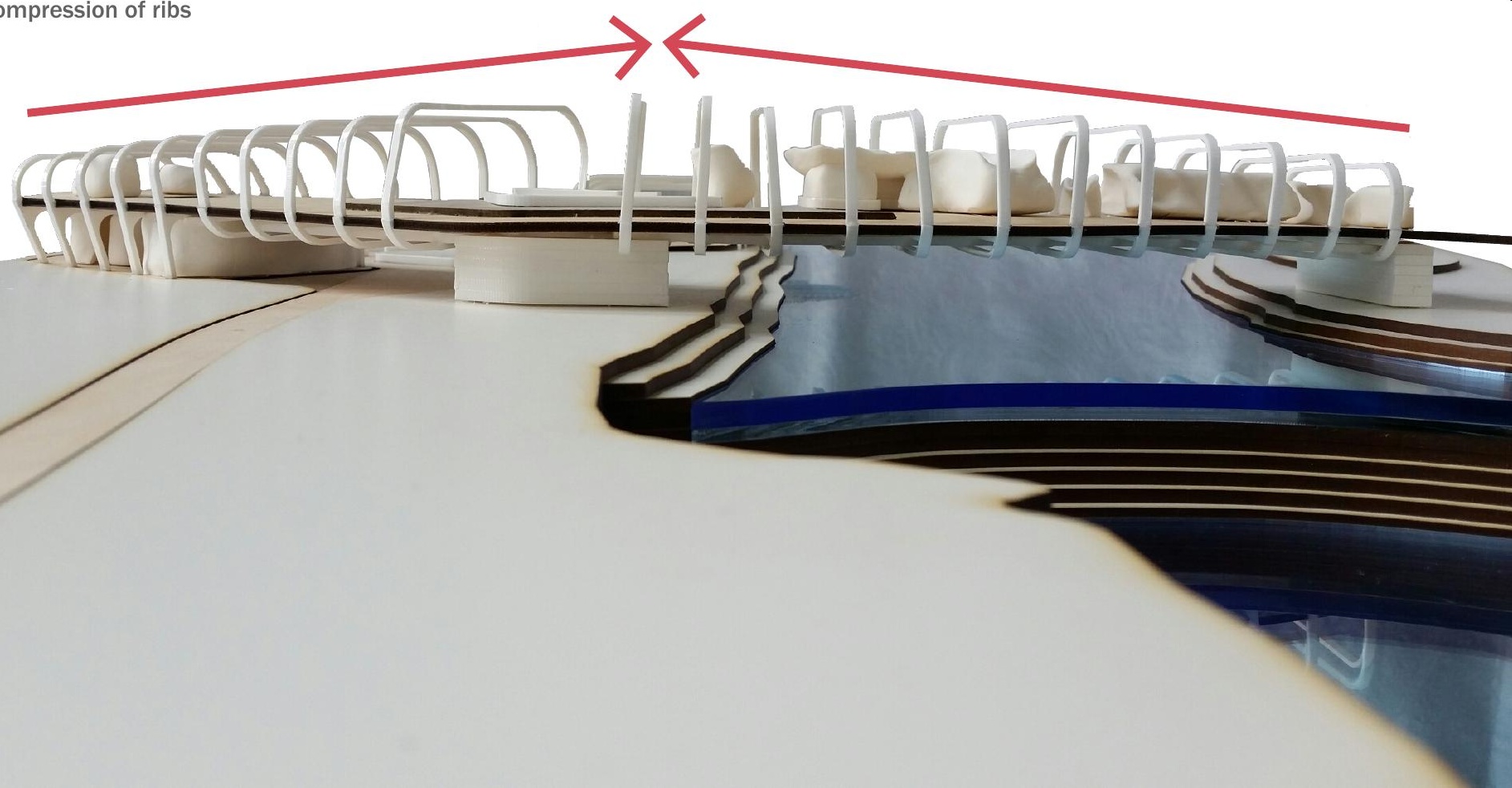





$$
7.0
$$


The final principle deals specifically with the discomforts faced by vulnerable groups who find themselves in social situations. It aims to architecturally formulate comfortable social environments for vulnerable groups to interact. Ayers (2007, p.23) identifies three inter-related variables that have the potential to indirectly influence the mood and health of those using a space. These variables are the perception of density, privacy and control. The following design strategies take a close look at each variable from a psychological and architectural point of view and makes design decisions around these theories:

\subsection{Control the perception of social and spatial density}

Controlling the perception of social and spatial density helps to regulate user comfort and increase their perception of control over ones social experience. To ensure that the open and enclosed spaces within this thesis project did not have the same effect as Potsdamer Platz, the following design decisions were made:

The bridge and the volumes that occupy the site are arranged in a way that reduces the perception of crowding. Unlike Potsdamer Platz that is relatively open to all the activity around the site, the courtyard, or intersection, on grade is bound by the ramp and activity nodes, which helps 
to distinguish this space from the rest of the open green space around the site (Figure 7.1.1). Since all the activity nodes are separate forms, it increases the architectural depth since the number of space one has to pass through to get from one activity to the next is increased. Distributing the programs in such a way also helps to reduce the overall social density across the site. It works by having various clusters of activity compared to one large overwhelming crowd.

The interior spaces are also designed with this strategy. Plaster volumes that hold programs and services are placed in strategic locations to break up the plan into various social areas. The periphery of these interior volumes not only divide social spaces, they simultaneously creates an edge effect. Placing the volumes that hold services (which do not need natural daylight) in the center of the activity node increases the surface area around the volume, thus increasing the useable edge area.

Within the Community Learning Node on the bridge, the space was divided by interior volumes that hold more private or quiet programs (Fig-

Opposite page:

Figure 7.1.2 Partitioned interior space ure 7.1.2). These volumes help divide the overall floor plan into smaller social spaces that reduce crowding (Figure 7.1.3).

Figure 7.1.3 Separated social sapces

Below:

Figure 7.1.1 Architectural Depth

through built form

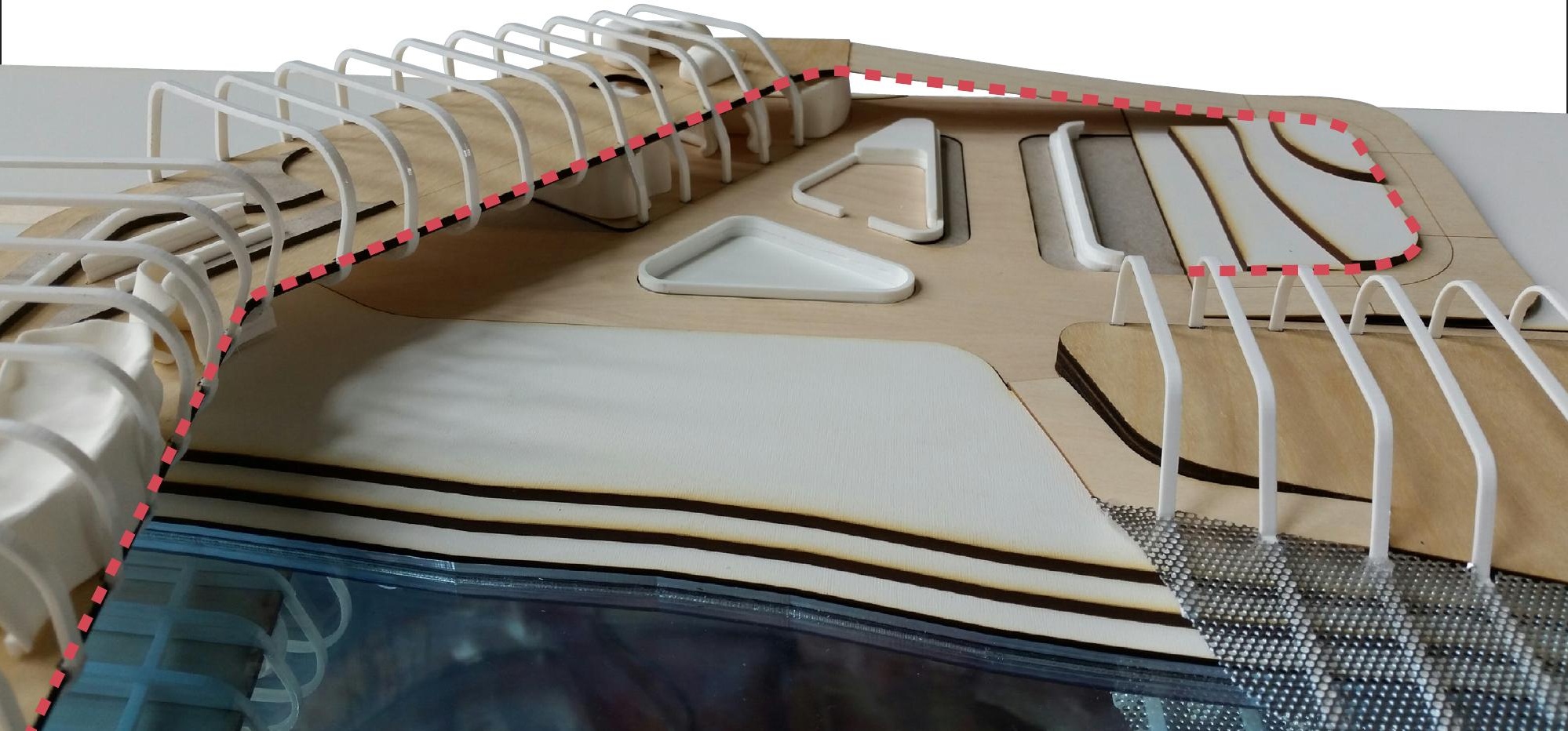




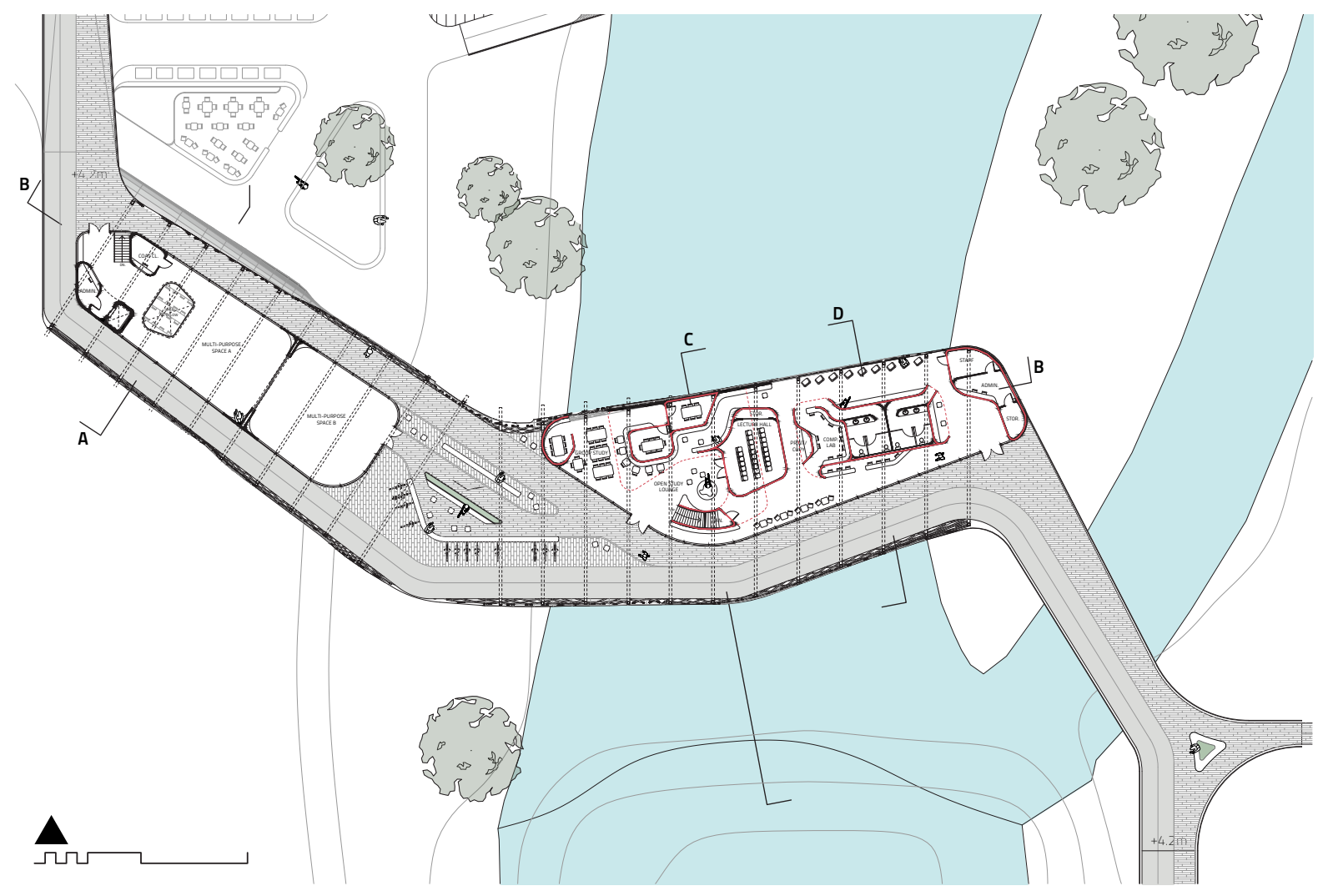

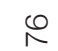

O
$\mathbb{1}$
ह
0
0
$\frac{1}{0}$
0
0

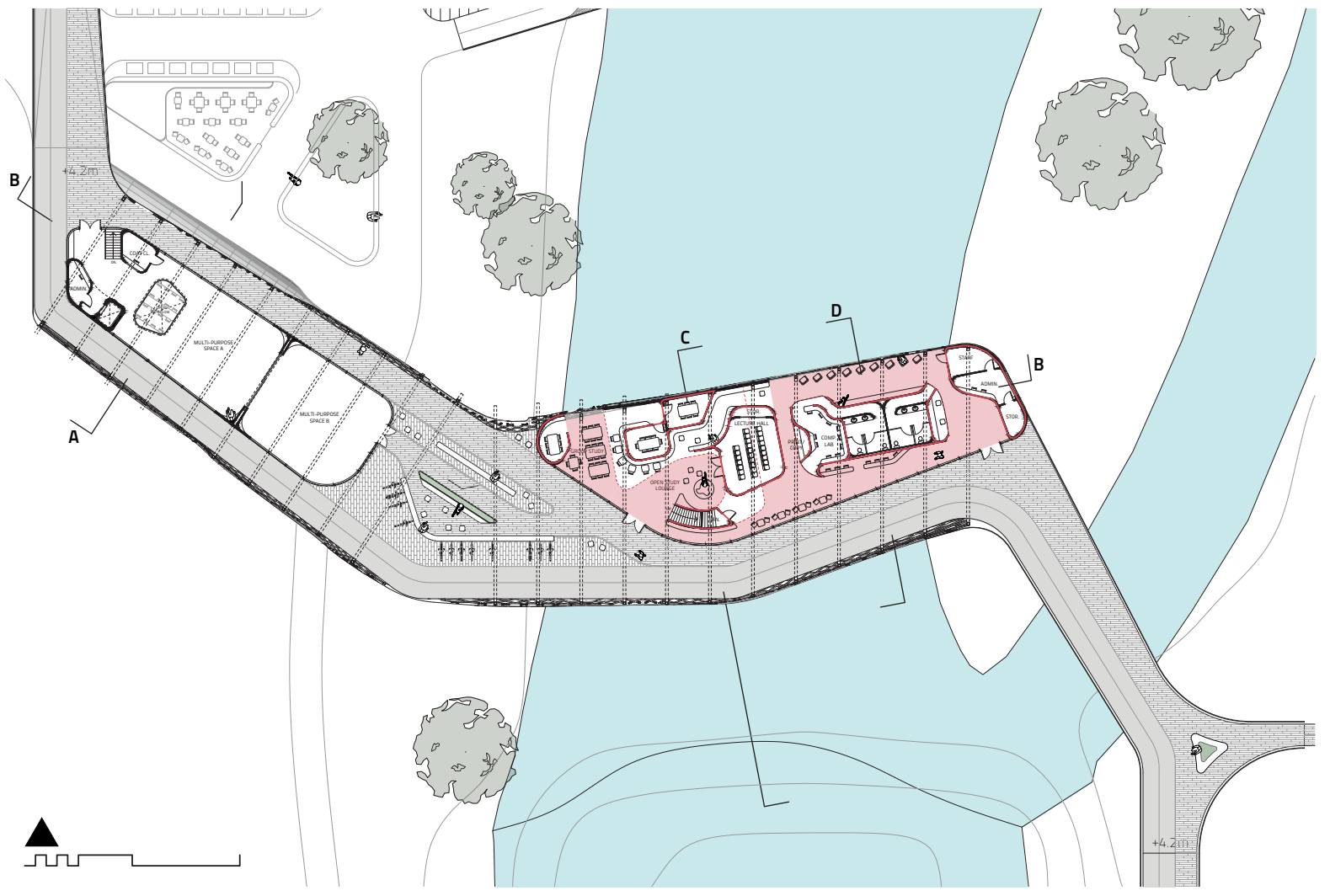




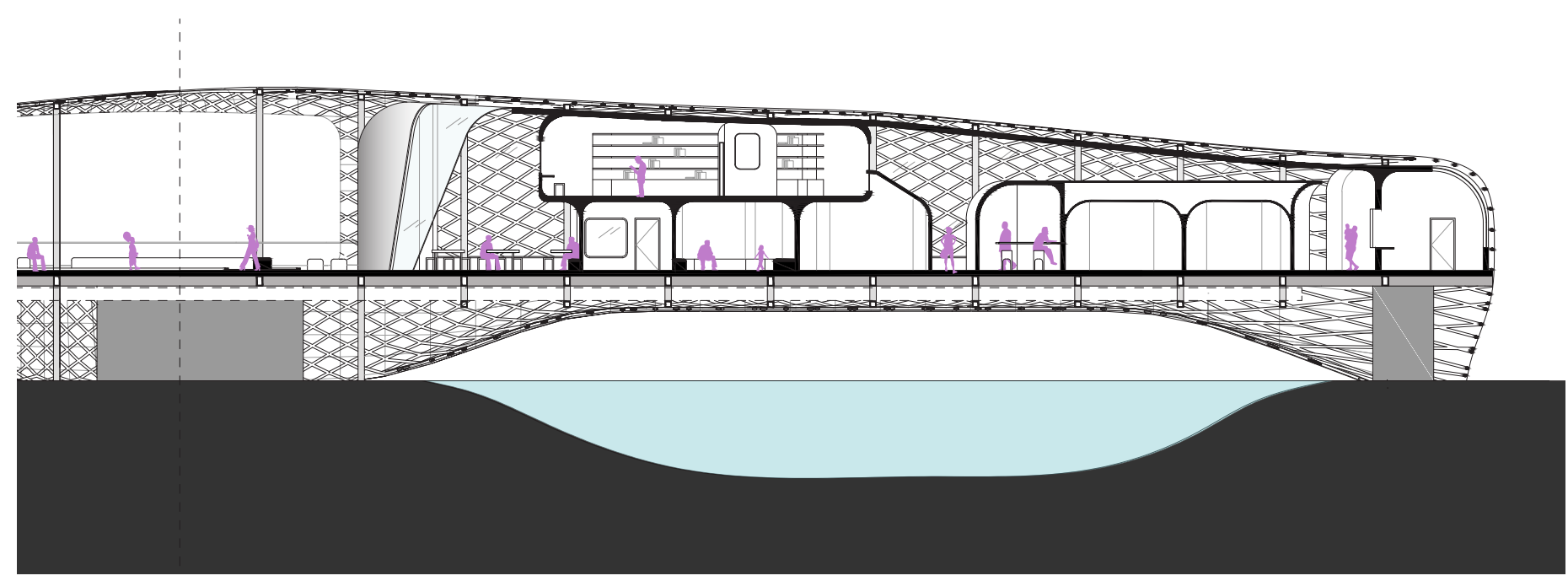

Open study areas dedicated to student interaction and educational exchanges are placed adjacent to the intersection where the space opens up vertically to the structures full height and opens up visually to the surrounding movement and activity passing by. The double height space is then divided into a two-storie volume creating a series of more compressed and secluded environments for those looking for more quiet areas to study or retreat from the social spaces. The space between the social environment and the private environments acts as a buffer zone that aims to filter one between the two distinct spaces. The use of overhangs and seating against edges creates a comfortable microenvironment for people to sit. As one moves away from the intersection the programs and volumes become more compressed and less oriented to social interaction.

The form of the bridge uses expansion and compression as well. The entry points on either end of the bridge are at a human scale and thus inviting for people to enter. As one passes through the bridge, the ribs start to slowly expand and reach their maximum height of 8 meters at the intersection where social interaction is at its highest. 


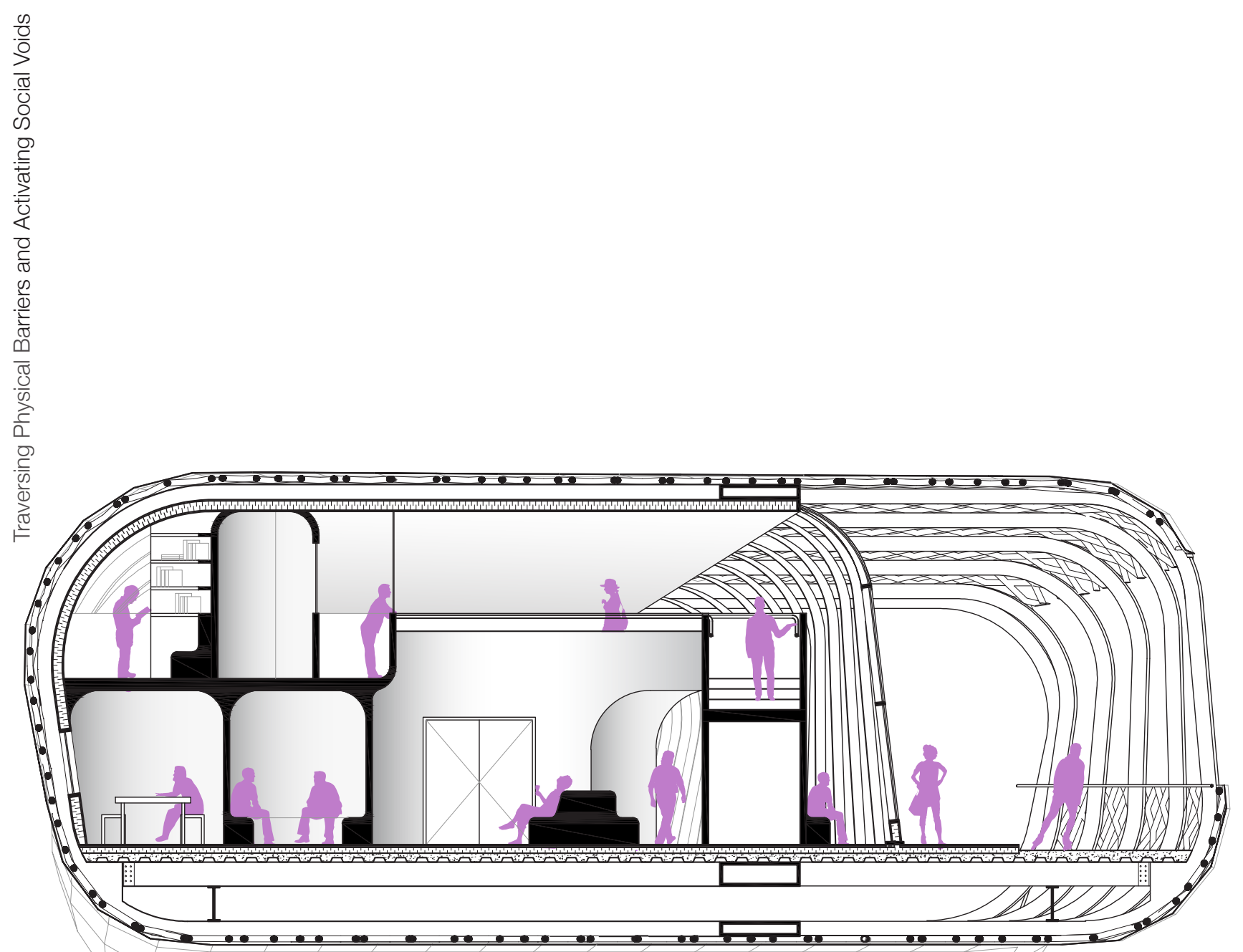


This cross section through the private and social study spaces shows the various spatial qualities that offer a gradient of social experiences. The use of expansion, compression, openness, closedness, and controlling visual and auditory interactions helps administer user comfort within the space. The open study lounge is the heart of the learning center where people enter or pass through, stop to study or chat with friends, or a spill out space for classes in the neighbouring lecture hall. The private study areas are physically and visually separated from this open study space and instead open up to views of the river and landscape north of the site. The resource center located on the mezzanine level is visually open to the open study space but is physically separated offering a semi-private environment. 


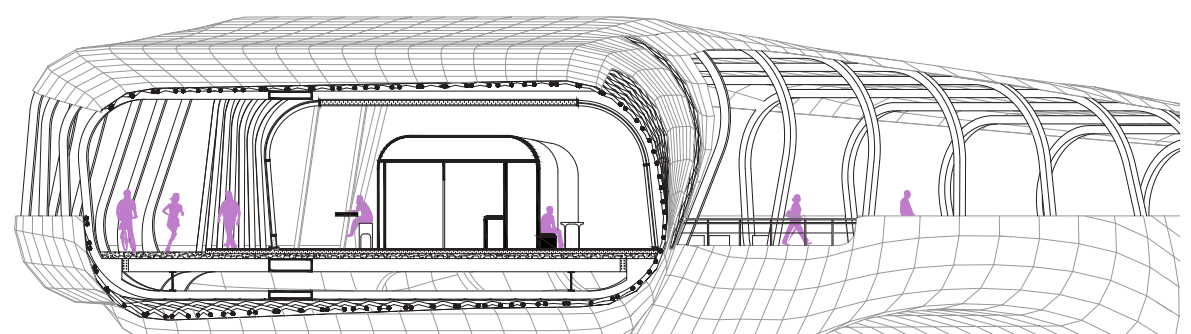

Services, such as washrooms, that do not need natural daylight are placed in the center of the enclosed activity node to help create spatial divisions and increase the useable perimeter area that doubles as an edge for seating. The study space to the left is a more social environment as it faces the path of movement with people walking and biking by. The bar height seats also make it easier to have conversations with those walking by. Another study area is placed on the other side of the washrooms, away from the main circulation path within the learning center. On this side, the seating looks out onto the river and the intersection on grade. The physical distance between the two is enough to keep this area more of a retreat space from the more social areas. 


$$
8.0
$$




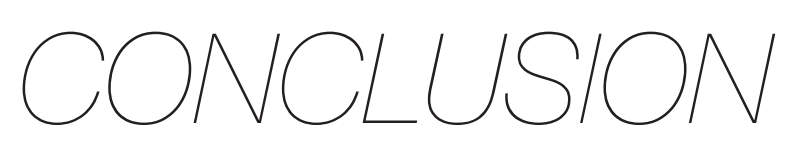

In an effort to reduce physical barriers that limit low-income areas from accessing services, and reduce socially constructed boundaries within Toronto's priority neighbourhoods, four principles were established based on a number of studies and research, particularly from the Longitudinal Survey of Immigrants to Canada. The strategies that were put forward in these studies were translated into architectural principles, including: connect, activate, engage, and control. Implementing these principles and strategies will ultimately work to increase the social integration of newcomers and eliminate socially constructed boundaries by: increasing access to social resources by physically connecting fragmented areas; providing an outlet for social integration by activating networks; increasing participation through design; and increasing contact between different social and ethnic groups by designing comfortable environments.

These principles have collectively worked to form a project that understands the relationship between the built environment and human behaviour. They create opportunities for people living in priority neighbourhoods to traverse physical barriers in the urban landscape and activate these new networks with programs that reflect the needs of the surrounding community. At the same time, the principles and architectural strategies adapted from research and studies within the field of environmental psychology, form comfortable social spaces by giving users control over 




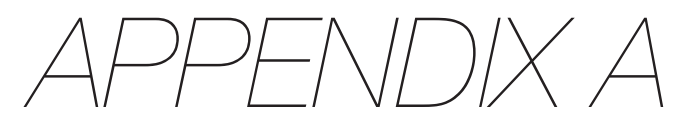

Weston-Mt. Dennis' social and community services

(1)

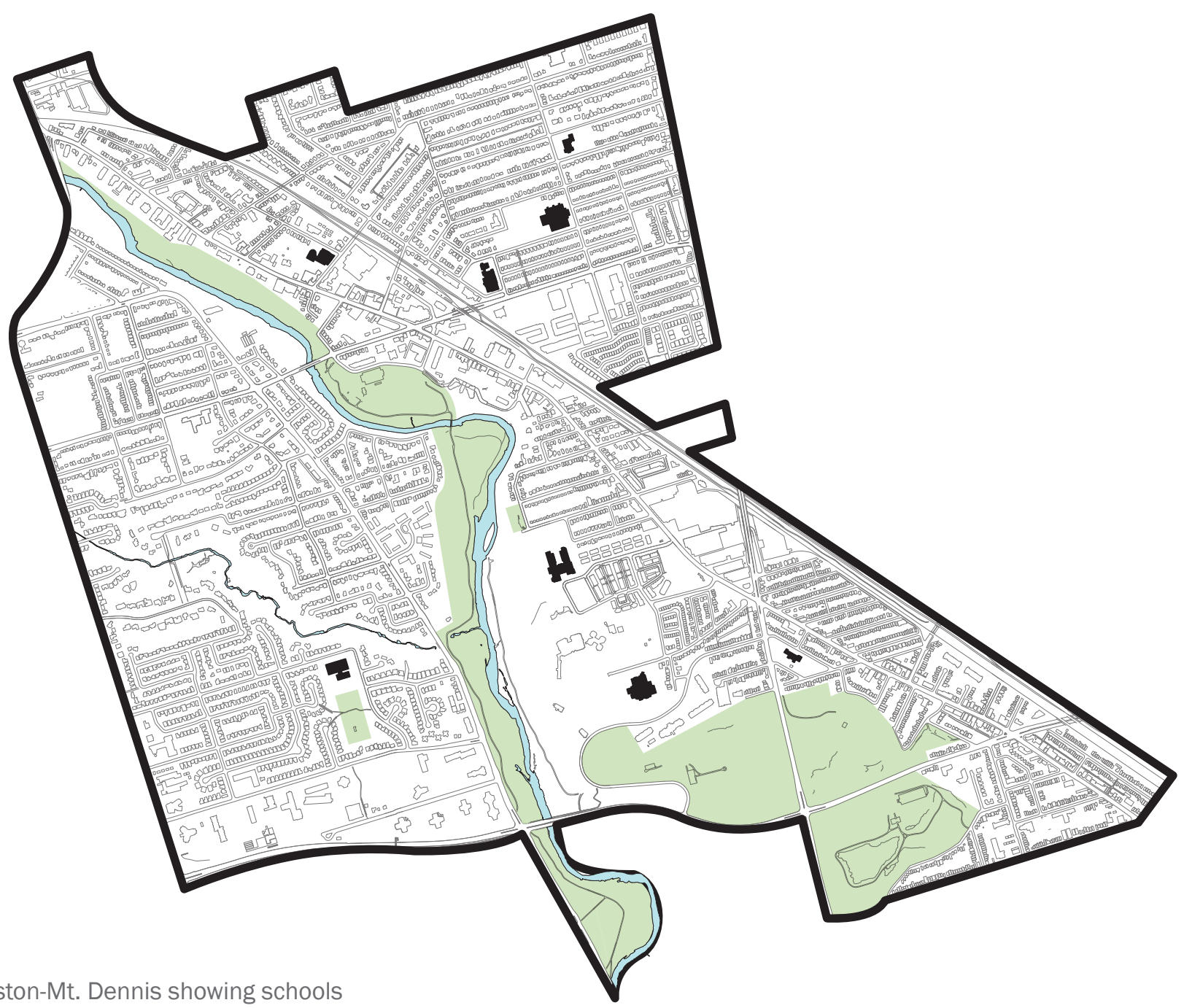




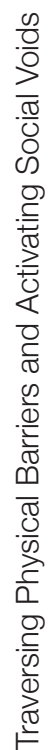

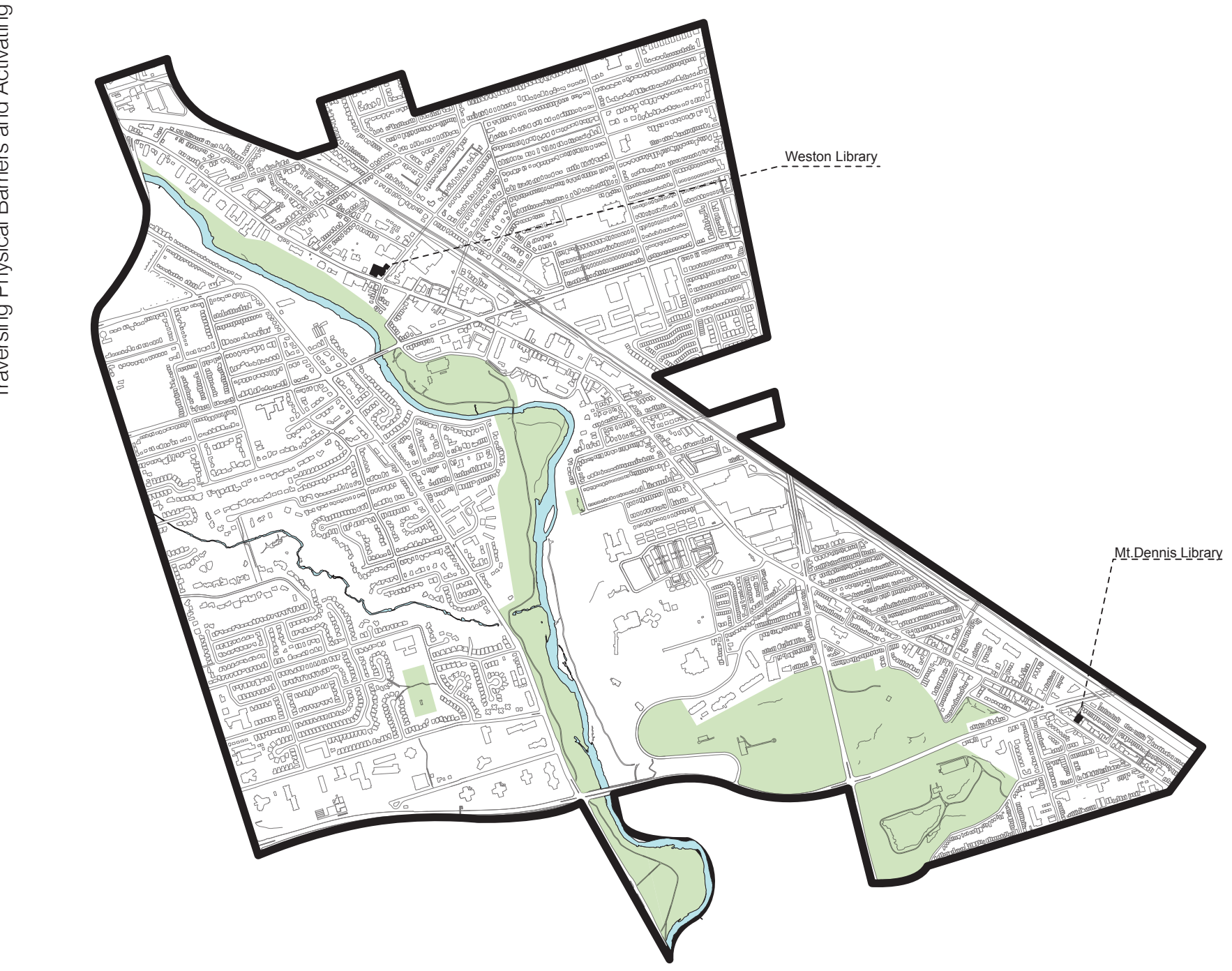

(1) 


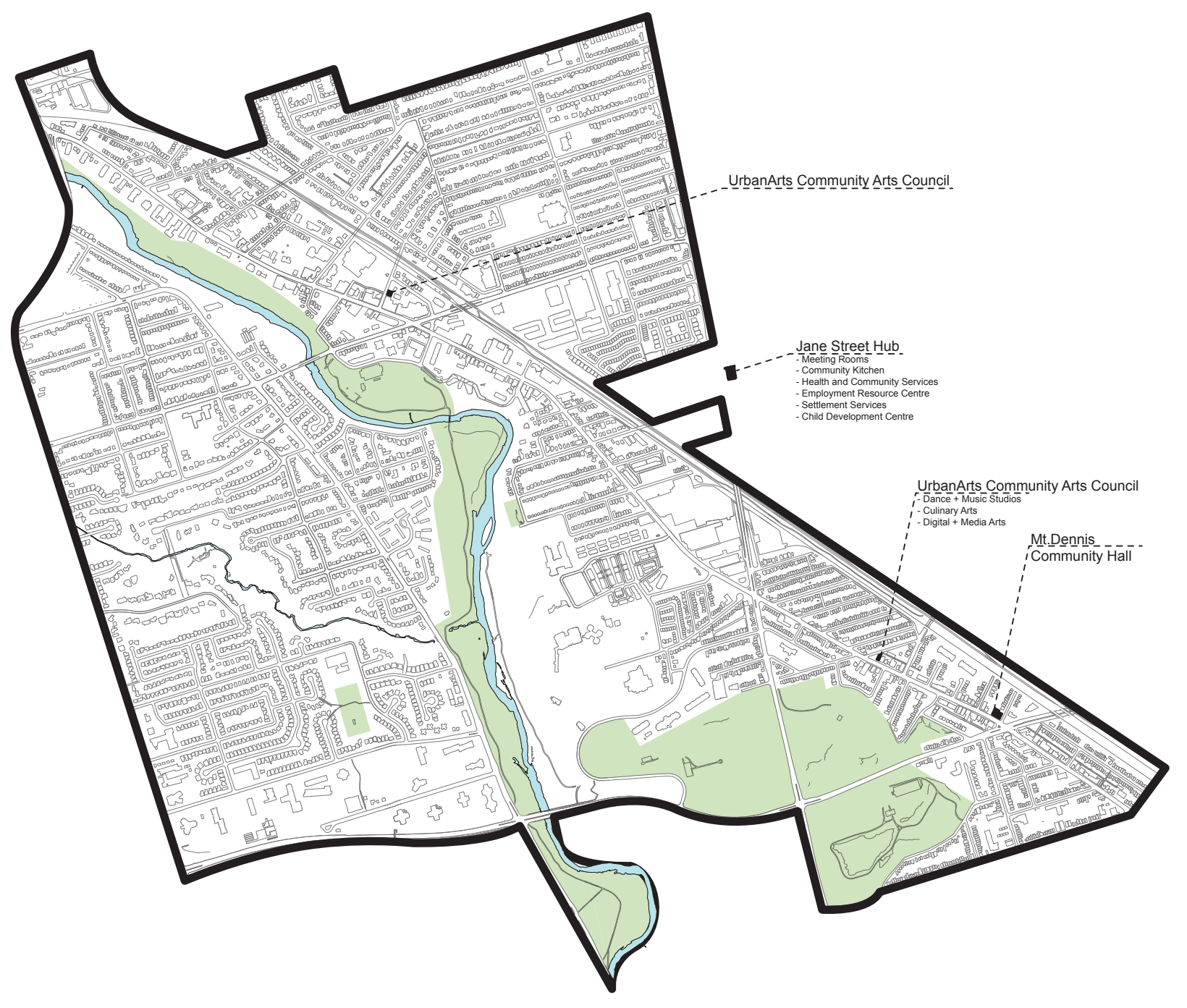




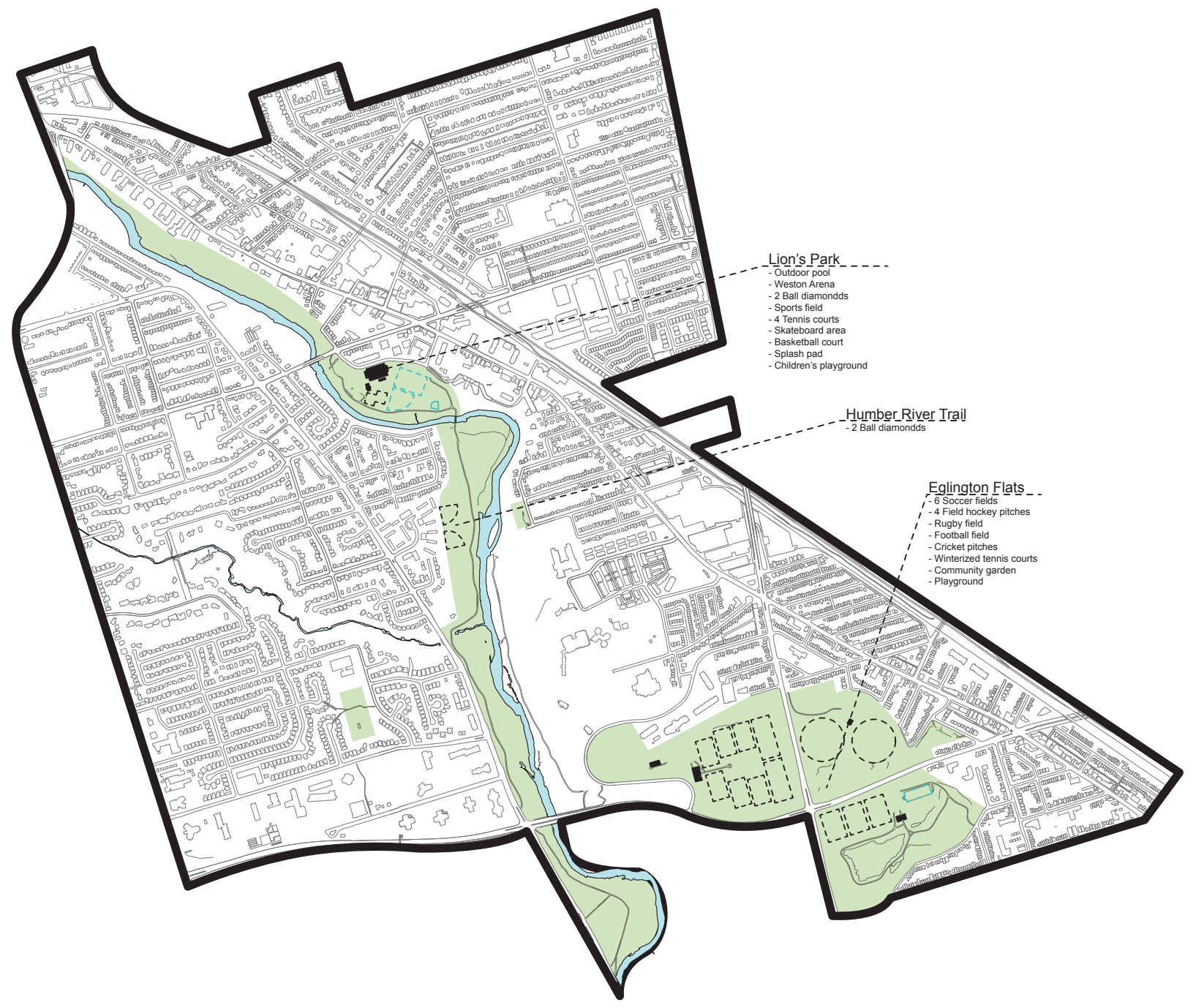

(1) 


APPENDIXB reference drawings 



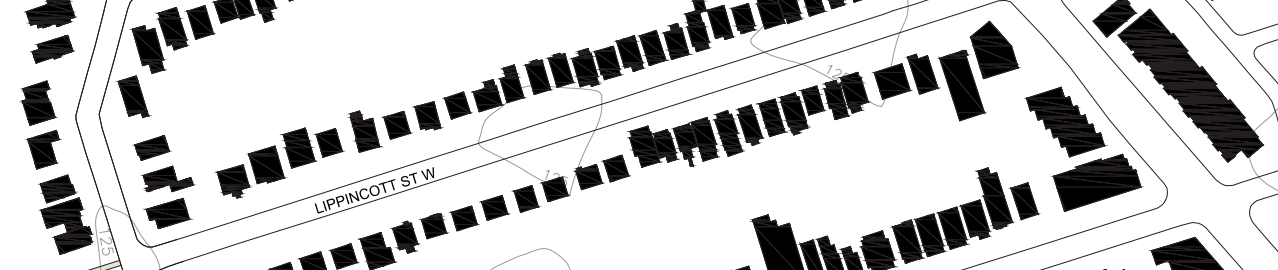

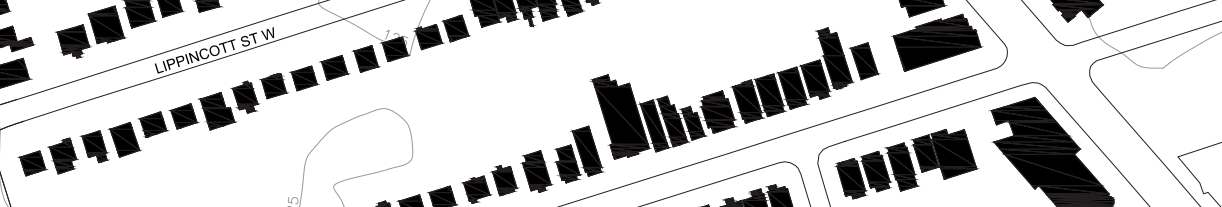

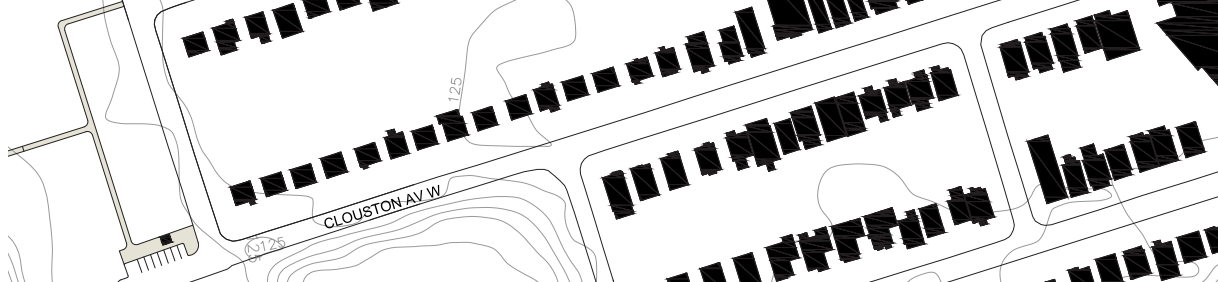
aull

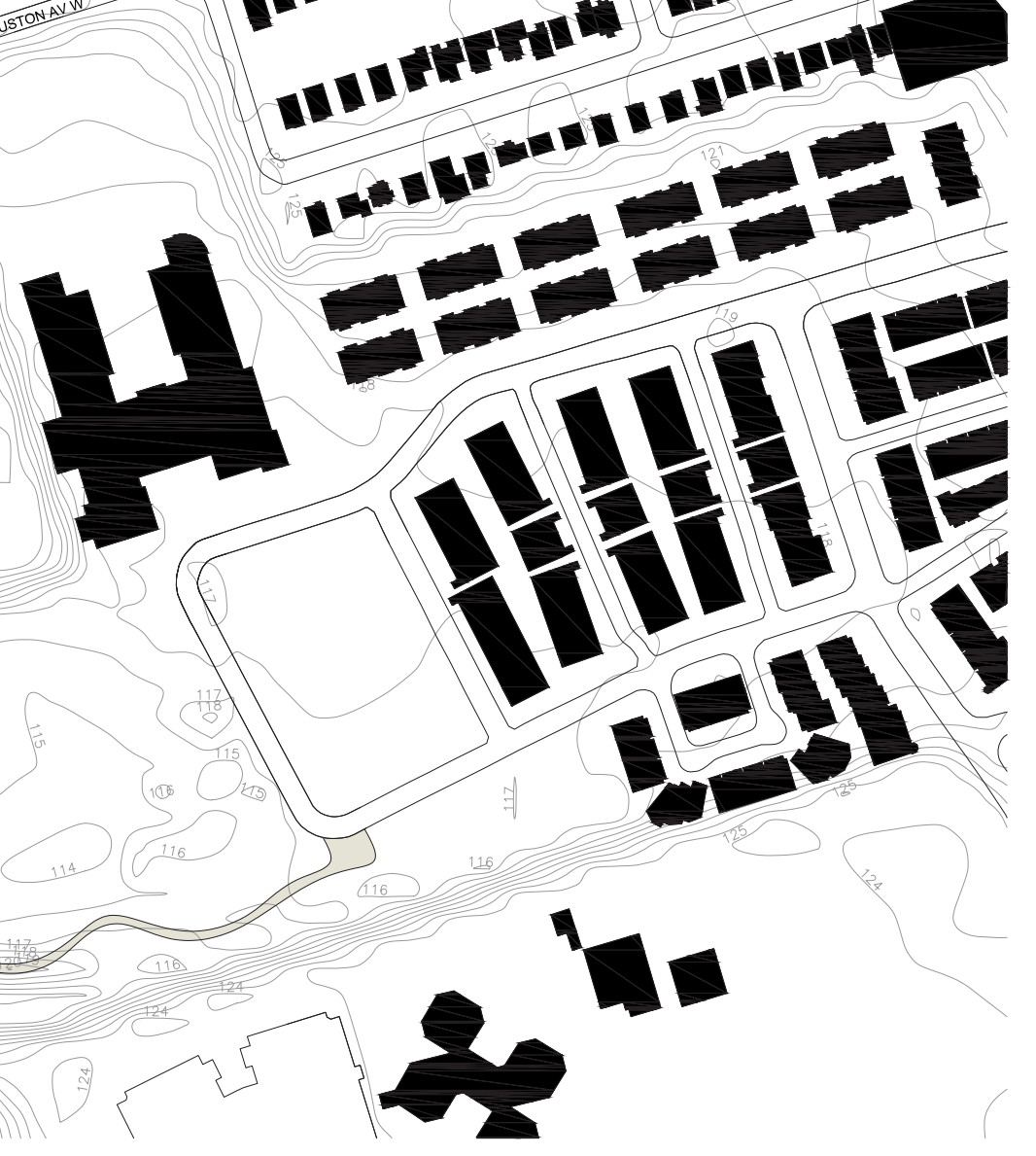



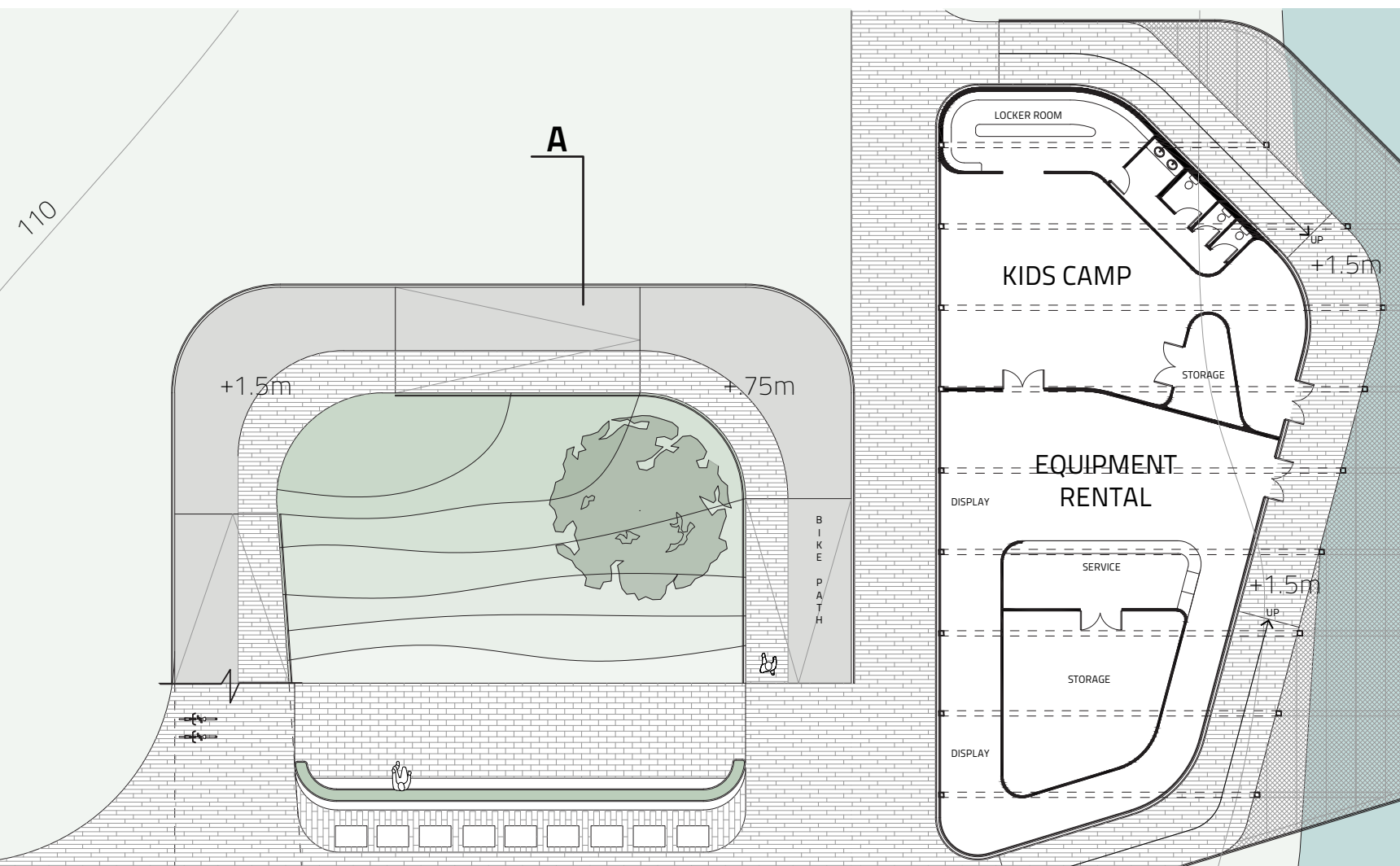

MARKET LANE

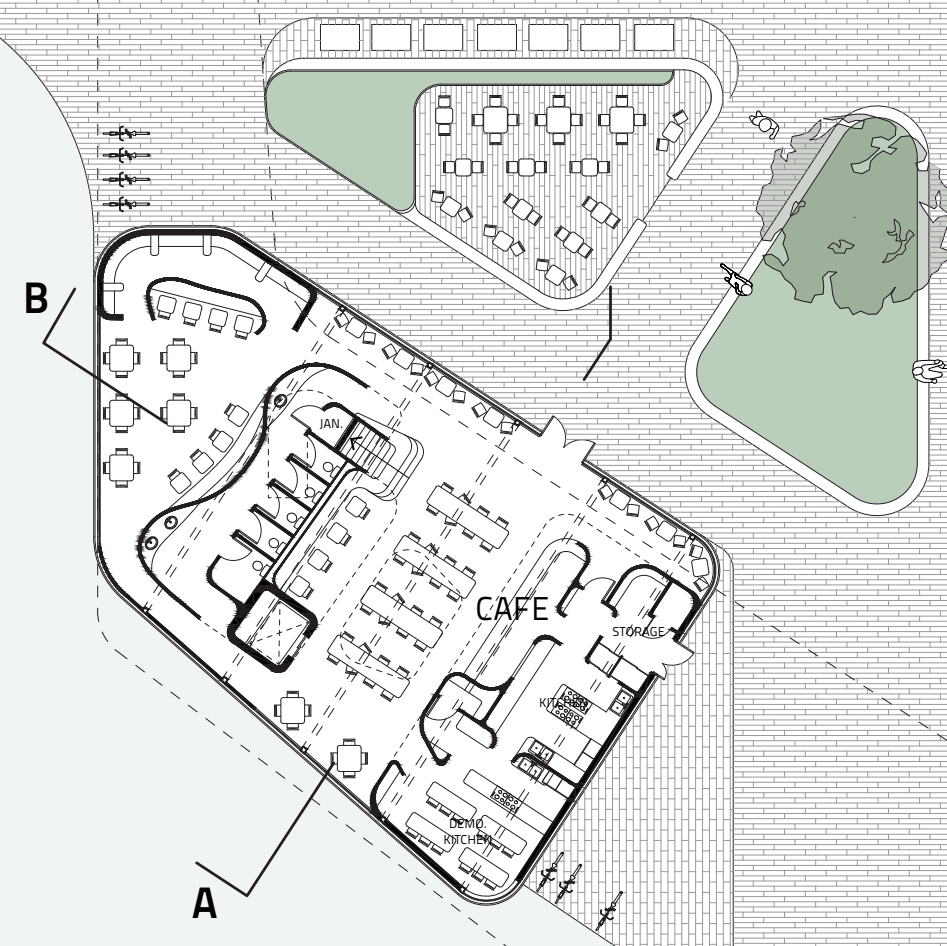

Ground Floor
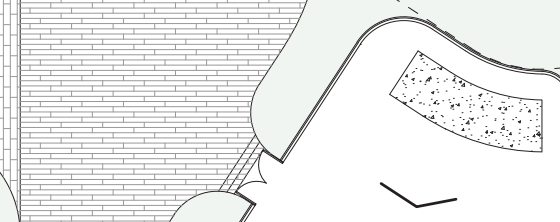

MECHANICAL
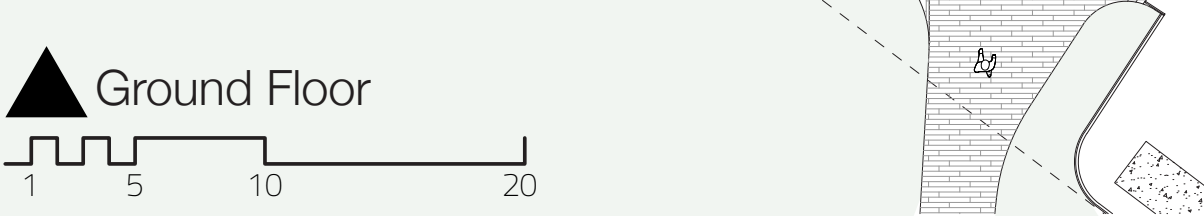

$$
\text { ROOM }
$$




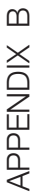




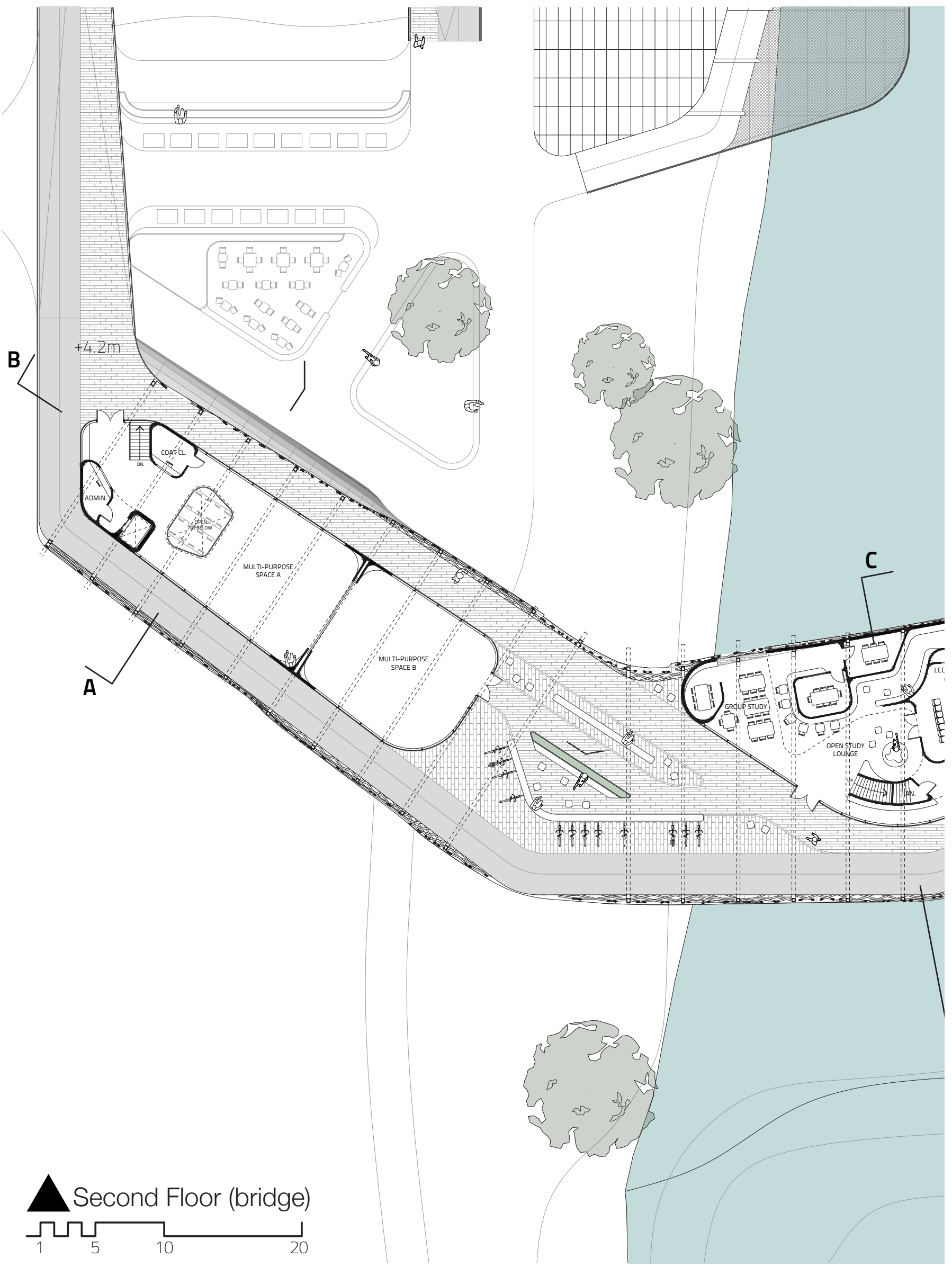




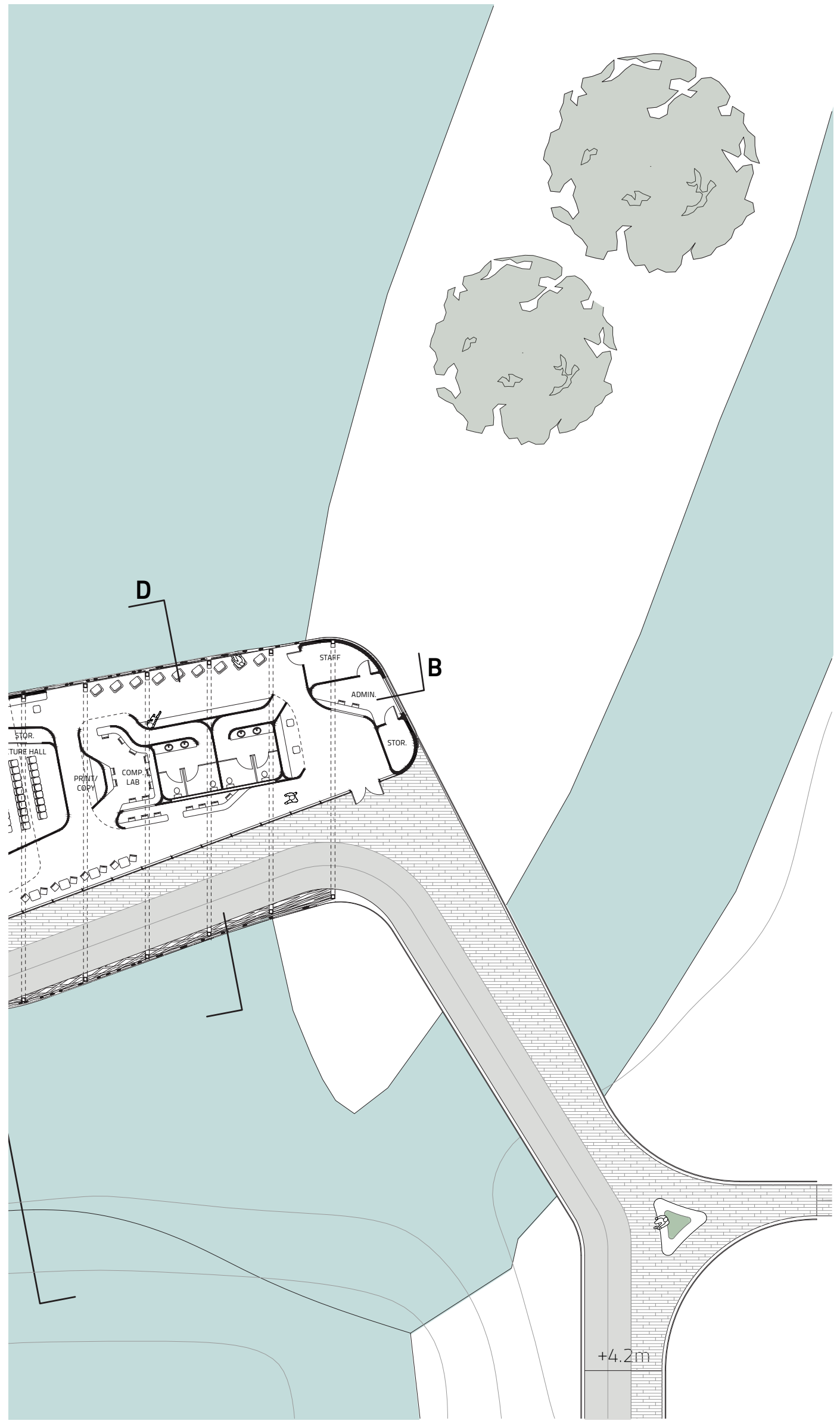

0
$\frac{x}{\bar{n}}$
$\frac{\mathrm{u}}{\mathrm{O}}$
$\frac{\mathrm{O}}{\mathrm{Q}}$ 


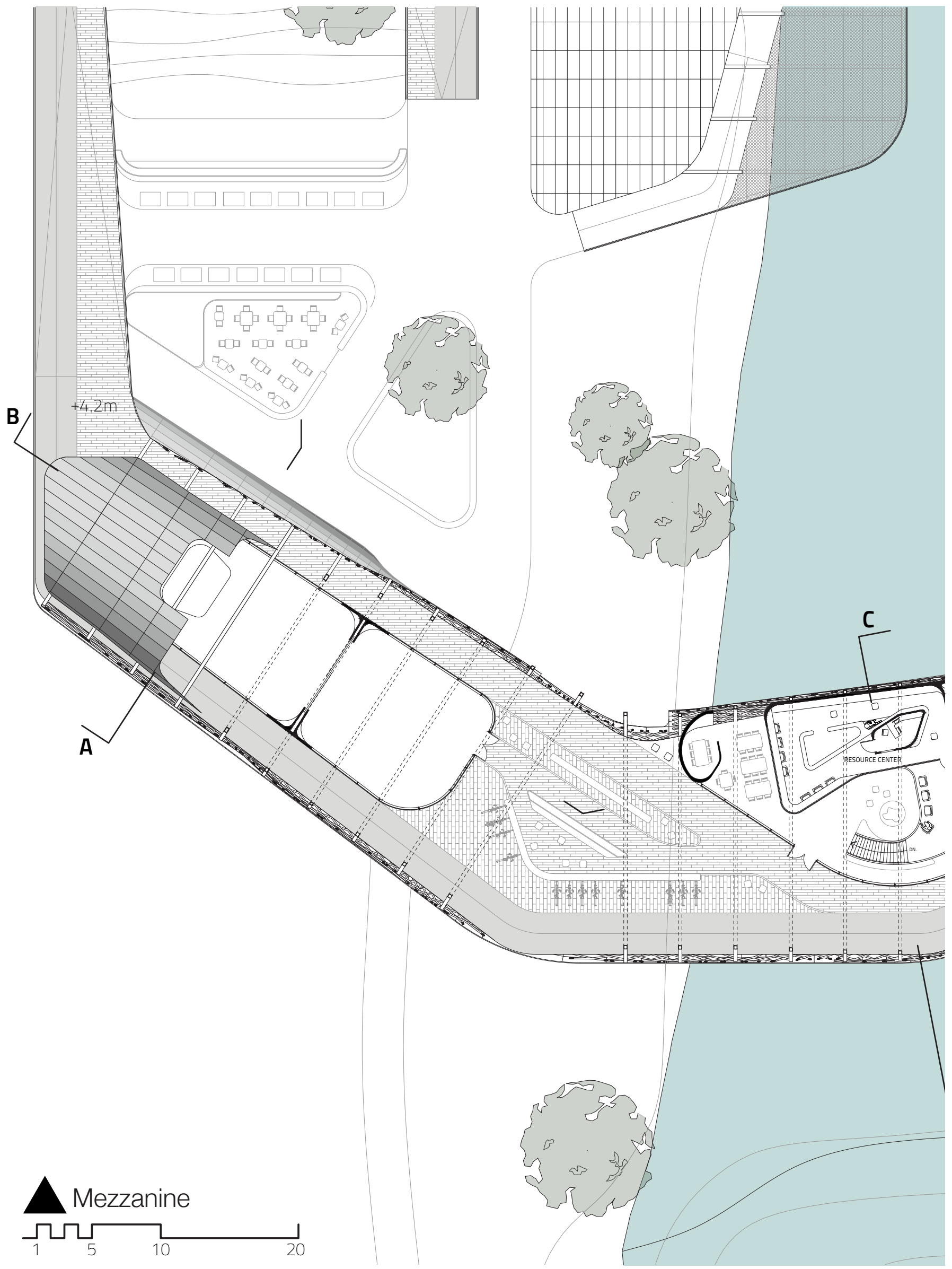




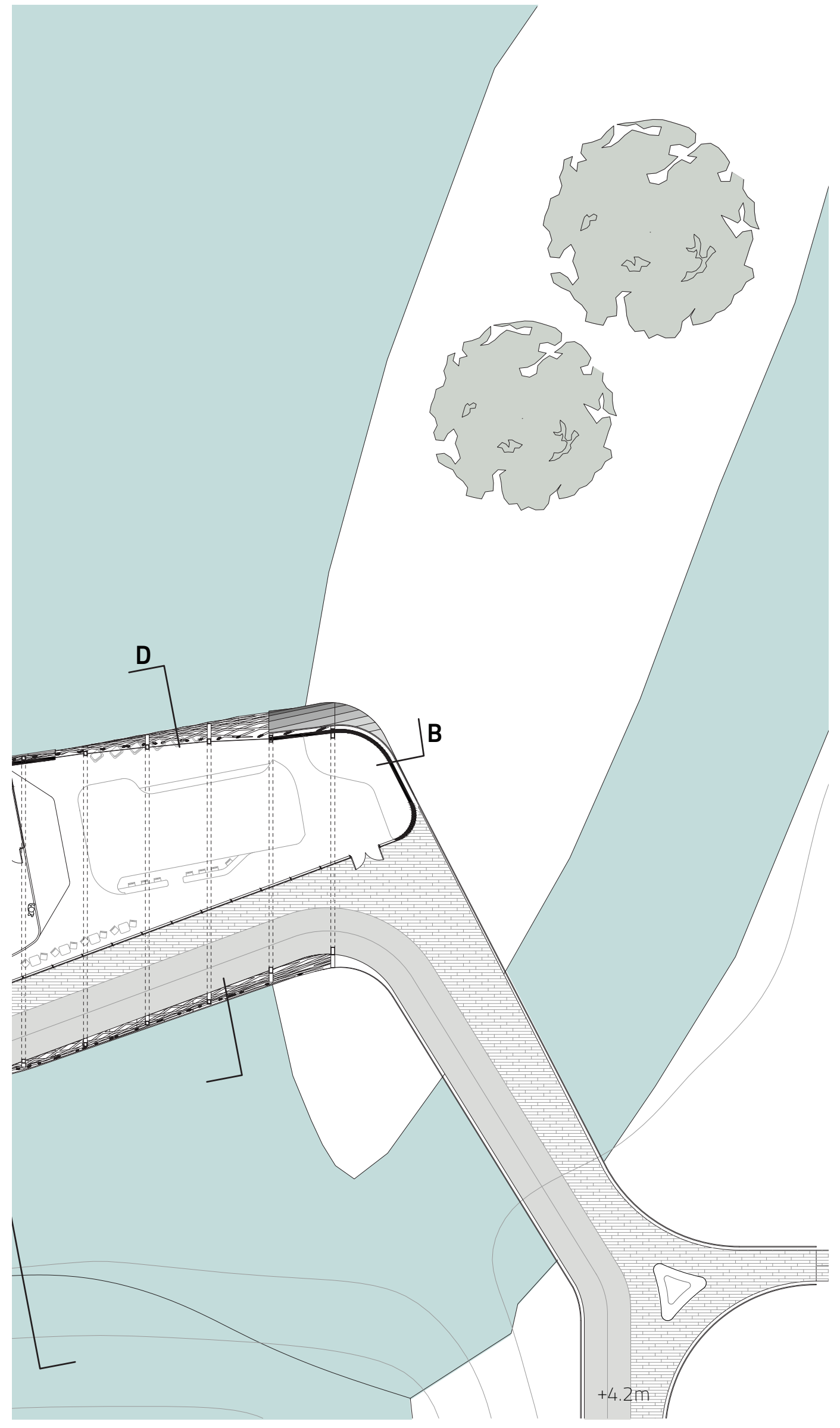

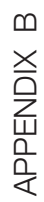




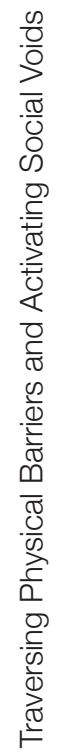

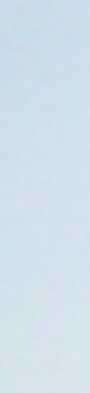

-
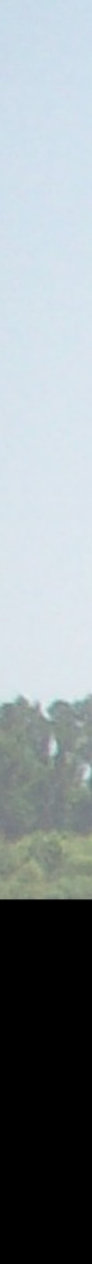
$\frac{0}{x}$

South Elevation
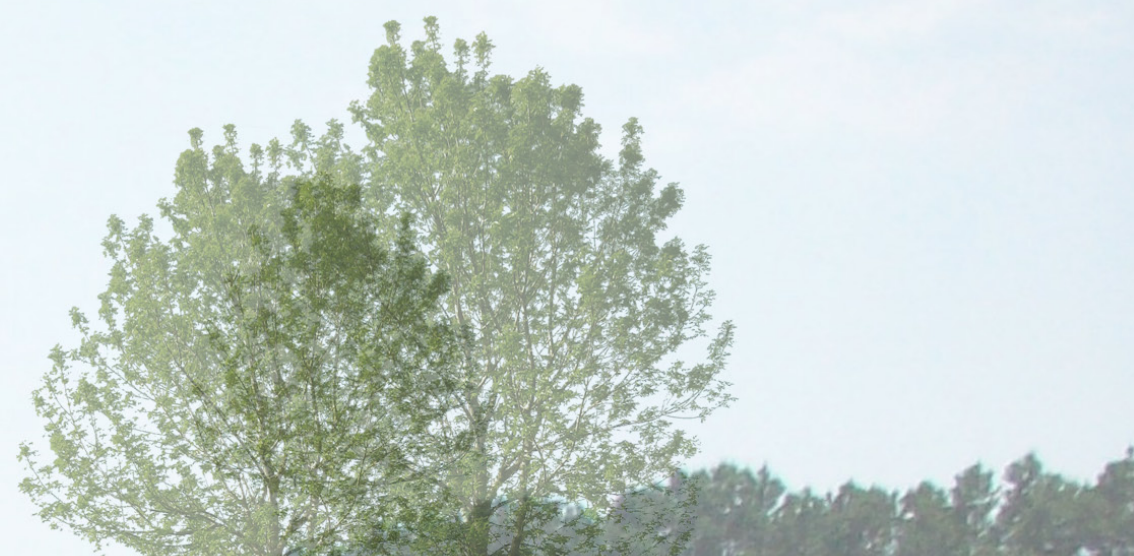


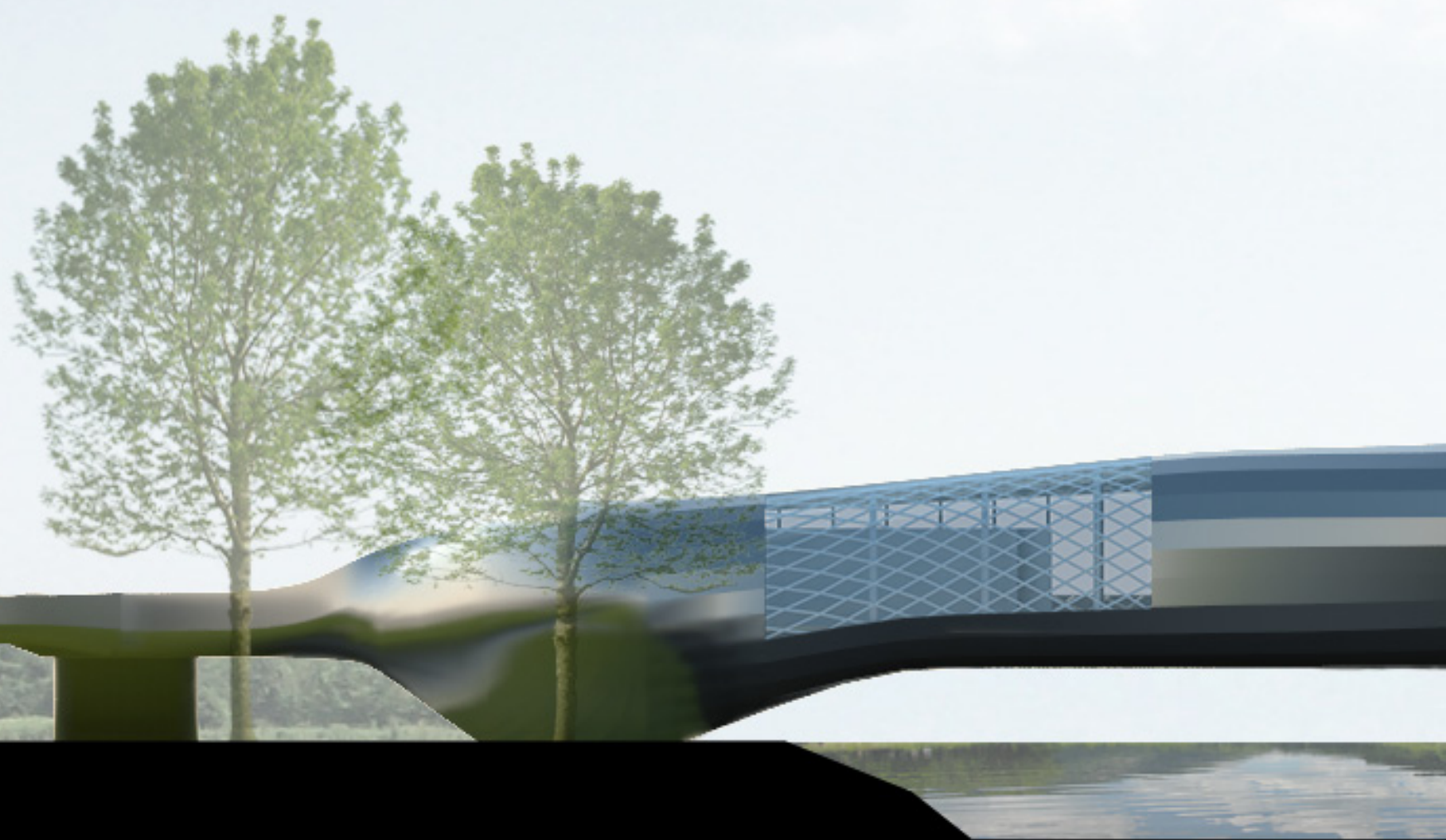




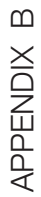

North Elevation 

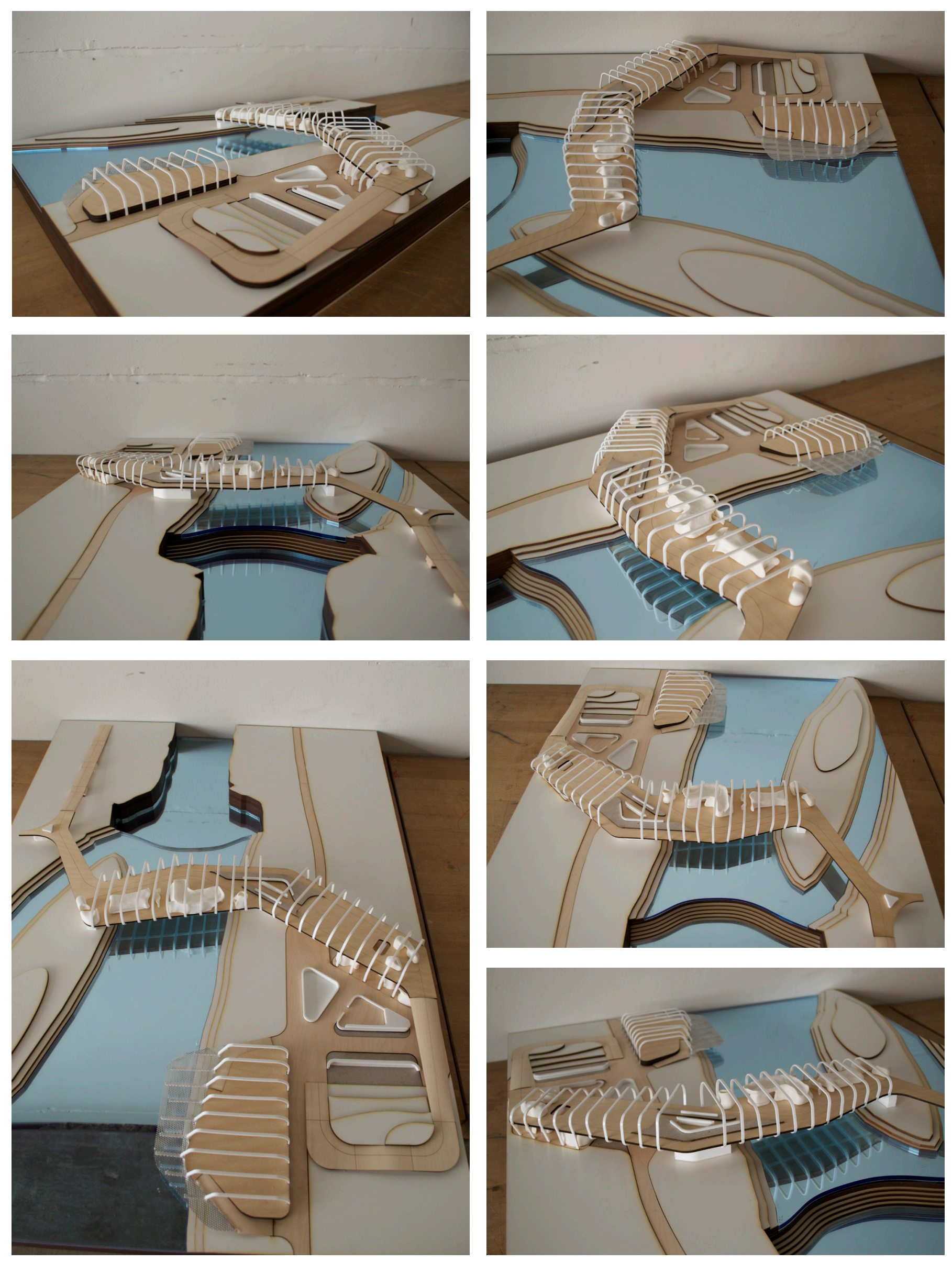




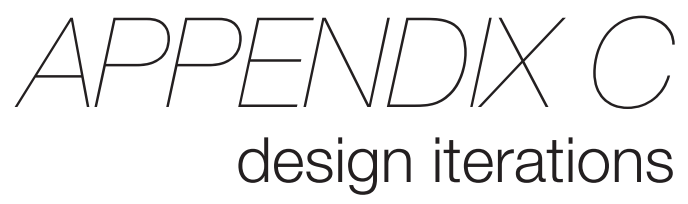




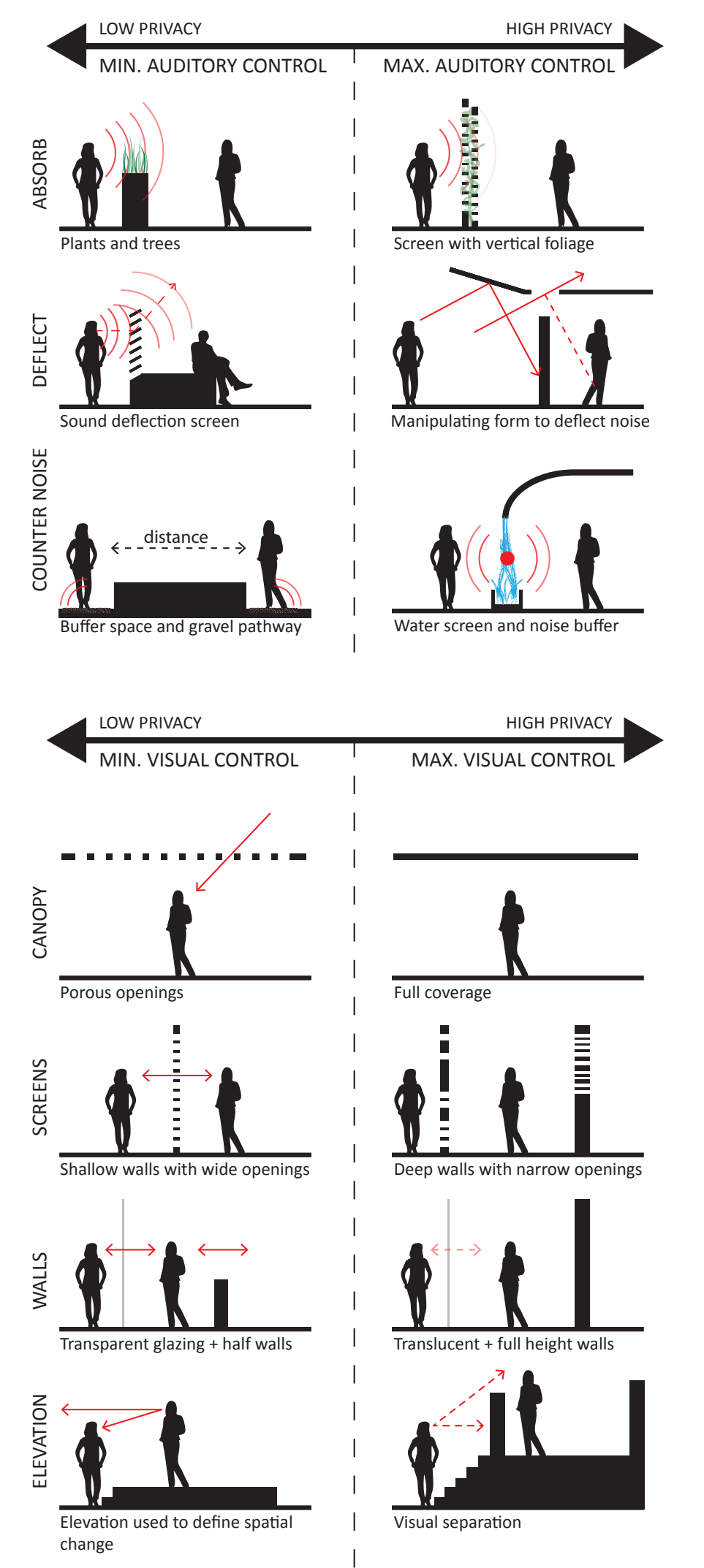


Design Iteration I:

These drawings are initial design studies that looked at how a range of openness, closedness, expansion, compression, and visual and auditory control could be achieved.
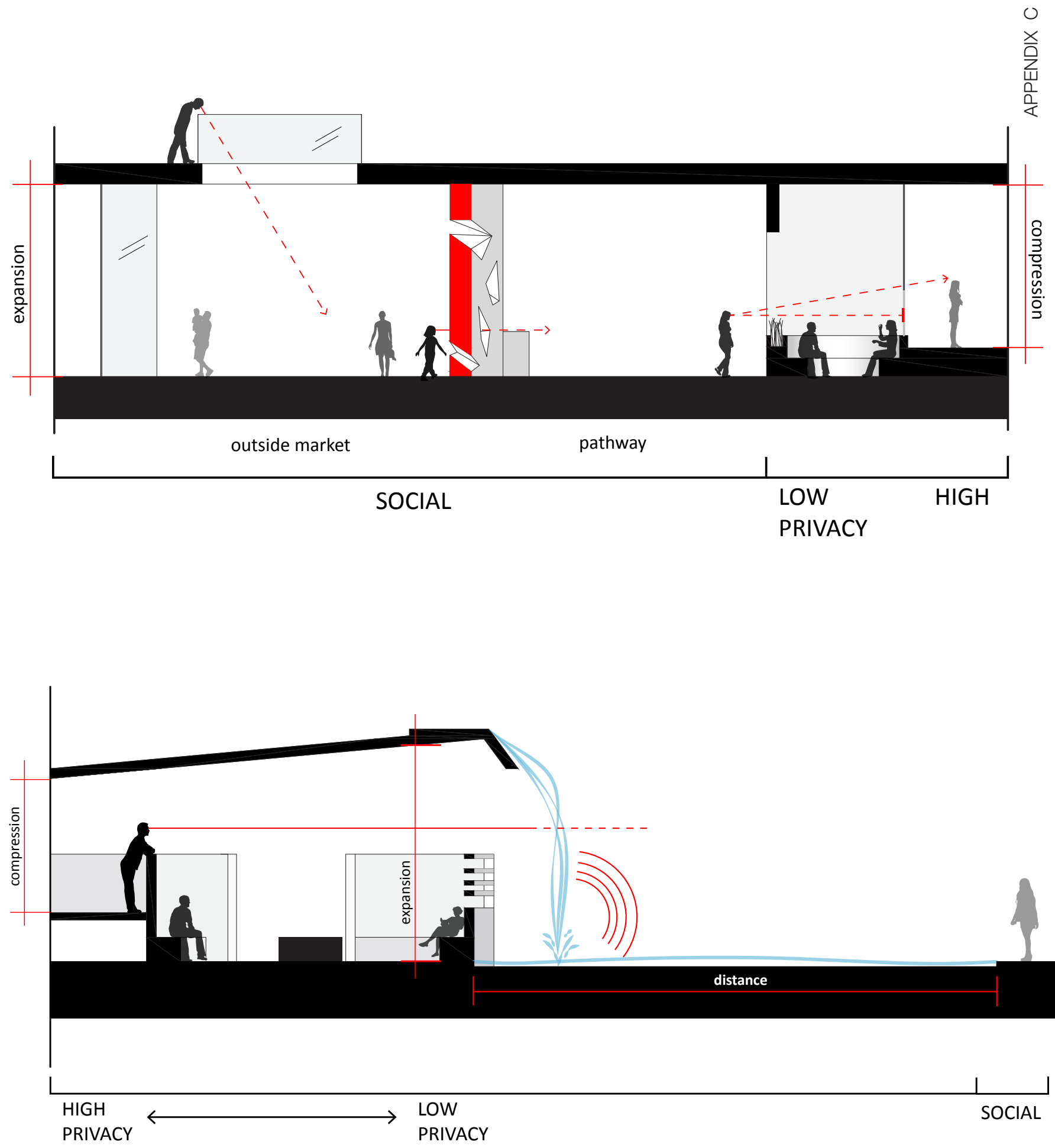

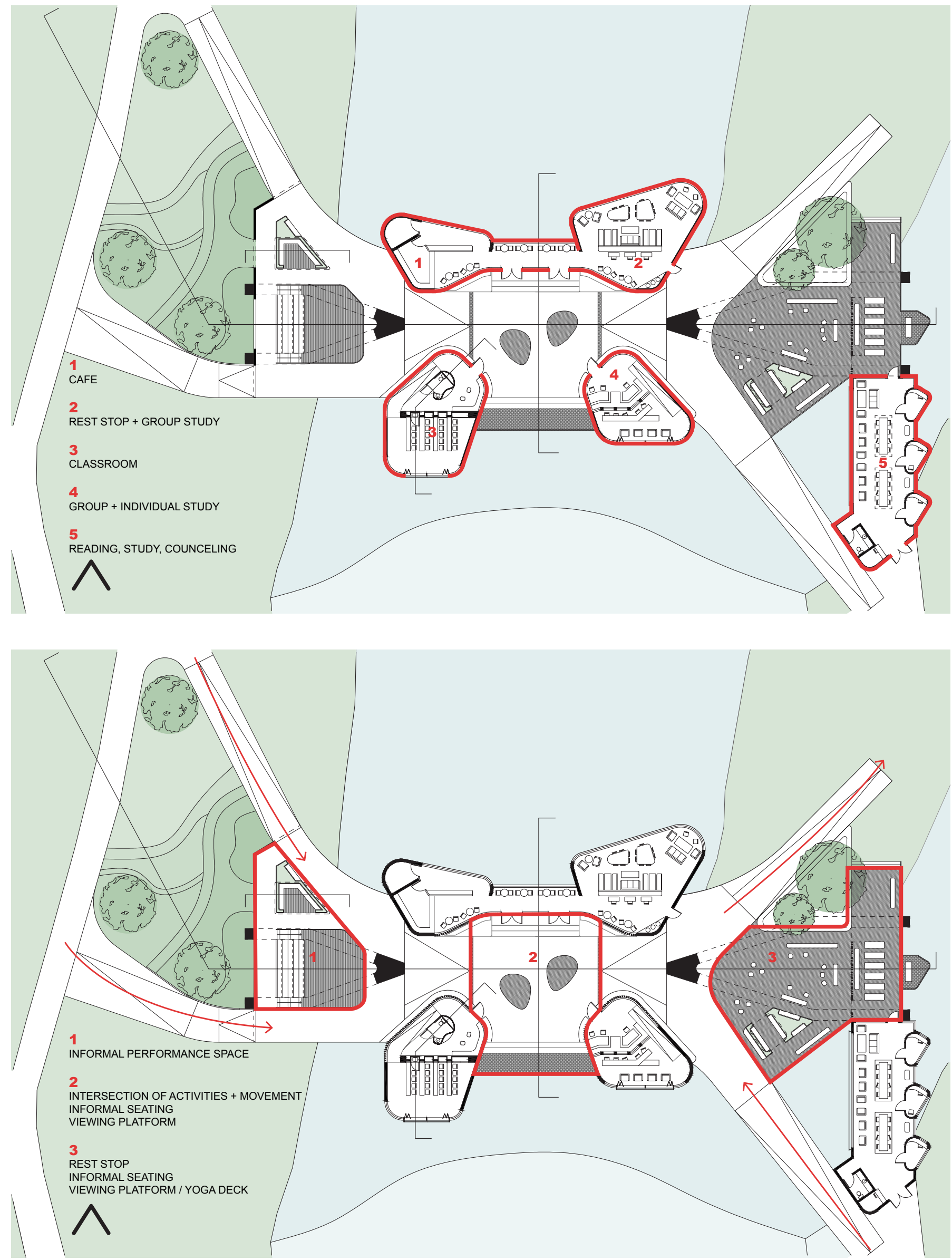


\section{Design Iteration II:}

This design iteration bridges over the Humber River with a platform structure that hovered over the water. The idea was to generate a structure that was a continuation of the ground plane. Enclosed pods that held various programs were meant to be a viewed as a juxtaposition from the surrounding context so one would recognize it as a marker or destination. These pods were designed with gradients of social and privacy spaces based on the programs held within them. Three social spaces were used as anchor points - one at each entry point and one at the center where flows movement and activity intersected.

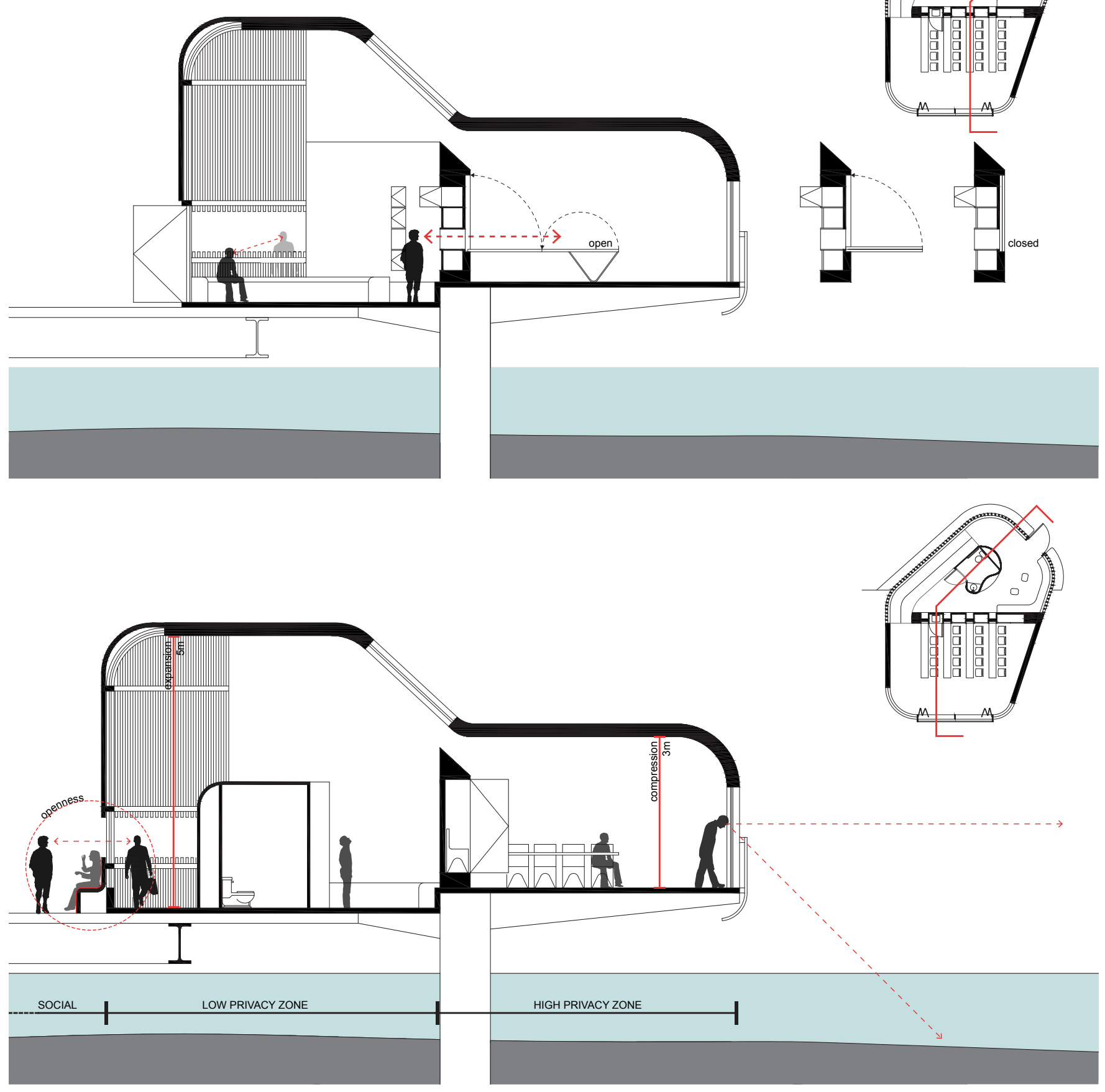



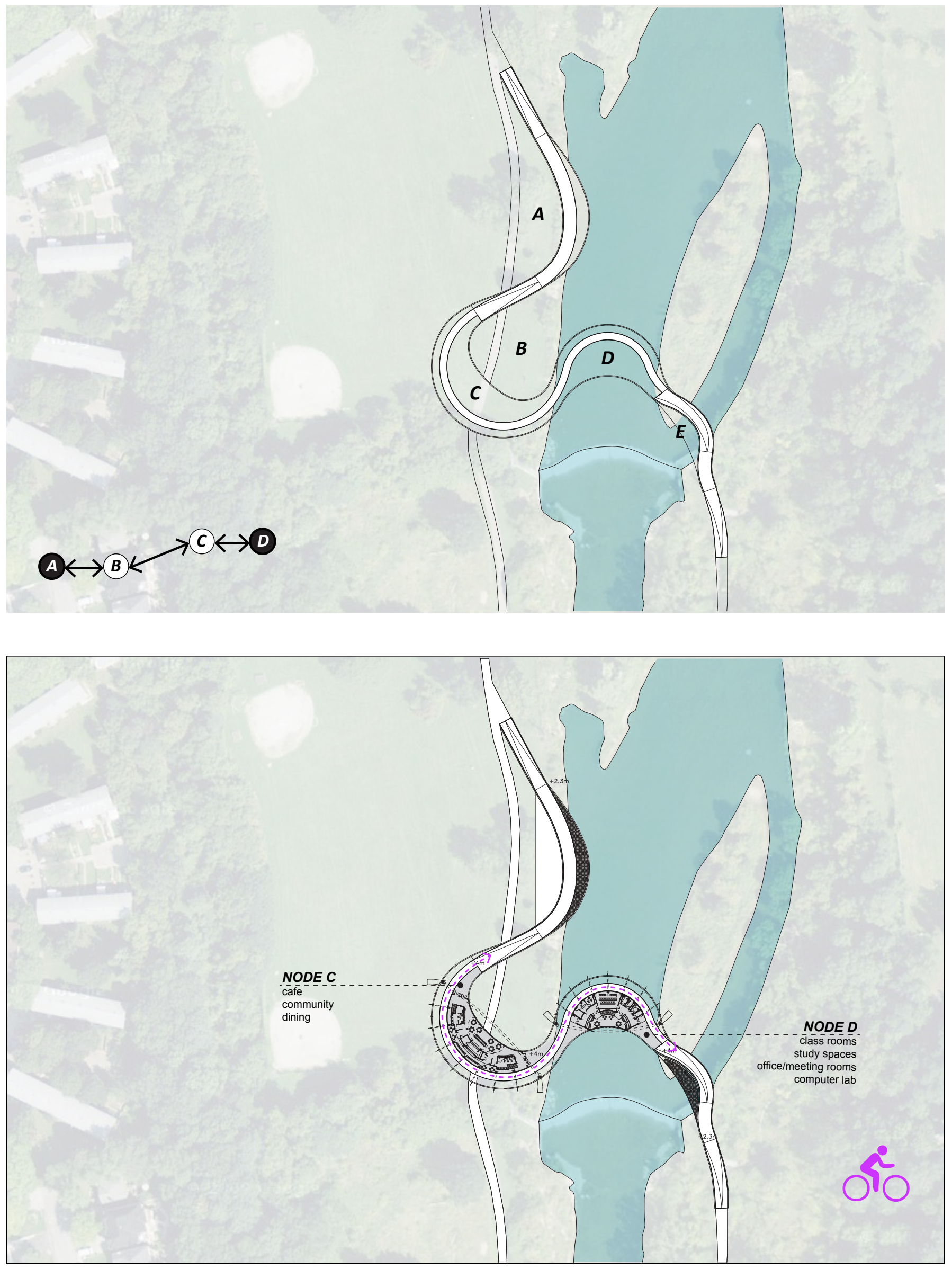
Design Iteration III:

The third design iteration moved away from a direct platform bridge and looked at ways to create a more dynamic network of movements that moved through and in-between different activity nodes.

The undulating path opens up in areas to hold programs and then turns on itself to maintain visual connections. The structure was also a very expressive feature that allowed these activity nodes to stand out in the open landscape.
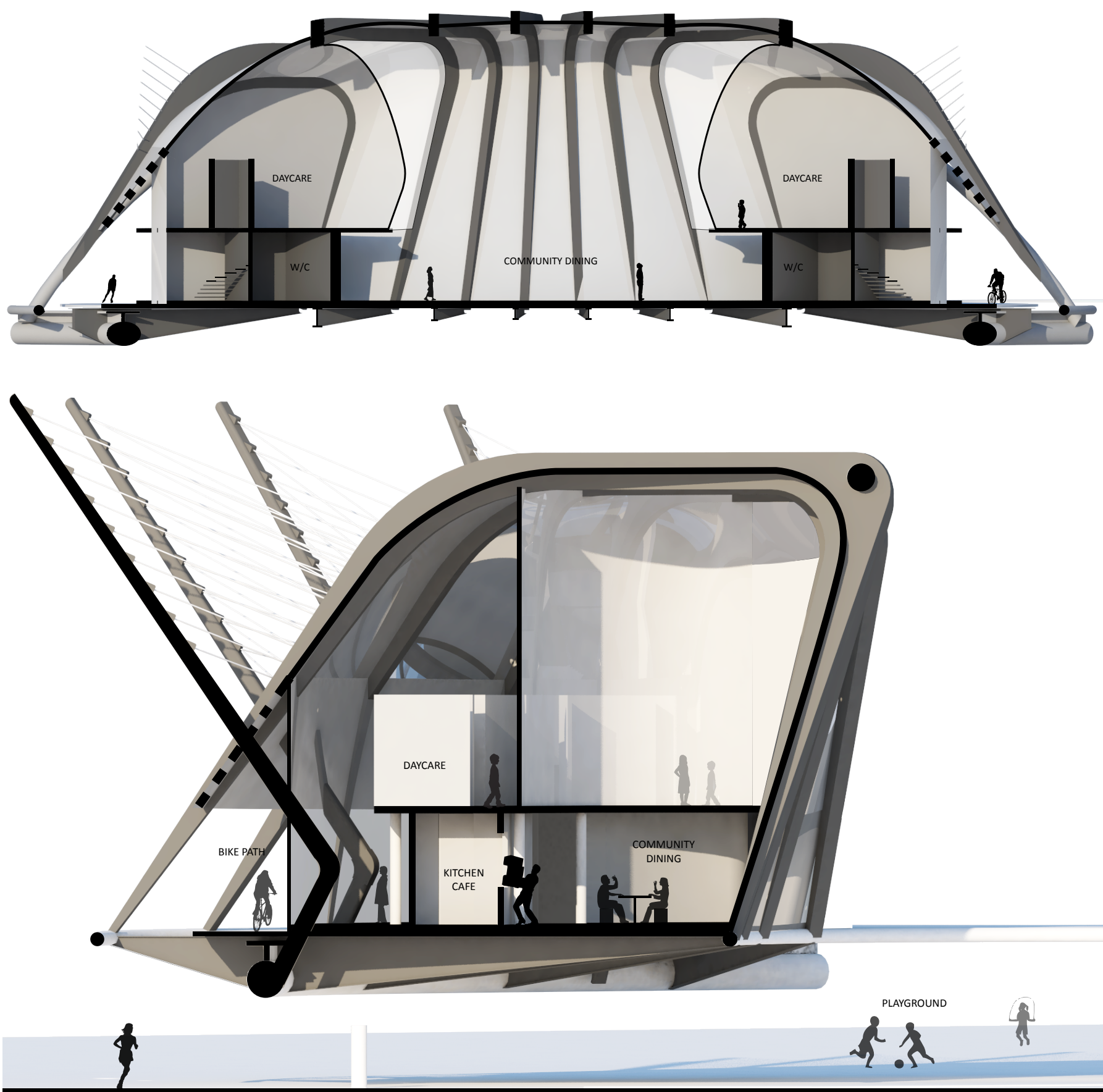

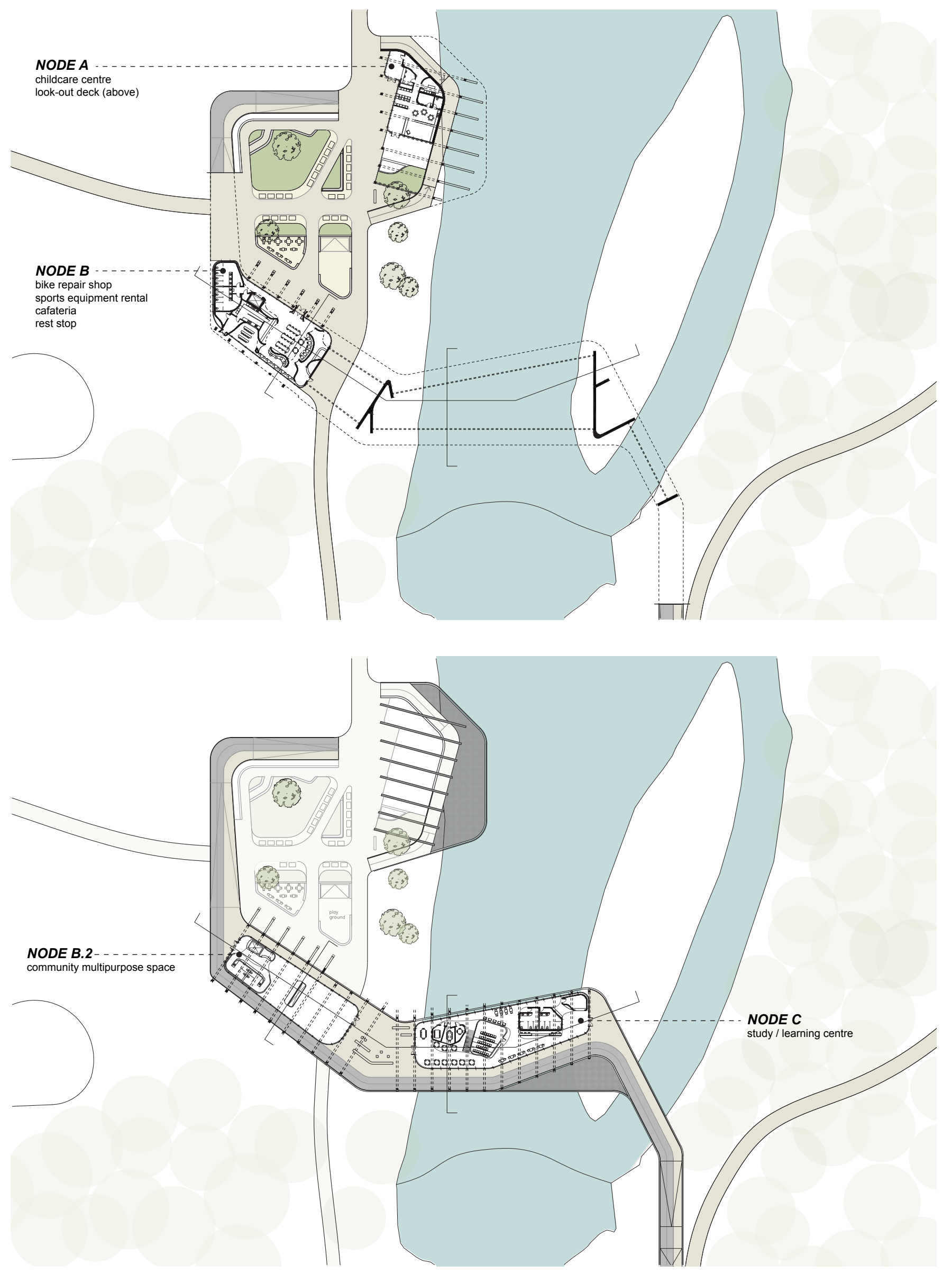
Design Iteration IV:

The fourth design iteration looked at creating a more direct and less complex pedestrian and bike network compared to iteration 3. It was also designed with a much more lightweight structure and reduced the scale of the structure to one that more welcoming for pedestrians. In this design, the ribs were left exposed along the entire length of the bridge and the enclosed spaces fit within the confides of that form.
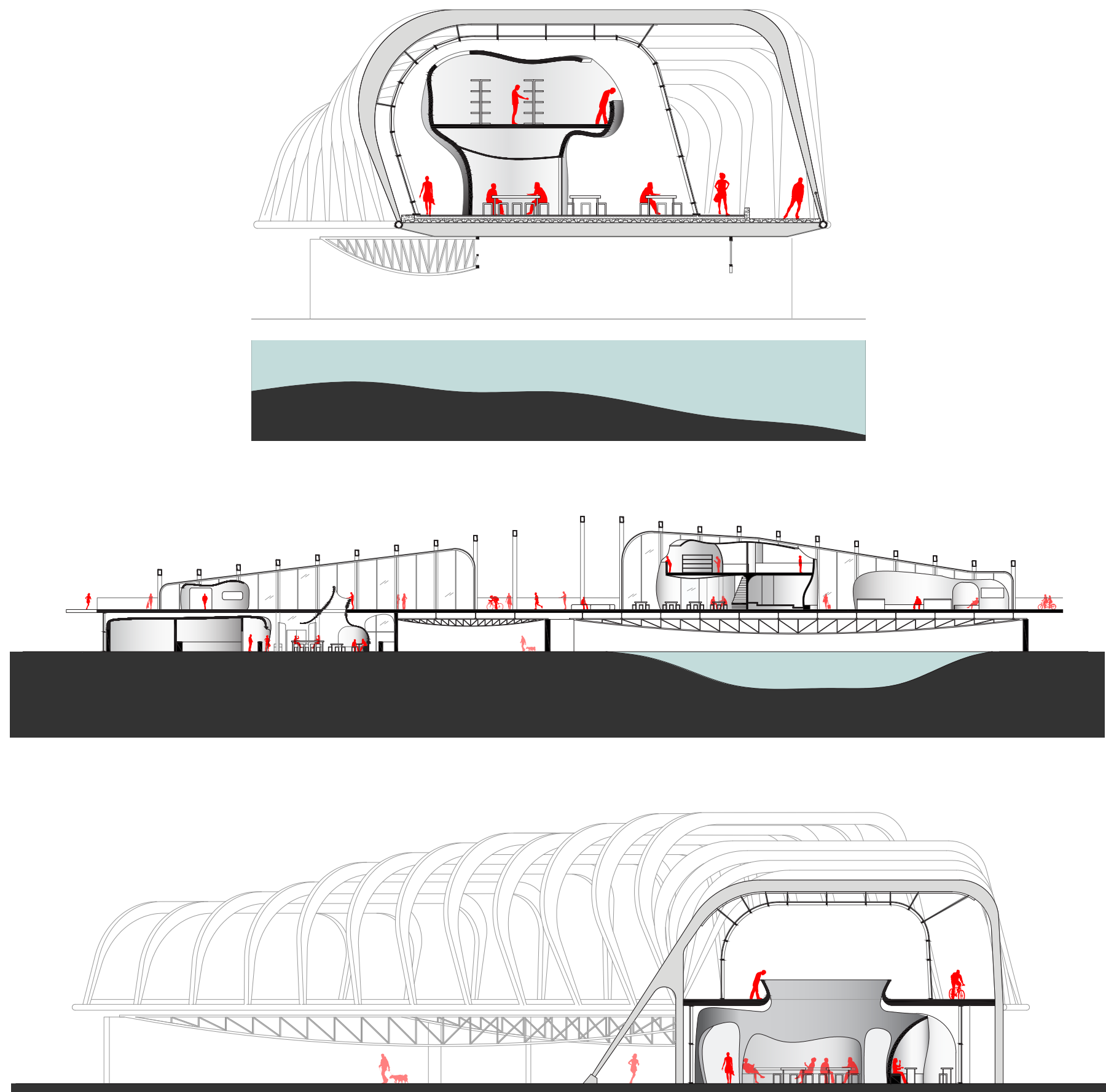

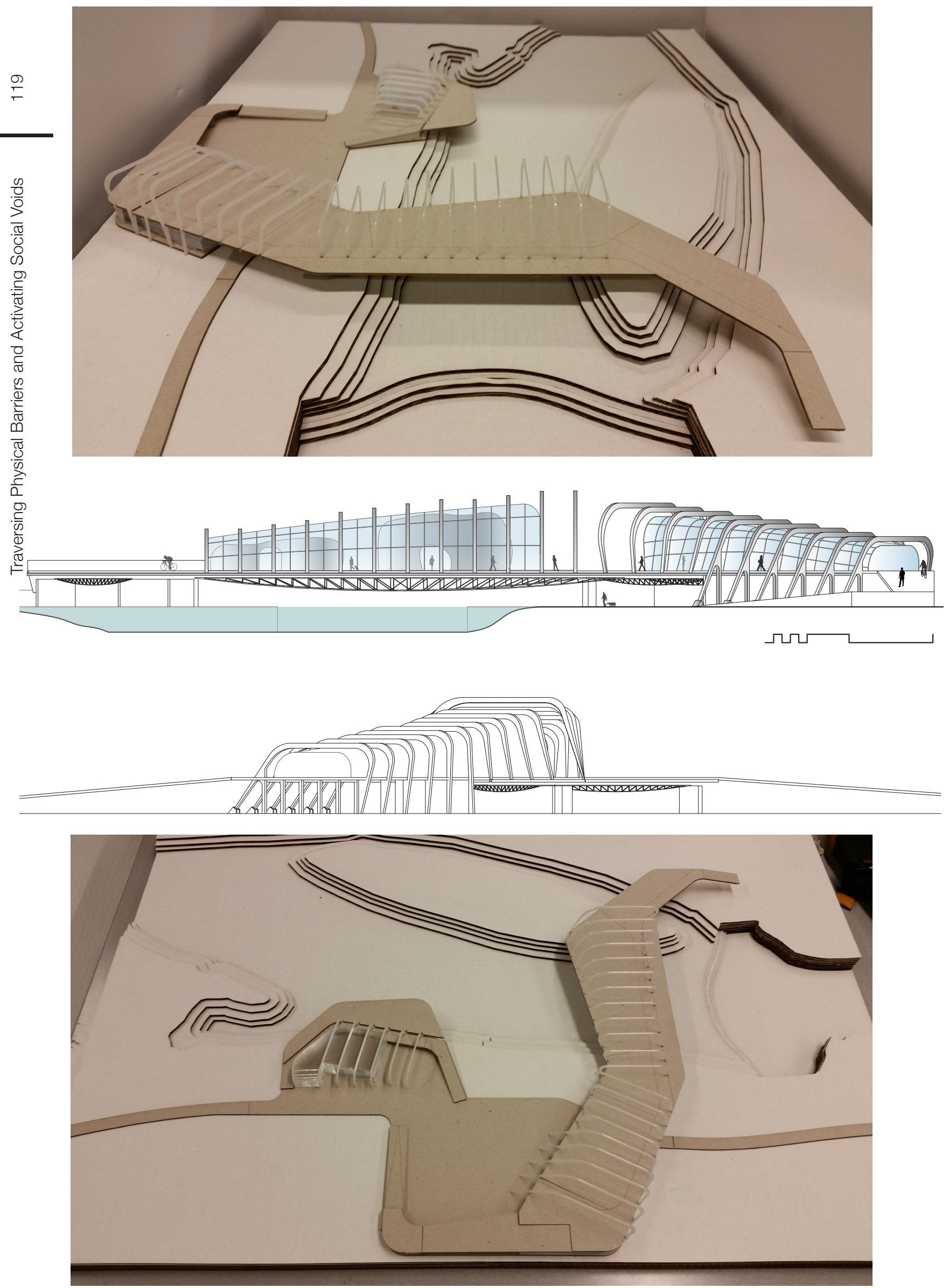


2006 Census update on social risk factors in the city's 13 priority neighbourhoods. (2008). City of Toronto. Retrieved September 20, 2013, from http://www.toronto.ca/demographics/pdf/ priority2006/backgrounder_socialriskfactors_priority.pdf

After you arrive: Adjusting to life in Canada. (2010, July 20). Government of Canada, Citizenship and Immigration Canada. Retrieved September 30, 2013, from http://www.cic.gc.ca/english/ newcomers/after-life.asp

Archer, B. (2013, August 29). Weston-Mt Dennis gets a new community hub. Toronto Community Foundation. Retrieved September 24, 2013, from http://www.tcf.ca/news/weston-mt-dennis-gets-new-community-hub

Ayers, S. (2007). Architecture and health. Cambridge handbook of psychology, health and medicine (2nd ed., p.23-25). Cambridge: Cambridge University Press.

Bolt, G., Özüekren, A.S., and Phillips, D. (2010) Linking Integration and Residential Segregation, Journal of Ethnic and Migration Studies, 36:2, 169-186.

Canter, D., \& Craik, K. (1981). Environmental Psychology. Journal of Environmental Psychology, 1(1),3.

City Center Pavilion and Main Square / Comac. (2013, September 20). ArchDaily. Retrieved November 15, 2013, from http://www.archdaily.com/429198/city-center-pavilion-and-mainsquare-comac/

Dion, K. L. (2002). The social psychology of perceived prejudice and discrimination. Canadian Psychology, 43(1), 1-10.

Discomfort. In The American Heritage Dictionary. Retrieved November 10, 2013 from http://www. ahdictionary.com/word/search.html?q=discomfort\&submit.x=47\&submit.y=14

Gehl, J. (2010). Cities for People. Washington, DC: Island Press.

Houle, R., \& Schellenberg, G. (2010). New immigrants' assessments of their life in Canada. Ottawa, ON: Statistics Canada.

Hulchanski, J. D. (2010). In University of Toronto. Cities Centre. (Ed.), The three cities within Toronto: Income polarization among Toronto's neighbourhoods, 1970-2005. Toronto: Cities Centre.

Kopec, D. (2012). Environmental psychology for design (2nd ed.). New York: Fairchild Books.

Lang, J. T. (1987). Creating architectural theory: The role of the behavioral sciences in environmental design. New York: Van Nostrand Reinhold Co.

Lawton, P. (2013). Understanding urban practitioners' perspectives on social-mix policies in Amsterdam: The importance of design and social space. Journal of Urban Design, 18(1), 98-118. 
Lehrer, J. (2011). The psychology of architecture. Wired. Retrieved October 20, 2013, from http:// wesleymeacham.hubpages.com/hubhttp://www.wired.com/wiredscience/2011/04/thepsychology-of-architecture/Examining-Sustainability-and-Architectural-Influence-in-Environmantal-Psychology

Meacham, W. (2012). Examining how sustainability and architecture influence human behavior in environmental Psychology. HubPages. Retrieved October 20, 2013, from http://wesleymeacham.hubpages.com/hub/Examining-Sustainability-and-Architectural-Influence-inEnvironmantal-Psychology

McCunn, L. (2014). Thinking about biophilic healthcare design. iEnvironment. Retrieved April 10, 2014 from http://www.psychologytoday.com/blog/ienvironment/201402/thinking-aboutbiophilic-healthcare-design

Nann, B. (n.d.). Common issues for newcomers. Victoria Immigrant \& Refugee Centre Society. Retrieved October 10, 2013, from http://www.vircs.bc.ca/settlement/common_issues.php

Nicholson Jr., N. R. (2009). Social isolation in older adults: An evolutionary concept analysis. Journal of Advanced Nursing, 65(6), 1342-1352.

Pati, D., \& Branch, P. (2010). Application of environmental psychology theories and frameworks to evidence-based healthcare design. In J. Valentin, \& L. Gamez (Eds.), Environmental psychology: New developments. New York: Nova Science Publishers.

Permeate. In The American Heritage Dictionary. Retrieved November 10, 2013 from http://www. ahdictionary.com/word/search.html?q=permeate\&submit.x=-784\&submit.y=-210

Policy Research Initiative. (2005). What impact does social capital have on the health of Canadians? Policy Research Initiative Project: Social Capital as a Public Policy Tool. Ottawa: Government of Canada.

Portage Trail Community School. Portage Trail Community Junior School. Retrieved April 2, 2014, from http://schoolweb.tdsb.on.ca/portagetrail/AboutUs.aspx

Priority Neighbourhoods News in Toronto. Inside Toronto. Retrieved October 20, 2013, from http://www.insidetoronto.com/toronto-topics/1308562-priority-neighbourhoods

Ray, B. (2008). A description of ethnic segregation/mixing within major Canadian areas project. Retrieved October 20, 2013 from http://www.cic.gc.ca/english/pdf/research-stats/ethnicsegregation.pdf

Ray, B., Preston, V. (2009). Geographies of discrimination: Variations in perceived discomfort and discrimination in Canada's gateway cities." Journal of Immigrant \& Refugee Studies 7:228249.

Robest, Z. Weston - Mount Dennis: A resident's perspective. APCOL. Retrieved September 24, 2013, from http://www.apcol.ca/Survey/Weston_-_Mt._Dennis.html 
Roessler, K. (2012). Healthy architecture! Can environments evoke emotional responses? Global Journal of Health Science, 4(4), 83-89.

Schellenberg, G. (2004). Perceptions of Canadians: A sense of belonging, confidence and trust. Canadian Social Trends, 16-21.

Schellenberg, G., \& Maheux, H. (2007). Immigrants' perspectives on their first four years in Canada: Highlights from three waves of the longitudinal survey of immigrants to Canada. Retrieved September 30, 2013 from http://www.statcan.gc.ca/pub/11-008-x/2007000/pdf/9627eng.pdf

Shaftoe, H. (2008). Convivial urban spaces creating effective public places. London: Earthscan.

Staber, U. (2006). Social capital processes in cross cultural management. International Journal of Cross Cultural Management, 6(2), 189-203.

Stokols, D. (1972). On the distinction between density and crowding: Some implications for future research. Psychological Review, 79(3), 275-277.

Strang, G. (1996). Infrastructure as landscape; landscape as infrastructure. Spaces. 10:3. Retrieved on September 13, 2013 from http://places.designobserver.com/media/pdf/Infrastructure_1045.pdf

Straub, R.O. (2007). Health psychology ( $2^{\text {nd }}$ ed.). New York, NY: Worth Publishers.

Van Kemenade, S., J. Roy, and L. Bouchard. (2006). Social networks and vulnerable populations: Findings from the GSS." Health Policy Research Bulletin 2: 16-20.

Werner, C., Brown, B.B., Altman, I. (2004). Privacy. Encyclopedia of Applied Psychology. (p. 109-119). New York: NY: Elsevier.

Weston-Mt. Dennis Priority Area Profile. City of Toronto 2006 Census. Retrieved March 14, 2013, from http://www1.toronto.ca/city_of_toronto/social_development_finance_administratio n/files/pdf/area_weston_full.pdf

Wu, Z., Schimmele, C. M., \& Hou, F. (2010). Social integration of immigrants and their children in Canada's urban neighbourhoods. Vancouver, BC: Metropolis British Columbia.

Zhao, J., Xue, L., Gilkinson, T. (2010). Heath status and social capital of recent immigrants in Canada: Evidence from the longitudinal survey of immigrants to Canada. Prepared for Citizenship and Immigration Canada. Retrieved October 20, 2013 from http://www.cic.gc.ca/ english/pdf/research-stats/immigrant-survey.pdf 
